\title{
EXPERIMENTAL INVESTIGATION OF GAS-LIQUID SEPARATION WITH A NEW COMBINED IMPACTING JUNCTION
}

\section{By}

\section{Mohamed A. Mohamed}

A Thesis submitted to the Faculty of Graduate Studies

The University of Manitoba

In Partial Fulfillment of the Requirements for the Degree of

\section{Master of Science}

\author{
Department of Mechanical Engineering \\ University of Manitoba \\ Winnipeg, Manitoba
}

Copyright $\odot 2021$ by M. A. M. 


\begin{abstract}
A novel system of combined impacting tee junctions was designed to generate partialand full-phase-separation data for air-water two phase flow. The system consisted of three horizontal and four vertical equal-sided impacting tee junctions of internal diameter $13.5 \mathrm{~mm}$, having one (horizontal) inlet and two vertical (top and bottom) outlets. The experiments were conducted at a nominal pressure of $200 \mathrm{kPa}$ (abs) and near-ambient temperature.

For the full-phase-separation experiments, the inlet gas and liquid superficial velocity ranged from 0.2 to $39 \mathrm{~m} / \mathrm{s}$ and from 0.0009 to $0.72 \mathrm{~m} / \mathrm{s}$, respectively. These conditions fell in the annular, slug and plug flow regimes. It was found that with the present system, the limiting conditions (gas and liquid inlet superficial velocities, $J_{\mathrm{G} 1}$ and $J_{\mathrm{L} 1}$, respectively) of full phase separation are almost double those of a system of three impacting junctions and quadruple those of a single impacting tee junction system.

Outside the region of full phase separation, ten data points were chosen to study partial phase separation with mass split ratios $\left(W_{3} / W_{1}\right)$ ranging from 0 to 1.0 . These data points fell in the annular and slug flow regimes. A set of experiments were conducted at fixed $J_{\mathrm{L} 1}$ of $0.6 \mathrm{~m} / \mathrm{s}$, with $J_{\mathrm{G} 1}$ of 10,20 and $30 \mathrm{~m} / \mathrm{s}$ and at fixed $J_{\mathrm{L} 1}$ of $0.3 \mathrm{~m} / \mathrm{s}$, with $J_{\mathrm{G} 1}$ of 10 and $20 \mathrm{~m} / \mathrm{s}$. Both sets of results show that as $J_{\mathrm{G} 1}$ decreases, more liquid exits through the bottom outlet (Outlet-3) which moves the partial-phase-separation curves in an anti-clockwise direction in the $F_{\mathrm{G} 3}$ versus $F_{\mathrm{L} 3}$ plot. The other set of experiments were conducted at fixed $J_{\mathrm{G} 1}$ of $40 \mathrm{~m} / \mathrm{s}$, with $J_{\mathrm{L} 1}$ of $0.01,0.04$ and $0.18 \mathrm{~m} / \mathrm{s}$. For these experiments, the partial-phase-separation curves did not show any consistent trend as $J_{\mathrm{L} 1}$ was varied. The present system showed better phase separation compared to other systems of combined junctions and a single junction system with more liquid and less gas leaving through the bottom outlet.
\end{abstract}


A phase separation parameter, $\eta$, was used to quantify the effectiveness of the system at separating the phases. It was found that $\eta$ decreases with increasing $J_{\mathrm{G} 1}$ or $J_{\mathrm{L} 1}$. With the present system, $\eta$ was higher for all partial-phase-separation experiments in comparison with a system of three impacting junctions and a single vertical tee junction system. In addition, the present system shows better phase-separation effectiveness when compared to other combined junctions reported in the literature. 


\section{ACKNOWLEDGEMENTS}

I would like to express my sincere gratitude to my supervisor, Dr. Hassan Soliman for giving me this opportunity and providing invaluable guidance throughout this research. It was a privilege and an honor to work and study under his guidance.

Special thanks to Mr. Zeev Kapitanker for his assistance in constructing the test facility and for his relentless support.

My gratitude extends to the Natural Sciences and Engineering Research Council of Canada (NSERC), the Faculty of Graduate Studies and the Department of Mechanical Engineering at the University of Manitoba for their financial support.

I could not have completed this thesis without the support of my family. I am extre mely grateful to my parents for their encouragement, support, and guidance. A debt of gratitude is also owed to my Fiancée for her kindness and patience throughout this journey.

Finally, I would like to thank and dedicate this thesis to my grandfather. It was you who always believed in my ability. You are gone but your belief in me has made this journey possible.

Praises and thanks to God, almighty, for His endless blessings. 


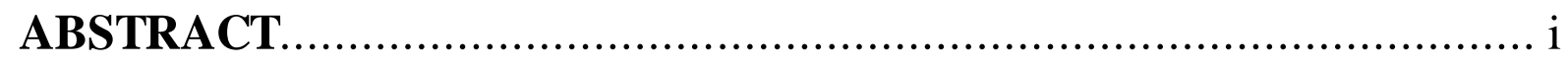

ACKNOWLEDGEMENTS ...................................................... iii

TABLE OF CONTENTS ........................................................iv

LIST OF FIGURES ............................................................

LIST OF TABLES .................................................................. viii

NOMENCLATURE...............................................................ix

\section{CHAPTERS}

1. INTRODUCTION ............................................................ 1

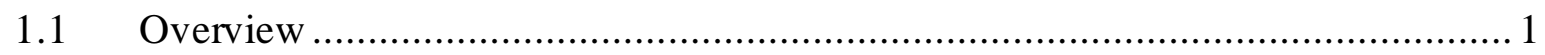

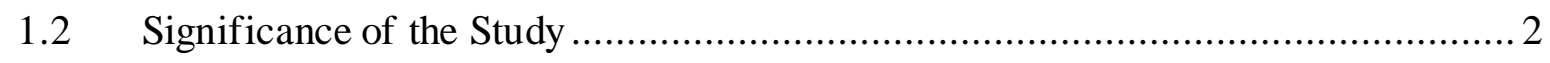

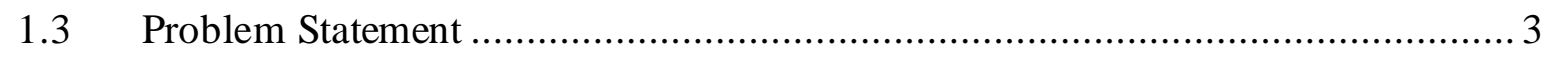

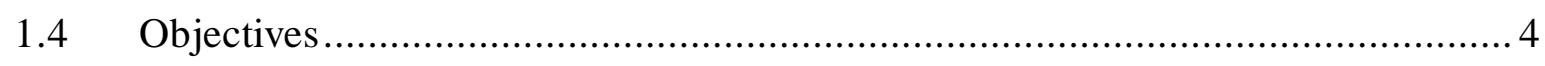

2. LITERATURE REVIEW ..................................................

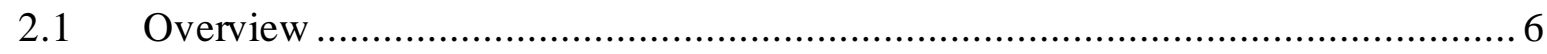

2.2 Studies on Single Impacting Tee Junctions ............................................... 7

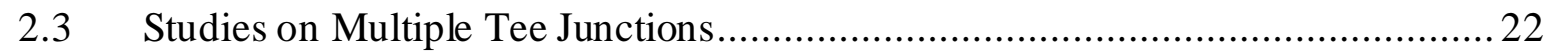

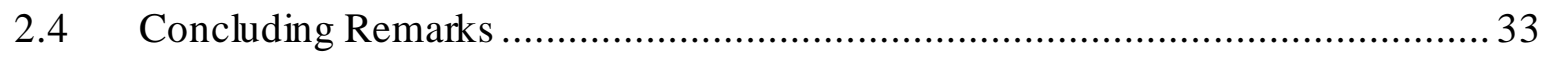

3. TEST RIG AND EXPERIMENTAL PROCEDURE....................... 34

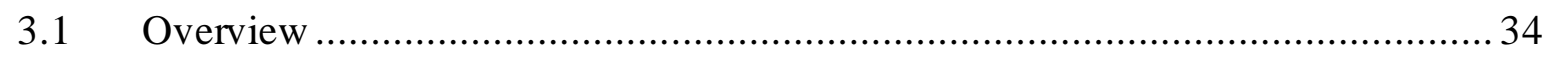

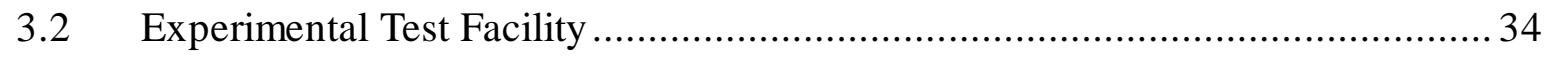

Experimental Procedure ...................................................................... 45

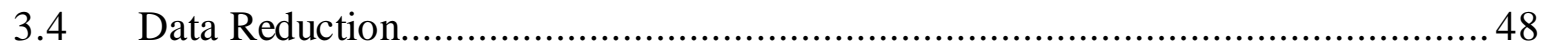




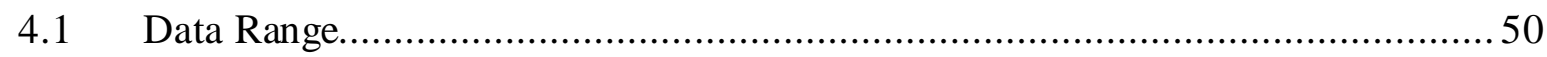

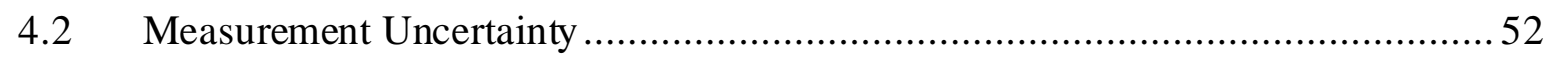

4.3 Reliability and Symmetry of the Test Section .................................................53

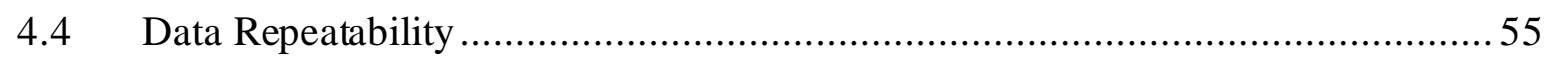

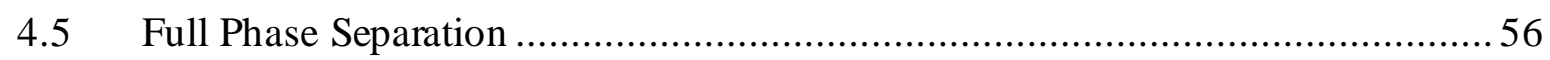

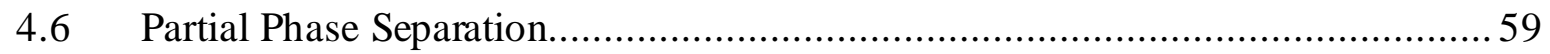

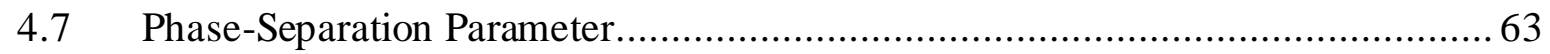

4.8 Comparison of Partial-Separation Data Points ..................................................... 67

4.9 Comparison with Other Systems Based on the Maximum Separation Parameter .. 71

5. CONCLUSIONS AND RECOMMENDATIONS...........................76

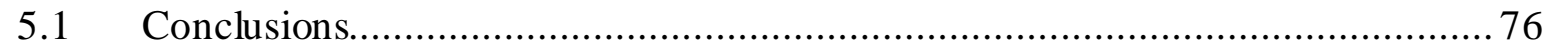

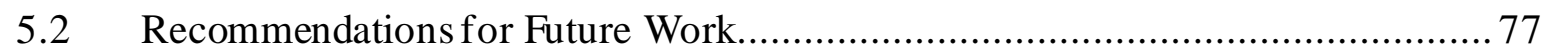

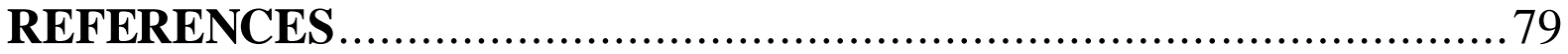

APPENDICES

A. CALIBRATION OF ROTAMETERS.......................................83

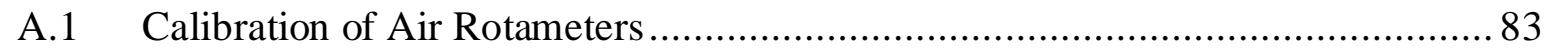

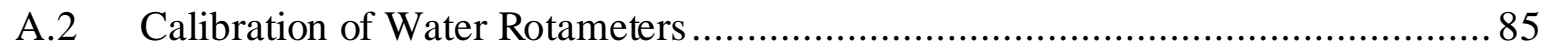

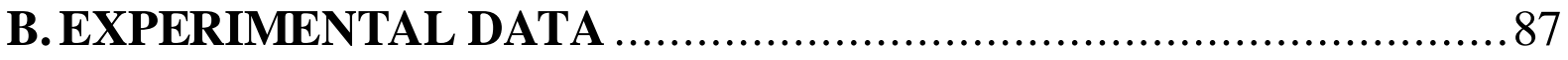

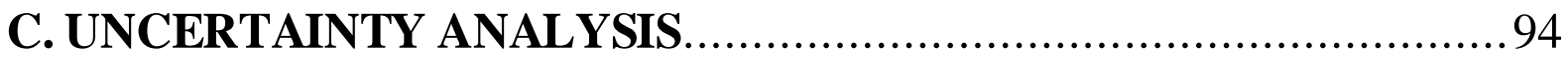




\section{LIST OF FIGURES}

FIGURE

PAGE

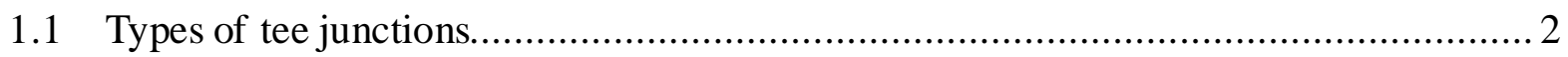

2.1 Detailed schematic of the tee junction separator used by Tuo and Hrnjak (2012) ...... 21

2.2 Schematic of junction layout used by Wren and Azzopardi (2004)........................ 24

2.3 Schematic of combined-junction layout used by Yang et al. (2010)....................... 27

2.4 Schematic of junction layout used by Chen et al. (2012) ................................... 28

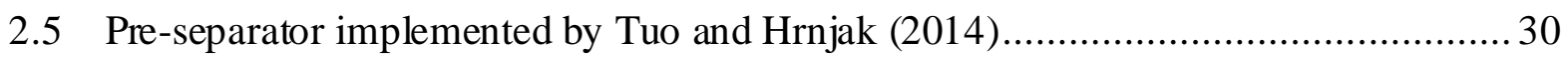

2.6 Schematic of the three-layer multitube separator unit implemented by Yang et al. (2017)

2.7 Noor and Soliman (2019) test section schematic.................................................. 33

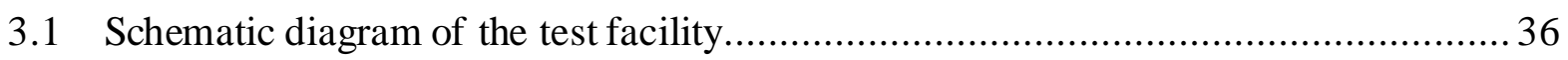

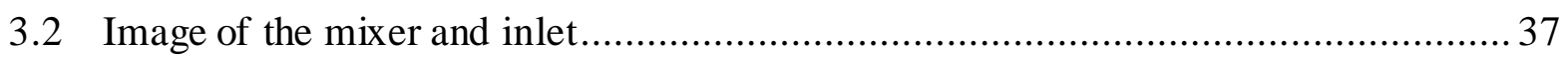

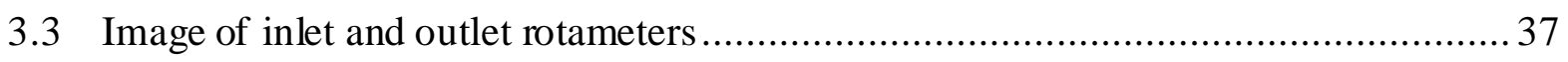

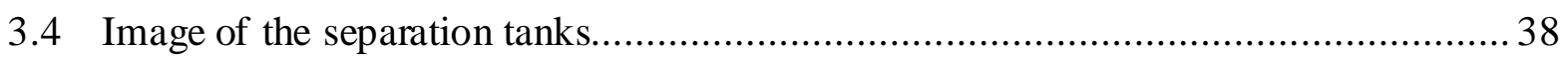

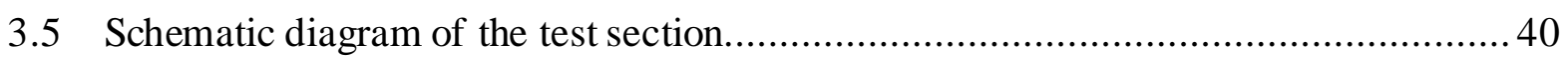

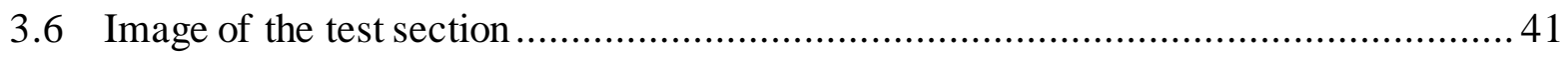

4.1 Inlet conditions for partial-phase-separation experiments plotted on Mandhane et al.

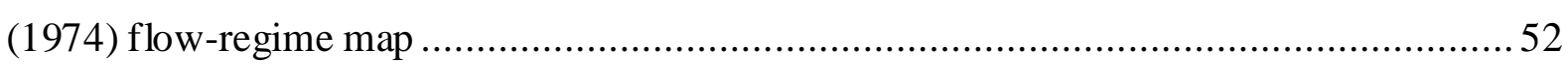

4.2 Comparison of data with Noor and Soliman (2019) at identical test conditions .......... 54

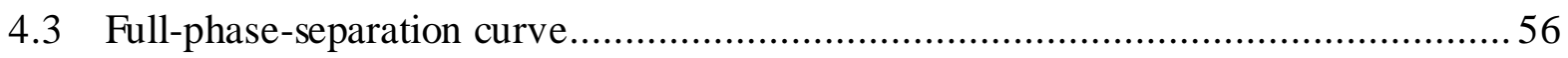

4.4 Limiting conditions of full phase separation plotted on Mandhane et al. (1974) flowregime map

4.5 Full-phase-separation curves from literature .............................................. 58

4.6 Inlet conditions for partial-phase-separation experiments plotted on Mandhane et al. (1974) flow-regime map.

4.7 Partial-phase-separation data atfixed $J_{\mathrm{L} 1}=0.6 \mathrm{~m} / \mathrm{s}$. 
4.8 Partial-phase-separation data atfixed $J_{\mathrm{L} 1}=0.3 \mathrm{~m} / \mathrm{s}$.

4.9 Partial-phase-separation data atfixed $J_{\mathrm{G} 1}=40 \mathrm{~m} / \mathrm{s}$.....

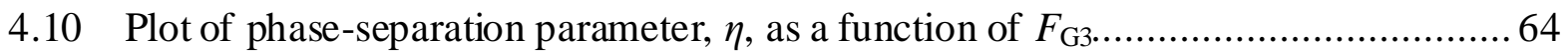

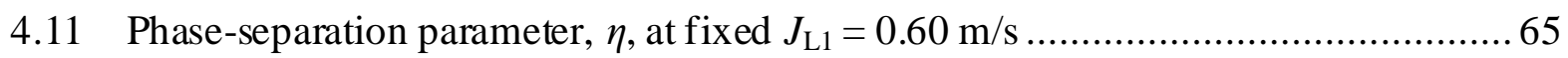

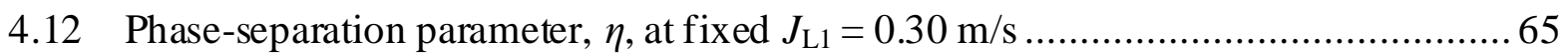

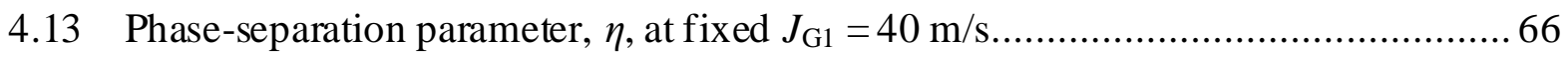

4.14 Comparison of partial-phase-separation data for P1 data point ............................ 68

4.15 Comparison of partial-phase-separation data for P2 data point ............................ 68

4.16 Comparison of partial-phase-separation data for P3 data point ............................ 69

4.17 Comparison of phase-separation parameter of the present system with literature P1 data point

4.18 Comparison of phase-separation parameter of the present system with literature P2 data point

4.19 Comparison of phase-separation parameter of the present system with literature P3 data point

4.20 Inlet conditions for the data reported by Yang et al. (2017) ............................... 72

4.21 Inlet conditions for the data reported by Noor and Soliman (2019)....................... 74 


\section{LIST OF TABLES}

TABLE

PAGE

2.1 Previous literature on phase redistribution using a single impacting tee junction ......... 8

2.2 Previous literature on phase separation using a single impacting tee junction............ 19

2.3 Literature on two-phase flows through multiple tee junction systems .....................23

3.1 Specifications and functions of the air-flow-measurement instruments................... 42

3.2 Specifications and functions of the water-flow-measurement instruments................ 43

3.3 Specifications and functions of the pressure-measurement instruments................... 44

4.1 Range of operating conditions for full-phase-separation data ..............................51

4.2 Range of operating conditions for partial-phase-separation data.............................51

4.3 Fixed uncertainties for partial- and full-phase-separation experiments....................53

4.4 Summary of uncertainty analysis for phase-separation experiments........................53

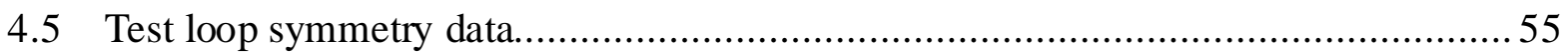

4.6 Repeatability of full-phase-separation data..................................................... 55

4.7 Comparison between the present system and Yang et al. (2017) ............................ 73

4.8 Comparison of partial-phase-separation data with Noor and Soliman (2019) ............ 75

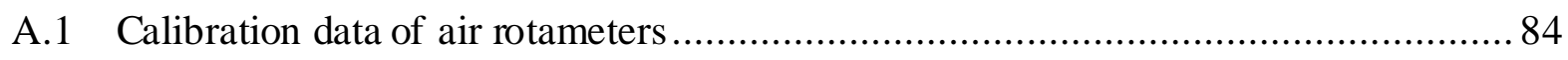

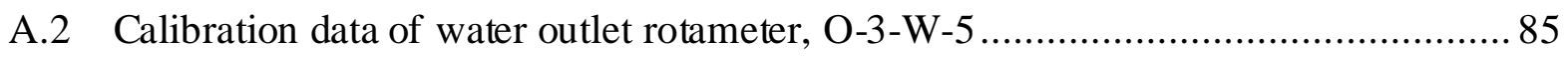

A.3 Calibration data of water inlet rotameter, IN-W-4 .......................................... 85

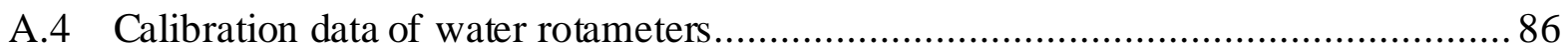

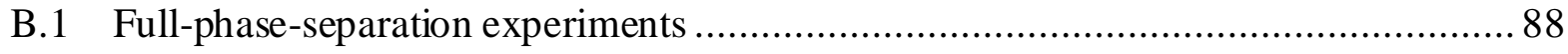

B.2 Mass flow rates for full-phase-separation experiments ....................................... 89

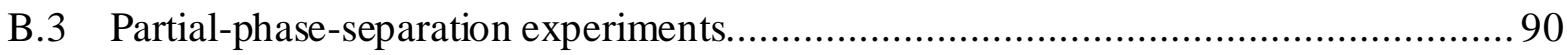

B.4 Mass flow rates for partial-phase-separation experiments................................. 92

C.1 Uncertainty analysis for full-phase-separation experiments ................................. 96

C.2 Uncertainty analysis for full-phase-separation experiments ............................. 97 
NOMENCLATURE

Symbol

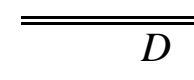

$F_{\mathrm{G}}$

$F_{\mathrm{L}}$

$J_{\mathrm{G}}$

$J_{\mathrm{L}}$

$P$

$P_{\mathrm{TS}}$

$T_{\mathrm{G}}$

$T_{\mathrm{L}}$

$V_{\mathrm{G}}$

$V_{\mathrm{L}}$

W

$W_{\mathrm{G}}$

$W_{\mathrm{L}}$

$\rho_{\mathrm{G}}$

$\rho_{\mathrm{L}}$

$\rho_{\mathrm{STD}}$
Description

Pipe diameter

Mass fraction of inlet gas exiting through an outlet

Mass fraction of inlet liquid exiting through an outlet

Superficial gas velocity

Superficial liquid velocity

Pressure

Pressure at the center of the first junction

Temperature of gas

Temperature of liquid

Gas volume flowrate

Liquid volume flowrate

Total mass flowrate

Gas mass flowrate

Liquid mass flowrate

Density of gas

Density of liquid

Standard density
Units

$\mathrm{m}$

$\mathrm{m} / \mathrm{s}$

$\mathrm{m} / \mathrm{s}$

$\mathrm{kPa}$

$\mathrm{kPa}$

K

K

SLPM

$\mathrm{cc} / \mathrm{min}$

$\mathrm{kg} / \mathrm{s}$

$\mathrm{kg} / \mathrm{s}$

$\mathrm{kg} / \mathrm{s}$

$\mathrm{kg} / \mathrm{m}^{3}$

$\mathrm{kg} / \mathrm{m}^{3}$

$\mathrm{kg} / \mathrm{m}^{3}$

\section{Subscripts:}

1 Inlet

2 Outlet-2

3 Outlet-3 


\section{CHAPTER 1}

\section{INTRODUCTION}

\subsection{Overview}

Single- and multi-phase fluids are commonly used in many industrial applications including but not limited to hydrocarbon production, conventional and nuclear energy systems, and oil and gas industry. Tee junctions are often a crucial element in the transportation and distribution of the fluids in these industries as they have no moving components and require little to no maintenance during their life cycle. There are different types of tee junctions based on the purpose and outlets configuration. The two main types of tee junctions are combining and dividing. Combining type tee junctions combine two inlet streams into a single outlet stream. Tee junctions which divide an inlet stream to produce two outlet streams, is a dividing tee junction. For each of these two types there are two configurations: branching or impacting. For dividing tee junction, when the two outlets are co-axial to each other it is called impacting type, and when the inlet and one of the outlets are co-axial to each other it is called branching type. For combining tee junction, when the two inlets are co-axial to each other it is called impacting type, and when one of the inlets and the outlet are co-axial to each other it is called branching type. These four configurations are shown in Figure 1.1.

Phase redistribution or phase separation occurs when a two-phase flow passes through a dividing junction. Phase separation is defined as the uneven split of the inlet flow between the two outlets. This redistribution of phases could be undesirable to components downstream from the junction and affect the operation and efficiency of the equipment. Cases of severe phase redistribution could occur, and full phase separation is achieved where each of the two outlets would have a single-phase flow. Research has been focused on factors affecting phase redistribution such as the inlet velocities of the gas and liquid, angle of inclination of the outlets, 
operating conditions, inlet flow regime etc. Fewer studies looked at full and partial phase separation using a single impacting tee junction.

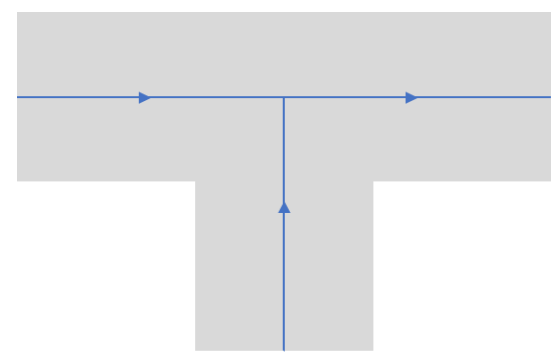

Combining branching

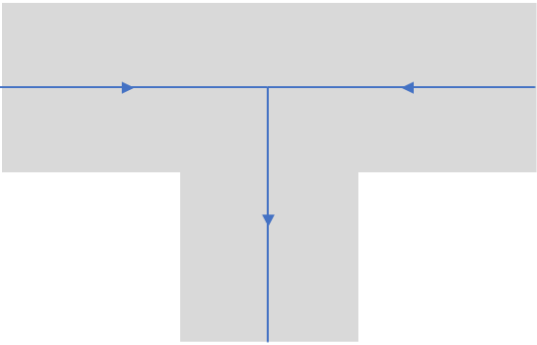

Combining impacting

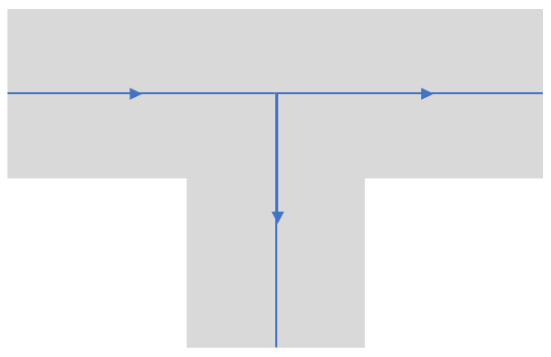

Dividing branching

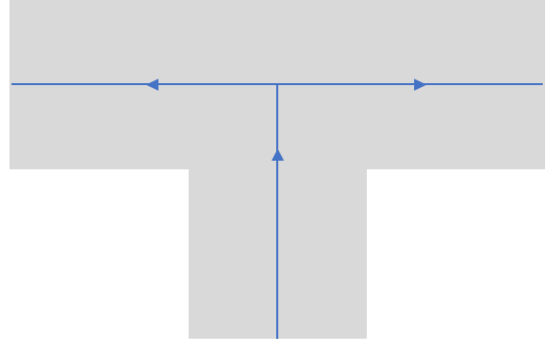

Dividing impacting

Figure 1.1: Types of tee junctions

Studies on the use of multiple tee junctions to enhance phase separation is becoming increasingly popular. The most recent work was conducted on a system of combined impacting tee junction by Noor and Soliman (2019), which is the only work in the literature on phase separation using a system of combined impacting junctions to date and to the author's best knowledge. In this thesis, air-water two-phase flow passing through a system of combined dividing impacting type tee junction is studied.

\subsection{Significance of the Study}

In many industrial applications, two-phase flow separation is a desirable process where a single-phase flow flowing through each outlet is required. Some of these applications include heat exchangers, oil and gas mining, nuclear reactors etc. Phase separation is traditionally achieved with bulky vessels using gravity to separate the phases. These gravity-based vessels 
are expensive to construct, operate and maintain, and they could also be dangerous to the environment if containing hazardous substances. In comparison, tee junctions are cheaper to manufacture and install, and require little to no maintenance. In this research, the limiting conditions of full phase separation for a system of combined junctions are experimentally investigated to explore the possibility of creating a separator using simple tee junctions and provide supporting experimental data. This could provide a simpler and more efficient alternative to gravity-based vessels.

\subsection{Problem Statement}

The study is conducted with air-water two phase flow in a system consisting of multiple impacting tee junctions (three horizontal and four vertical junction), which has a horizontal inlet (side 1) and two vertical outlets (top and bottom outlets represented by sides 2 and 3, respectively). The inlet air mass flowrate, $W_{\mathrm{G} 1}$, and inlet water mass flowrate $W_{\mathrm{L} 1}$ enter the test loop. The total inlet mass flowrate is denoted by $W_{1}$ and thus,

$$
W_{1}=W_{\mathrm{G} 1}+W_{\mathrm{L} 1}
$$

and the inlet quality is $x_{1}$ and defined as

$$
x_{1}=W_{\mathrm{G} 1} / W_{1}
$$

The inlet mass flow rate $\left(W_{1}\right)$ is divided into two streams with mass flow rates $W_{2}$ and $W_{3}$, where

$$
W_{1}=W_{2}+W_{3}
$$

The liquid and gas mass flowrates in Outlets 2 and 3 are represented by $W_{\mathrm{L} 2}, W_{\mathrm{G} 2}$ and $W_{\mathrm{L} 3}$, $W_{\mathrm{G} 3}$, respectively, and thus,

$$
W_{2}=W_{\mathrm{G} 2}+W_{\mathrm{L} 2}
$$




$$
W_{3}=W_{\mathrm{G} 3}+W_{\mathrm{L} 3}
$$

Other relevant parameters used in the data analysis are:

Overall mass-split ratio, $\quad W_{\mathrm{R}}=W_{3} / W_{1}$

Mass fraction of gas in Outlet-2, $\quad F_{\mathrm{G} 2}=W_{\mathrm{G} 2} / W_{\mathrm{G} 1}$

Mass fraction of liquid in Outlet-2, $\quad F_{\mathrm{L} 2}=W_{\mathrm{L} 2} / W_{\mathrm{L} 1}$

Mass fraction of gas in Outlet-3, $\quad F_{\mathrm{G} 3}=W_{\mathrm{G} 3} / W_{\mathrm{G} 1}$

Mass fraction of liquid in Outlet-3, $\quad F_{\mathrm{L} 3}=W_{\mathrm{L} 3} / W_{\mathrm{L} 1}$

Superficial gas velocity, $\quad J_{\mathrm{G}}=W_{\mathrm{G}} /\left(\rho_{\mathrm{G}} \times \pi \times D^{2} / 4\right)$

Superficial liquid velocity, $\quad J_{\mathrm{L}}=W_{\mathrm{L}} /\left(\rho_{\mathrm{L}} \times \pi \times D^{2} / 4\right)$

The aim of the present study is to produce partial- and full- phase separation data with airwater two-phase flows in a system of combined junctions at various inlet conditions. Partial phase separation or phase redistribution is when there is unequal fractions of liquid and gas in each of the two outlets, i.e., $F_{\mathrm{G} 2} \neq F_{\mathrm{L} 2} \neq 0.5$ or $F_{\mathrm{G} 3} \neq F_{\mathrm{L} 3} \neq 0.5$. Equal phase split refers to when $F_{\mathrm{G} 3}=F_{\mathrm{L} 3}$. For full phase separation, all the inlet gas mass flow rate flows through Outlet-2 and all the inlet liquid mass flow rate flows through Outlet-3 (i.e., $F_{\mathrm{G} 3}=0$ and $F_{\mathrm{L} 3}=1$ or $F_{\mathrm{G} 2}=1$ and $\left.F_{\mathrm{L} 2}=0\right)$.

\subsection{Objectives}

The following is a list of the objectives of this experimental study:

I. To investigate the limiting conditions of inlet gas and liquid superficial velocities, $J_{\mathrm{Gl}}$ and $J_{\mathrm{L} 1}$, up to which a system of combined impacting tee junction can totally separate phases. Results will be generated for an internal diameter of $13.5-\mathrm{mm}$. 
II. To generate partial-phase-separation data for inlet conditions outside the range of full phase separation using the present system of combined junctions.

III. To apply the phase-separation effectiveness parameter defined by Noor and Soliman (2019) on the present experimental data.

IV. To compare the present data with data of other systems of combined junctions in the literature. 


\section{CHAPTER 2}

\section{LITERATURE REVIEW}

\subsection{Overview}

Gas-liquid two-phase flow plays a vital role in various engineering applications such as condensers, evaporators, heat exchangers etc. The flow distribution network of many of these systems includes pipe junctions (tees and wyes) of the dividing and combining types. There are two types of dividing tees: branching tees and impacting tees. In branching tees, one outlet flow is in the same direction of the inlet and the other is at $90^{\circ}$ from the inlet. In impacting tees, the two outlets are normal to the inlet. A common phenomenon that occurs when a gasliquid two-phase flow arrives at a dividing tee junction is the redistribution of phases (Azzopardi and Whalley, 1982). Therefore, due to the uneven distribution of phases, a liquidrich and a gas-rich streams form in the outlet branches causing the outlet qualities to be different from the inlet quality. This distortion could affect the equipment downstream of the junction as it may create an unsuitable working condition. Many investigations have focused on the behavior of two-phase flow through dividing tees. These studies explored the effects of inlet conditions, mass distribution at the junction, fluid properties, and junction geometry on the phase redistribution. The large number of studies on this topic emph asizes the importance and complexity of the issue. Most studies were done using branching junctions. On the contrary, fewer studies looked at the use of impacting junctions. Regardless of the similarities between the branching and impacting junctions, they are evaluated independently in the literature.

Recent studies have examined the phenomenon of phase redistribution and utilizing it for desirable outcomes such as achieving partial- or full-phase separation (Azzopardi et al., 2002). For example, full-phase separation is desirable in many applications where a single- 
phase flow leaving from each outlet is favored, such as in oil and gas pipelines, evaporators and condensers.

Gas-liquid separation is of ten performed using conventional equipment which rely on gravity and centrifugal force to split the mixture. The conventional set-up is usually bulky, expensive and requires significant maintenance. An alternative solution is to pass the two-phase flow through a single tee junction which can be considered compact, economical, and safer, but due to its low separation efficiency proved to be unsuccessful.

Another solution proposed by Yang et al. (2010), was using multi-tube tee junctions to enhance the separation efficiency. It was found that increasing the number of connecting tubes in the multi-tube tee junction separator can increase the separation efficiency. More research has been done on phase separation using tee junctions. Amongst these are the notable work of Wren and Azzopardi (2004), Baker et al. (2007), Yang et al. (2010), Tuo and Hrnjak (2012), Yang et al. (2017) and Noor and Soliman (2019).

As far as one can tell from the literature up to date, most of the studies on gas-liquid separation with combined tees used junctions of the branching type. Very limited open publications presented gas-liquid separation in combined impacting tee junctions (see for example Noor and Soliman, 2019). This thesis will be a continuation of the work by Noor and Soliman and it will tackle the problem of extending the phase-separation potential to a wider range of inlet conditions. This review would be divided into two main sections: studies with a single impacting junction and studies on multiple tee junctions.

\subsection{Studies on Single Impacting Tee Junctions}

Studies were performed on single impacting tee junctions over a wide range of inlet conditions and the effects of many parameters were analyzed; some of which were the junction geometry, inlet quality, inlet flow regime, inlet liquid and gas superficial velocities, angle of 
inclination, and effect of inlet pressure. One common observation amongst all was that equalphase distribution occurs only when there is equal mass split in the two outlets. Phase separation has not been the objective of much of this work. Literature on single impacting tee junctions in this review will be categorized according to their objective in two parts:

1. Studies on partial-phase separation with single impacting tee junction.

2. Studies on full-phase separation with single impacting tee junction.

\subsubsection{Studies on Partial-Phase Separation with Single Impacting Tee Junctions}

Over the years, significant number of studies have been done on partial-phase separation with single impacting junction, looking at the effect of operational conditions, flow regimes and junction orientation. Most of the studies done on this topic were experimental and few were analytical as it is very challenging to simulate the physics for this kind of study and that is due to the complexity of simulating the flow through the junction and the large number of variables involved. Studies on phase redistribution with impacting junction were mostly done with air-water two-phase flow. Fewer studies were done using various refrigerants, airnitrogen and wet steam mixtures.

Table 2.1 summarizes some of the work done on phase redistribution using a single impacting tee.

Table 2.1: Previous literature on phase redistribution using a single impacting tee junction

\begin{tabular}{|c|c|c|c|c|c|c|c|}
\hline Author(s) & $\begin{array}{c}\text { Inlet } \\
\text { Diameter } \\
(\mathbf{m m})\end{array}$ & $\begin{array}{c}\text { Test } \\
\text { Fluids }\end{array}$ & $\begin{array}{c}\boldsymbol{J}_{\mathbf{G} 1} \\
(\mathbf{m} / \mathbf{s})\end{array}$ & $\begin{array}{c}\boldsymbol{J}_{\mathbf{L} 1} \\
(\mathbf{m} / \mathbf{s})\end{array}$ & $\begin{array}{c}\text { System } \\
\text { Pressure } \\
(\mathbf{b a r})\end{array}$ & $\begin{array}{c}\text { Tee } \\
\text { Junction } \\
\text { Orientation }\end{array}$ & $\begin{array}{c}\text { Inlet } \\
\text { Flow- } \\
\text { Regime }\end{array}$ \\
\hline $\begin{array}{c}\text { Hong } \\
(1978)\end{array}$ & 9.5 & $\begin{array}{c}\text { Air- } \\
\text { Water }\end{array}$ & 27.4 & 0.02 & $\begin{array}{c}1.22 \\
(\mathrm{abs})\end{array}$ & Horizontal & An \\
\hline $\begin{array}{c}\text { Azzopardi } \\
\text { et al. } \\
(1986 \mathrm{a})\end{array}$ & 31.8 & $\begin{array}{c}\text { Air- } \\
\text { Water }\end{array}$ & $\begin{array}{c}9.8- \\
21.6\end{array}$ & $\begin{array}{c}0.03- \\
0.08\end{array}$ & $1.7(\mathrm{abs})$ & $\begin{array}{c}\text { Vertical } \\
\text { inlet and } \\
\text { horizontal } \\
\text { outlets }\end{array}$ & An \\
\hline
\end{tabular}




\begin{tabular}{|c|c|c|c|c|c|c|c|}
\hline Author(s) & $\begin{array}{c}\text { Inlet } \\
\text { Diameter } \\
(\mathbf{m m})\end{array}$ & $\begin{array}{l}\text { Test } \\
\text { Fluids }\end{array}$ & $\begin{array}{c}J_{\mathbf{G 1}} \\
(\mathbf{m} / \mathbf{s})\end{array}$ & $\begin{array}{c}J_{\mathbf{L} 1} \\
(\mathbf{m} / \mathbf{s})\end{array}$ & $\begin{array}{l}\text { System } \\
\text { Pressure } \\
\text { (bar) }\end{array}$ & $\begin{array}{c}\text { Tee } \\
\text { Junction } \\
\text { Orientation }\end{array}$ & $\begin{array}{c}\text { Inlet } \\
\text { Flow- } \\
\text { Regime }\end{array}$ \\
\hline $\begin{array}{c}\text { Azzopardi } \\
\text { et al. } \\
(1986 b)\end{array}$ & 31.8 & $\begin{array}{c}\text { Air- } \\
\text { Water }\end{array}$ & $\begin{array}{l}1.6- \\
3.7\end{array}$ & $\begin{array}{c}0.08- \\
0.8\end{array}$ & 1.7 (abs) & $\begin{array}{c}\text { Vertical } \\
\text { inlet and } \\
\text { horizontal } \\
\text { outlets }\end{array}$ & $\mathrm{Ch}$ \\
\hline $\begin{array}{l}\text { Hwang et } \\
\text { al. (1989) }\end{array}$ & 38 & $\begin{array}{c}\text { Air- } \\
\text { Water }\end{array}$ & $\begin{array}{c}1.4- \\
5.7\end{array}$ & $\begin{array}{l}1.3- \\
2.7\end{array}$ & $\begin{array}{c}1.3-1.9 \\
(\mathrm{abs})\end{array}$ & Horizontal & $\mathrm{B}, \mathrm{B}-\mathrm{St}$ \\
\hline $\begin{array}{c}\text { Chien and } \\
\text { Rubel } \\
(1992)\end{array}$ & 50.8 & $\begin{array}{l}\text { Steam- } \\
\text { Water }\end{array}$ & $\begin{array}{c}12.2 \\
- \\
39.6\end{array}$ & $\begin{array}{c}0.04- \\
1.5\end{array}$ & $\begin{array}{c}27.6- \\
41.4 \\
\text { (gauge) }\end{array}$ & Horizontal & $\begin{array}{c}\text { An, An- } \\
\text { Mt }\end{array}$ \\
\hline $\begin{array}{l}\text { Hong and } \\
\text { Griston } \\
(1995) \\
\end{array}$ & $\begin{array}{c}19.05,50.8 \\
101.6\end{array}$ & $\begin{array}{c}\text { Air- } \\
\text { Water }\end{array}$ & $\begin{array}{l}4.6- \\
22.9\end{array}$ & $\begin{array}{l}0.045- \\
1.35\end{array}$ & 1 (abs) & Horizontal & $\begin{array}{c}\text { An-Mt, } \\
\text { St }\end{array}$ \\
\hline $\begin{array}{c}\text { Fujii et al. } \\
\text { (1995) }\end{array}$ & 10 & $\begin{array}{l}\text { Nitrogen- } \\
\text { Water }\end{array}$ & $\begin{array}{l}0.03 \\
-12\end{array}$ & $\begin{array}{c}0.05- \\
0.5\end{array}$ & 1 (abs) & Horizontal & $\begin{array}{l}\text { St, W, } \\
\text { Sl, Pl, } \\
\text { An }\end{array}$ \\
\hline $\begin{array}{c}\text { Fujii et al. } \\
(1996)\end{array}$ & 10.5 & $\begin{array}{c}\text { Air- } \\
\text { Water }\end{array}$ & $\begin{array}{l}0.1- \\
7.0\end{array}$ & $\begin{array}{c}0.05- \\
0.5 \\
\end{array}$ & 1 (abs) & $\begin{array}{l}\text { Horizontal } \\
\text { and wye }\end{array}$ & $\mathrm{An}, \mathrm{Pl}$ \\
\hline $\begin{array}{c}\text { El- } \\
\text { Shaboury } \\
\text { et al. } \\
(2007) \\
\end{array}$ & 37.8 & $\begin{array}{c}\text { Air- } \\
\text { Water }\end{array}$ & $\begin{array}{c}0.5- \\
40\end{array}$ & $\begin{array}{l}0.01- \\
0.18\end{array}$ & $1.5(\mathrm{abs})$ & Horizontal & $\begin{array}{l}\text { St, W, } \\
\text { An }\end{array}$ \\
\hline $\begin{array}{c}\text { Mohamed } \\
\text { et al. } \\
(2011)\end{array}$ & 13.5 & $\begin{array}{c}\text { Air- } \\
\text { Water }\end{array}$ & $\begin{array}{l}2- \\
40\end{array}$ & $\begin{array}{l}0.01- \\
0.18\end{array}$ & $2(\mathrm{abs})$ & $\begin{array}{c}\text { Horizontal } \\
\text { inlets and } \\
\text { inclined } \\
\text { outlets }\end{array}$ & $\begin{array}{l}\text { St, W, } \\
\text { An }\end{array}$ \\
\hline $\begin{array}{l}\text { Elazhary } \\
\text { and } \\
\text { Soliman } \\
(2012)\end{array}$ & $\begin{array}{c}1.87 \times 20 \\
{[\text { rectangular] }}\end{array}$ & $\begin{array}{c}\text { Air- } \\
\text { Water }\end{array}$ & $\begin{array}{l}0.04 \\
-10\end{array}$ & $\begin{array}{c}0.02- \\
0.7\end{array}$ & $2(\mathrm{abs})$ & Horizontal & $\begin{array}{l}\mathrm{B}, \mathrm{Ch} \text {, } \\
\mathrm{Pl}, \mathrm{An}\end{array}$ \\
\hline $\begin{array}{c}\text { Mohamed } \\
\text { et al. } \\
(2014)\end{array}$ & $13.5,37.8$ & $\begin{array}{c}\text { Air- } \\
\text { Water }\end{array}$ & $\begin{array}{l}2- \\
40\end{array}$ & $\begin{array}{l}0.01- \\
0.18\end{array}$ & $\begin{array}{l}1.5,2 \\
(\mathrm{abs})\end{array}$ & Horizontal & $\begin{array}{l}\text { St, W, } \\
\text { An }\end{array}$ \\
\hline $\begin{array}{c}\text { Chen et } \\
\text { al. }(2014)\end{array}$ & $\begin{array}{l}0.5 \times 0.5 \\
\text { [square] }\end{array}$ & $\begin{array}{l}\text { Nitrogen- } \\
\text { Water }\end{array}$ & $\begin{array}{c}13- \\
30\end{array}$ & $\begin{array}{l}0.018 \\
-0.08 \\
\end{array}$ & $1.2(\mathrm{abs})$ & Horizontal & An \\
\hline $\begin{array}{l}\text { Chen et } \\
\text { al. (2015) }\end{array}$ & $\begin{array}{l}0.5 \times 0.5 \\
\text { [square] }\end{array}$ & $\begin{array}{l}\text { Nitrogen- } \\
\text { Water }\end{array}$ & $\begin{array}{l}0.36 \\
-2.4\end{array}$ & $\begin{array}{c}0.1- \\
0.9\end{array}$ & $\begin{array}{l}1.06- \\
1.15 \\
(\mathrm{abs}) \\
\end{array}$ & Horizontal & $\mathrm{Sl}$ \\
\hline $\begin{array}{l}\text { Sun et al. } \\
(2018)\end{array}$ & $\begin{array}{c}1 \times 0.5 \\
{[\text { rectangular] }}\end{array}$ & $\begin{array}{l}\text { Nitrogen- } \\
\text { Water }\end{array}$ & $\begin{array}{c}0.47 \\
- \\
15.1\end{array}$ & $\begin{array}{c}0.01- \\
0.41\end{array}$ & $1.2(\mathrm{abs})$ & Horizontal & $\begin{array}{l}\text { An, Sl, } \\
\text { Sl-An }\end{array}$ \\
\hline
\end{tabular}

* St - Stratified, W - Wavy, An - Annular, Sl- Slug, PI - Plug, B - Bubbly, Mt - Mist, Ch - Churn, B-St Bubbly-Stratified, An-Mt-Annular-Mist, St-An-Stratified-Annular

One of the earliest studies on impacting tee junctions with air-water two-phase flow was by Hong (1978). For his set-up, the author used a 9.5-mm diameter horizontal impacting 
tee junction. Data were obtained for one set of inlet conditions only. The inlet superficial liquid velocity used, $J_{\mathrm{L} 1}$, was $0.02 \mathrm{~m} / \mathrm{s}$ and inlet superficial gas velocity, $J_{\mathrm{G} 1}$, was $27.4 \mathrm{~m} / \mathrm{s}$ which fell in the annular flow regime according to Mandhane et al. (1974) map. It was found that equal phase split occurs for vapor extraction ratio of 0.15 to 0.85 which contradicts the results of other researchers, as will be shown later. It was then suspected that due to the small diameter used, Hong's data were influenced by strong surface tension.

Azzopardi et al. (1986a) also worked with air-water two-phase flows in an impacting tee junction with vertical inlet and horizontal outlets. The authors used a 31.8 -mm pipe diameter for both the inlet and outlets. The liquid flow rate ranged from 0.0252 to $0.0630 \mathrm{~kg} / \mathrm{s}$ and the gas flow rate ranged from 0.0157 to $0.0346 \mathrm{~kg} / \mathrm{s}$ which corresponded to an annular inlet flow regime. The inlet quality ranged from 0.21 to 0.58 and the operating pressure was 1.7 bar. The authors found thatequal phase split in the two outlets occurs only when there is equal mass split. For mass-split ratio less than 0.5 , the outlet with the lower air flow has proportionately more liquid. For mass-split ratios higher than 0.5 , the data were mirror image of the low-masssplit-ratio data. A model was also proposed to predict phase separation for annular flow through an impacting junction with vertical or horizontal inlet.

Azzopardi et al. (1986b) continued the work of Azzopardi et al. (1986a) with air-water two-phase flow using the same experimental set-up. The authors extended the range of inlet conditions while maintaining the same operating pressure of 1.7 bar. The inlet liquid flow rate was varied from 0.06 to $0.620 \mathrm{~kg} / \mathrm{s}$ and the inlet gas flow rate was varied from 0.0025 to 0.006 $\mathrm{kg} / \mathrm{s}$ which identifies as churn flow. A similar trend of phase redistribution for annular flow to that of Azzopardi et al. (1986a) was found. Gas flow splits 50/50 in the two outlets only when liquid splits equally. The authors found that phase redistribution was not affected by the inlet liquid and gas flow rates under these test conditions. The model presented by Azzopardi et al. (1986a) for annular flow was modified to predict phase redistribution for churn flow. 
Hwang et al. (1989) conducted experimental and analytical studies with a horizontal equal-sided tee and two wye junctions with 38 -mm internal diameter pipes using air-water twophase flows. For this study, an operating pressure of $0.13-0.19 \mathrm{MPa}$ was used. The inlet mass fluxes were 1350,2050 and $2700 \mathrm{~kg} / \mathrm{m}^{2} \mathrm{~s}$ and the inlet qualities were $0.002,0.003$ and 0.004 . The corresponding inlet flow regimes were bubbly and bubbly-stratified flows. The authors reached the same conclusion as Azzopardi et al. (1986a, 1986b) that equal phase split in the outlet branches happens only when there was equal mass split. This verifies that this condition applies for both horizontal and vertical inlets. The authors presented the data in terms of quality ratio $\left(x_{3} / x_{1}\right)$ versus mass split ratio $\left(W_{3} / W_{1}\right)$ graphs. The graphs showed that all the gas entered Outlet-3 when $W_{3} / W_{1}>0.6$. Only a little amount of the gas that entered, left through Outlet-3 for $W_{3} / W_{1}<0.4$. In between, both gas and liquid were present in Outlet-3 for all inlet conditions tested. In addition to the experimental data, an analytical model was derived based on the "dividing streamline concept", which was able to predict $95 \%$ of the presented data within $\pm 25 \%$.

Chien and Rubel (1992) conducted phase-redistribution experiments with an equal sided 50.8-mm diameter horizontal impacting tee using wet steam. The inlet pressure was varied from 27.6 to 41.4 bars, the inlet quality $\left(x_{1}\right)$ ranged from 0.2 to 0.8 , gas extraction ratio $\left(F_{\mathrm{G} 3}\right)$ ranged from 0.2 to 0.5 , and inlet vapor superficial velocity $\left(J_{\mathrm{G} 1}\right)$ ranged from 12 to $40 \mathrm{~m} / \mathrm{s}$ which corresponded to annular and annular-mist flow regimes. Chien and Rubel findings matched those of previous authors that gas flow splits 50/50 in the two outlets only when liquid splits equally. The authors presented the data in terms of quality ratio $\left(x_{3} / x_{1}\right)$ versus mass split ratio $\left(W_{3} / W_{1}\right)$ graphs. From the graphs, it was observed that as the gas extraction ratio $\left(F_{\mathrm{G} 3}\right)$ increased from 0 to 0.5 , the difference between outlet and inlet steam qualities reduces under the tested conditions. Keeping other parameters constant, when $J_{\mathrm{G} 1}$ was varied $(12.2,18.3,24.4$ and 33.5 $\mathrm{m} / \mathrm{s}$ ) only a slight change in outlet steam quality $\left(x_{3}\right)$ was observed for a given $x_{1}$. Varying the 
inlet pressure had no significant effect on the data. Therefore, it was concluded that $F_{\mathrm{G} 3}$ and $x_{1}$ had more influence on phase redistribution in impacting tees as compared to inlet steam pressure and velocity.

Hong and Griston (1995) looked at phase redistribution through a 19.05-mm diameter horizontal equal-sided impacting tee using air-water two-phase flow. The aim of this study was to discover a method to predict the qualities of the outlet streams and to test insert devices to increase the range of $F_{\mathrm{G} 3}$ for even phase split. In this study, $F_{\mathrm{G} 3}$ ranged from 0.05 to 0.95 , upstream liquid volume fraction varied from 0.005 to 0.06 , and inlet gas superficial velocity ranged from $4.6 \mathrm{~m} / \mathrm{s}$ to $22.9 \mathrm{~m} / \mathrm{s}$. In agreement with previous studies on impacting junctions, it was observed that the vapor does not divide equally in the two outlets except when the liquid streams split equally in the two outlets. It was also found that at the lowest $J_{\mathrm{G} 1}$ of $4.6 \mathrm{~m} / \mathrm{s}$ and upstream liquid volume fraction of 0.01 , equal phase split occurs throughout the entire range of extraction ratio. As $J_{\mathrm{G} 1}$ increased at a constant volume fraction, phase-redistribution extent increased such that no gas was observed flowing through Outlet-3 until the mass split ratio reached a value between 0.15 and 0.3 . The effect of $J_{\mathrm{G} 1}$ on phase redistribution lessens as the input liquid fraction increased further, which is in agreement with the findings of Chien and Rubel (1992).

In addition, Hong and Griston (1995) studied the behavior of phase redistribution when the junction diameter is varied through a series of field tests. Two different nominal diameters, 50.8-mm and 101.6-mm were investigated.Furthermore, multiple tee insert devices were tested to find the most suitable device that would improve the range of mass extraction ratio over which even phase split occurs. The tests were conducted with inlet superficial gas velocities ranging from 1.48 to $21.44 \mathrm{~m} / \mathrm{s}$. The inlet liquid volume fraction varied from 0.007 to 0.145 . For the smaller diameter, even phase distribution occurs only at even mass split. For the larger diameter, even phase split occurred over the entire range of test conditions, when $J_{\mathrm{G} 1}$ was kept 
below $6 \mathrm{~m} / \mathrm{s}$. A pre-separator vane, downstream nozzles and vane/nozzle combinations were some of the insert devices that showed the best results.

Fujii et al. (1995) worked on phase redistribution through a horizontal impacting equalsided tee junction of $10-\mathrm{mm}$ diameter using nitrogen-water mixtures. The purpose of their study was to analyze the effect of inlet conditions on phase redistribution. In their experiments, the liquid superficial velocities were between 0.05 and $0.5 \mathrm{~m} / \mathrm{s}$, gas superficial velocities varied between 0.03 and $12 \mathrm{~m} / \mathrm{s}$, and the junction pressure was maintained at 1.0 bar. These conditions corresponded to plug, slug, annular, stratified, and wavy flow regimes. Phase-redistribution data were acquired over the whole range of extraction ratios ranging from 0 to 1 . The authors conducted experiments under microgravity to determine the potential of impacting tee junction in space application such as a phase separator for two-phase flow in thermal control systems. As predicted, the qualities of both inlet and outlet were equal at the point $F_{\mathrm{L} 3}=F_{\mathrm{G} 3}=0.5$. The authors found that phase redistribution is highly influenced by the inlet flow regime. In addition, at higher inlet gas velocity, the effect of inlet liquid velocity on phase redistribution intensifies. These findings match the observations by Hwang et al. (1989) and Hong and Griston (1995).

Fujii et al. (1996) presented phase-redistribution data for two-phase (air-water) flow through horizontal impacting tee and wye junctions of 10.5 -mm internal diameter. The inlet conditions tested corresponded to annular and plug inlet flow regimes. For $W_{3} / W_{1}<0.5$, no gas flow was detected in Outlet-3. As the extraction ratio was increased, gas started to flow through Outlet-3 until a point where all the gas left through Outlet-3. Similar pattern to that obtained for impacting tees was observed for impacting wyes. The point of $F_{\mathrm{G} 3}=1$ occurred at a lower extraction ratio for the impacting wye junctions due to the reduced angle between the inlet and Outlet-3. 
El-Shaboury et al. (2007) studied the effects of flow regime and inlet quality on phase redistribution in a horizontal equal-sided impacting tee junction using air-water two-phase flow. The internal diameter of all pipes was $37.8 \mathrm{~mm}$. In their experiments, the authors used inlet velocities $J_{\mathrm{G} 1}$ and $J_{\mathrm{L} 1}$ of $0.5-40 \mathrm{~m} / \mathrm{s}$ and $0.01-0.18 \mathrm{~m} / \mathrm{s}$, respectively. These inlet conditions corresponded to stratified, wavy, and annular flow regimes. Data for the whole range of extraction ratios were tested. The junction was maintained at $1.5 \mathrm{bar}$ (abs) and ambient temperature. The authors generated pressure-drop data, from which a model was proposed that could predict the pressure drop and phase redistribution. The proposed model was able to predict the phase distribution and pressure drop for the studied inlet conditions, which was in good agreement with the experimental data and other data from the literature. The authors concluded that, an even phase split is obtained only at the point $F_{\mathrm{L} 3}=F_{\mathrm{G} 3}=0.5$. In addition, for a single flow regime at fixed $J_{\mathrm{L} 1}$, increasing $J_{\mathrm{G} 1}$ caused the phase-redistribution curves to rotate in counter-clockwise direction around the equal phase split point on a $F_{\mathrm{L} 3}$ versus $F_{\mathrm{G} 3}$ graph. The opposite was observed for increasing $J_{\mathrm{L} 1}$ at fixed $J_{\mathrm{G} 1}$. Furthermore, the inlet quality $\left(x_{1}\right)$ was tested for each flow regime. As the inlet quality $\left(x_{1}\right)$ increased, the phase-redistribution data lines rotated in counter-clockwise direction around the point $(0.5,0.5)$. In the boundary of stratified and wavy flow regime, the influence of inlet quality and velocity were found to be continuous, and not in the boundary between wavy and annular flow regime. In summary, phase redistribution at the junction depended heavily on the inlet conditions, flow regime and total mass split at the junction.

Mohamed et al. (2011) studied the effects of inlet flow regime, mass extraction ratio at the junction, and angle of inclination of the outlets $(\theta)$ on phase separation through an equalsided impacting tee junction with a horizontal inlet and inclined outlets. The authors varied the angle of inclination of the outlet branches $(\theta)$ from $0^{\circ}$ to $90^{\circ}$. The experiments were conducted with a $13.5-\mathrm{mm}$ I.D. junction. In their experiments, air-water two phase flow were used as the 
working fluids with inlet liquid superficial velocities of 0.01 to $0.18 \mathrm{~m} / \mathrm{s}$ and gas superficial velocities of 2 to $40 \mathrm{~m} / \mathrm{s}$, which corresponded to stratified, wavy and annularflow regimes. The junction was maintained at a pressure of $200 \mathrm{kPa}(\mathrm{abs})$, and the inlet quality varied from 0.1 to 0.9. It was found that, as the angle of inclination increases and/or $J_{\mathrm{G} 1}$ decreases, the partialphase-separation curve moves in the counter-clockwise direction away from the equal phase split point on $F_{\mathrm{G} 3}$ vs. $F_{\mathrm{L} 3}$ plot, for all inlet conditions and all mass split ratios. Phase separation in stratified flow is very sensitive to the outlet angle and full-phase separation was obtained at angles as low as $0.7^{\circ}$. Phase separation in wavy flow regime is less sensitive to inclination angle, followed by annular flow regime. The authors concluded that, phase separation is affected by the inlet conditions, the mass split ratio at the junction, and the inclination angle of the outlets.

Elazhary and Soliman (2012) conducted phase-redistribution experiments on a horizontal impacting tee junction with a rectangular cross-section of $1.87 \mathrm{~mm} \times 20 \mathrm{~mm}$ using air-water two-phase flow at $200 \mathrm{kPa}$ (abs) nominal junction pressure and room temperature. The inlet velocities $J_{\mathrm{G} 1}$ and $J_{\mathrm{L} 1}$ ranged from 0.04 to $10 \mathrm{~m} / \mathrm{s}$ and 0.02 to $0.7 \mathrm{~m} / \mathrm{s}$, respectively. These inlet conditions corresponded to bubbly, plug, churn and annular flow regimes. In addition, a model was proposed based on that devised by Hwang et al. (1989), which would help predict phase redistribution of two-phase flows. The model constructed was in good agreement with the experimental results with a deviation range of only $-15 \%$ to $+20 \%$. Similar trends of phase-redistribution curves were observed to those obtained using macro-sized horizontal impacting junctions with circular cross-section of 37.8-mm diameter by ElShaboury et al. (2007). However, under similar conditions, $J_{\mathrm{L} 1}$ had a significantly larger effect on the values of $F_{\mathrm{L}}$ for the macro junctions used by El-Shaboury et al. (2007) as compared to the mini-sized junctions used in this study. 
Mohamed et al. (2014) studied the effect of varying the pipe diameter and operating pressure on phase redistribution through a horizontal impacting junction using air-water twophase flow. For their experiments, $J_{\mathrm{G} 1}$ and $J_{\mathrm{L} 1}$ ranged from 2 to $40 \mathrm{~m} / \mathrm{s}$ and from 0.01 to 0.18 $\mathrm{m} / \mathrm{s}$, respectively, which fell in the stratified, wavy and annular flow regimes. The experiments were performed at operating pressures of 150 and $200 \mathrm{kPa}(\mathrm{abs})$. The data obtained with their set-up $(D=13.5 \mathrm{~mm})$ were compared with the data obtained by El-Shaboury et al. (2007) with $D=37.8 \mathrm{~mm}$, under $150 \mathrm{kPa}$ (abs) operating pressure. It was found that the diameter had no significant effect on phase redistribution irrespective of flow regimes, and that the system pressure affected phase redistribution more as either $J_{\mathrm{G} 1}$ or $J_{\mathrm{L} 1}$ decreased for stratified and wavy flows.

Chen et al. (2014) compared the phase-redistribution behavior between mini and macro channels of impacting tee junction with square cross-section of $0.5 \mathrm{~mm} \times 0.5 \mathrm{~mm}$ using nitrogen-water two-phase mixture. In their work, $J_{\mathrm{G} 1}$ and $J_{\mathrm{L} 1}$ were varied from 13 to $30 \mathrm{~m} / \mathrm{s}$ and from 0.018 to $0.08 \mathrm{~m} / \mathrm{s}$, respectively, which corresponded to annular flow regime. Data were presented in $F_{\mathrm{G} 3}$ versus $F_{\mathrm{L} 3}$ graphs. It was found that the inlet velocities, $J_{\mathrm{G} 1}$ and $J_{\mathrm{L} 1}$, have minor effect on phase redistribution for micro-channels for the whole range of inlet conditions. As expected, equal phase separation was observed at $W_{3} / W_{1}=0.5$. For mass-split ratios higher than 0.5 , the data were an inverted mirror image of the low-mass-split-ratio data. The phaseredistribution curve gradient from $F_{\mathrm{G} 3}=0$ to 0.15 is higher compared to that from 0.15 to 0.5 , which indicates that there is a peak in phase redistribution at $F_{\mathrm{G} 3}=0.15$. It was also found that increasing surface tension causes a significant increase in phase redistribution particularly at $F_{\mathrm{G} 3 \neq} 0.5$. In addition, phase redistribution was more severe in slug flow as compared to annular flow. Furthermore, under all tested conditions, phase redistribution was not affected by viscous forces. In comparison with the results of Azzopardi et al. (1986a) with hydraulic diameter of 31.8-mm (macro-channel) and Elazhary and Soliman (2012) with hydraulic diameter of 3.4- 
mm (mini-channel), Chen et al. (2014) phase redistribution was less severe with their testsection of $0.5 \mathrm{~mm} \times 0.5 \mathrm{~mm}$ micro-channel.

Chen et al. (2015) used the same experimental set-up as Chen et al. (2014). The gas and liquid inlet superficial velocities were varied from 0.36 to $2.4 \mathrm{~m} / \mathrm{s}$ and 0.1 to $0.9 \mathrm{~m} / \mathrm{s}$, respectively, which corresponded to slug flow regime. The junction was maintained at $18^{\circ} \mathrm{C}$ and $0.106-0.115 \mathrm{MPa}(\mathrm{abs})$ test pressure. Data were presented in terms of $F_{\mathrm{G} 3}$ versus $F_{\mathrm{L} 3}$ graphs. At $F_{\mathrm{G} 3}=0.5$, the qualities at the inlet and both outlets were equal, which agrees with all previous studies. In addition, due to symmetry of test section and mass balance, the two parts of the curve before and after the point $(0.5,0.5)$ are an inverted mirror image of each other. It was found that, at constant $J_{\mathrm{L} 1}$, an increase in $J_{\mathrm{G} 1}$ causes an increase in length of inlet gas slugs $\left(L_{\mathrm{GS}}\right)$. However, at constant $J_{\mathrm{G} 1}$, an increase in $J_{\mathrm{L} 1}$ causes a decrease in $L_{\mathrm{GS}} . J_{\mathrm{G} 1}$ has a larger influence than $J_{\mathrm{L} 1}$ on phase redistribution. Furthermore, the authors established that surface tension affects the lengths of inlet gas slugs $\left(L_{\mathrm{GS}}\right)$ which influences phase redistribution. Phase redistribution increased with large $L_{\mathrm{GS}}\left(>5 D_{\mathrm{h}}\right)$ and decreased surface tension. The opposite is true for small $L_{\mathrm{GS}}\left(<5 D_{\mathrm{h}}\right)$ and decreased surface tension.

Sun et al. (2018) experimented with nitrogen-water through a horizontal microimpacting tee junction to study the effect of the cross-sectional diameter of the outlets on phase redistribution. The test conditions in this study were varied from 0.47 to $15.1 \mathrm{~m} / \mathrm{s}$ and from 0.0130 to $0.4102 \mathrm{~m} / \mathrm{s}$ for gas and liquid inlet superficial velocities, respectively, at a system pressure of $120 \mathrm{kPa}(\mathrm{abs})$ and room temperature. These conditions corresponded to slug, annular and slug-annular flow regimes. The inlet cross-section was $1000 \mu \mathrm{m} \times 500 \mu \mathrm{m}$ while the outlets' dimensions were varied $(400 \mu \mathrm{m} \times 500 \mu \mathrm{m}, 600 \mu \mathrm{m} \times 500 \mu \mathrm{m}$ and $800 \mu \mathrm{m} \times 500$ $\mu \mathrm{m})$. The authors introduced two parameters in their work. One is the separation efficiency, $\eta$ $=\left|F_{\mathrm{G} 3}-F_{\mathrm{L} 3}\right|$, which was formulated by Chen et al. (2015) to evaluate the separation effect, where a low $\eta$ indicates uniform phase redistribution in the two outlets, and the second is the 
influencing degree, $I$, which was introduced to quantify the effect of branch channel diameter on phase redistribution. The parameter $I$ was defined as:

$$
I=\frac{\Delta F_{L, \max }}{\Delta F_{L, 800 \mu m}} \times 100 \%
$$

where $\Delta F_{\mathrm{L}, \max }=$ maximum difference in $F_{\mathrm{L}}$ at fixed $F_{\mathrm{G}}=\left[F_{\mathrm{L}, 400 \mu \mathrm{m}}-F_{\mathrm{L}, 800 \mu \mathrm{m}}\right]_{\max }$ and $F_{\mathrm{L}, 400 \mu \mathrm{m}}$, $F_{\mathrm{L}, 600 \mu \mathrm{m}}, F_{\mathrm{L}, 800 \mu \mathrm{m}}=F_{\mathrm{L} 3}$ at branch diameters $400 \mu \mathrm{m}, 600 \mu \mathrm{m}$ and $800 \mu \mathrm{m}$, respectively.

The results obtained by Sun et al. (2018) were consistent with all other previous work in the observation that equal phase split was obtained only at equal mass extraction and data points were inverted mirror image around the point $(0.5,0.5)$ in $F_{\mathrm{L} 3}$ versus $F_{\mathrm{G} 3}$ graphs. The authors found that data points for annular flow were the closest to the equal phase-redistribution line in $F_{\mathrm{L} 3}$ versus $F_{\mathrm{G} 3}$ graphs, followed by slug flows and slug-annular flows. Furthermore, decreasing the cross sections of the outlets enhanced phase redistribution, for all flow regimes. On the other hand, influence degree, $I$, was lowest for annular flow (13.08\%), followed by slug $(13.13 \%)$ flow and highest for slug-annular flow (37.15\%) which indicates that varying the cross-sectional diameter has the most influence on phase redistribution for slug-annular flow. The separation efficiency, $\eta$, decreased as the gas extraction ratio increased from 0 to 0.5 and increased beyond $F_{\mathrm{G} 3}>0.5$, for all flow regimes. The parameter $\eta$ was highest for slug-annular flow, followed by slug flow and annular flow, which indicates that phase redistribution is most uniform in annular flow.

\subsubsection{Studies on Full-Phase Separation with Single Impacting Tee Junctions}

Only few studies in the literature looked at full-phase separation of two-phase flow through a single impacting tee junction. Most studies were aimed at finding the range of mass split ratios for which even phase split is attainable, at specific working conditions. In this thesis, full-phase separation is defined as the complete separation of phases where each of the two outlets receive a single-phase flow for a specific operating condition. Even though Hwang et 
al. (1989) and Fujii et al. (1995) used the term "phase separation" in reporting their results, their definition of phase separation does not match the one used in this thesis therefore cannot be cited as work on full-phase separation. Details on these works can be found in Section 2.2.1. Table 2.2 summarizes the available literature on phase separation using a single impacting tee junction.

Table 2.2: Previous literature on phase separation using a single impacting tee junction

\begin{tabular}{|c|c|c|c|c|c|c|c|c|}
\hline Author(s) & $\begin{array}{l}\text { Inlet } \\
\text { Dia. } \\
(\mathbf{m m})\end{array}$ & $\begin{array}{c}\text { Outlet } \\
\text { Dia. } \\
\text { (mm) }\end{array}$ & $\begin{array}{c}\text { Test } \\
\text { Fluids }\end{array}$ & $\begin{array}{c}J_{\text {G1 }} \\
(\mathbf{m} / \mathbf{s})\end{array}$ & $\begin{array}{c}J_{\mathbf{L} 1} \\
(\mathbf{m} / \mathbf{s})\end{array}$ & $\begin{array}{c}\text { System } \\
\text { Pressure } \\
\text { (bar) }\end{array}$ & $\begin{array}{c}\text { Tee } \\
\text { Junction } \\
\text { Orientation }\end{array}$ & $\begin{array}{c}\text { Inlet } \\
\text { Flow- } \\
\text { Regime }\end{array}$ \\
\hline $\begin{array}{c}\text { Mohamed } \\
\text { et al. } \\
(2012)\end{array}$ & 13.5 & 13.5 & $\begin{array}{c}\text { Air- } \\
\text { Water }\end{array}$ & $2-40$ & $\begin{array}{c}0.01- \\
0.18\end{array}$ & 2 (abs) & $\begin{array}{c}\text { Horizontal } \\
\text { inlet and } \\
\text { inclined } \\
\text { outlets }\end{array}$ & $\begin{array}{l}\text { St-W, } \\
\text { St, An, } \\
\text { Ch, D }\end{array}$ \\
\hline $\begin{array}{l}\text { Tuo and } \\
\text { Hrnjak } \\
(2012)\end{array}$ & 8.7 & $\begin{array}{c}13.4 \\
\& \\
18.3\end{array}$ & R134a & $\begin{array}{l}0.5- \\
5.6\end{array}$ & $0.1-0.4$ & - & $\begin{array}{c}\text { Horizontal } \\
\text { inlet and } \\
\text { vertical } \\
\text { outlets }\end{array}$ & $\begin{array}{c}\text { St-W, } \\
\text { St, An, } \\
\text { Ch, D }\end{array}$ \\
\hline $\begin{array}{l}\text { Zheng et } \\
\text { al. (2016) }\end{array}$ & 8 & 17.5 & R134a & $\begin{array}{l}2.2- \\
5.8\end{array}$ & $\begin{array}{c}0.02- \\
0.43\end{array}$ & - & $\begin{array}{c}\text { Horizontal } \\
\text { inlet and } \\
\text { vertical } \\
\text { outlets }\end{array}$ & $\begin{array}{c}\text { Sl, St- } \\
\text { W, An, } \\
\text { Int }\end{array}$ \\
\hline
\end{tabular}

*St - Stratified, W - Wavy, An - Annular, Sl - Slug, Ch - Churn, Int - Intermittent, D - Droplet, St-W Stratified-Wavy

Mohamed et al. (2012) managed to obtain full-phase separation at 200-kPa (abs) pressure using a 13.5-mm diameter single equal-sided impacting tee. In their work, the authors reported inlet velocities of liquid and gas for which full separation of phases was obtained at multiple inclination angles of the outlet branches, $\theta=2.5^{\circ}, 7.5^{\circ}, 15^{\circ}, 30^{\circ}, 60^{\circ}, 75^{\circ}$ and $90^{\circ}$ while keeping the inlet horizontal. As $\theta$ increased, the values of the limiting conditions of the inlet velocities for full-phase separation increased. At $\theta=90^{\circ}$ (vertical outlets), the largest range of inlet velocities, $J_{\mathrm{G} 1}$ and $J_{\mathrm{L} 1}$, was obtained. The authors reported that for all values of $\theta$, the influence of $J_{\mathrm{L} 1}$ on the value of $J_{\mathrm{G} 1}$ for full separation decreases as $J_{\mathrm{L} 1}$ decreases. In addition, the influence of $J_{\mathrm{G} 1}$ on the value of $J_{\mathrm{L} 1}$ for full separation decreases as the $J_{\mathrm{G} 1}$ 
decreases. The authors proposed a model to predict the values of $J_{\mathrm{G} 1}$ and $J_{\mathrm{L} 1}$ at which full separation of phase occurs at various $\theta$. This model was based on observations near limiting conditions of phase separation. The model was in good agreement with the results obtained experimentally, within $\pm 20 \%$.

Tuo and Hrnjak (2012) looked at the effects of altering various parameters on phase separation of two-phase refrigerant R134a through an impacting tee junction with vertical outlets, shown in Figure 2.1. The parameters varied were inlet quality, outlet branch diameter, inlet mass flux, and angle of inclination of the inlet tube. The angle of inclination of inlet tube from horizontal $(\theta)$ ranged from $0^{\circ}$ to $45^{\circ}$. The inlet quality and inlet flow rate ranged from 0.1 to 0.3 and $10 \mathrm{~g} / \mathrm{s}$ to $35 \mathrm{~g} / \mathrm{s}$, respectively. These conditions corresponded to stratified-wavy, stratified, churn, annular and droplet flow regimes as visualized at the inlet of the junction. Two parameters were used by the author, separation efficiency of liquid and vapor $\left(\eta_{1}\right.$ and $\left.\eta_{v}\right)$, which were defined as:

$$
\begin{gathered}
\eta_{1}=\frac{W_{l, b}}{W_{l, i}} \\
\eta_{\mathrm{v}}=\frac{W_{v, t}}{W_{v, i}}
\end{gathered}
$$

where i, b and trepresent the inlet, bottom and top outlets, respectively. The authors found that $J_{\mathrm{G} 1}$ and $J_{\mathrm{L} 1}$ increased when the inlet mass flow rate and inlet quality increased, causing the separation efficiency to decrease. The increase in the inlet velocities forced more liquid to flow to the upper outlet due to vapor drag force and liquid inertial force. At $\theta=0^{\circ}$ and inlet quality of 0 to 0.26 , the liquid separation efficiency was $100 \%$ for inlet flow rates up to $20 \mathrm{~g} / \mathrm{s}$. As the flowrate increases to reach $35 \mathrm{~g} / \mathrm{s}, \eta_{1}$ drops down to almost $75 \%$. Increasing from $\theta=0^{\circ}$ (horizontal) to $\theta=45^{\circ}$, had a positive effect on liquid separation efficiency due to the downward component of inlet velocity. On the contrary, decreasing the outlet diameter from 
$18.3 \mathrm{~mm}$ to $13.4 \mathrm{~mm}$ had a drastic effect on $\eta_{1}$, dropping from $80 \%$ to $62 \%$. In addition, the authors stated that the use of dual inlet tee junction as a pre-separation mechanism improved the separation performance as compared to the single inlet configuration.

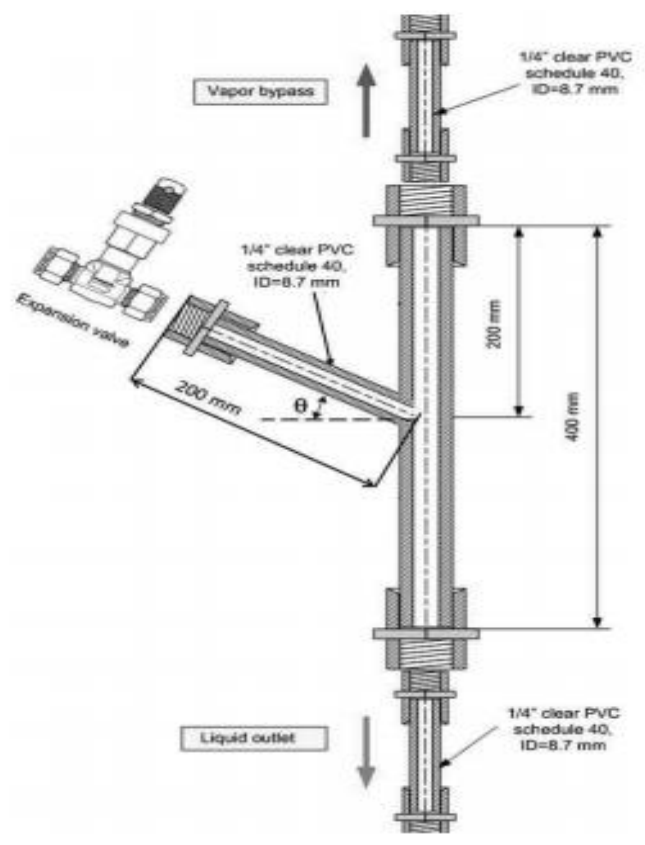

Figure 2.1: Detailed schematic of the tee junction separator used by Tuo and Hrnjak (2012)

Zheng et al. (2016) examined the viability of using a vertical impacting tee junction as a phase separator. For their experiments, two-phase R134a refrigerant was used. The internal diameter of the inlet and outlets were $8 \mathrm{~mm}$ and $17.5 \mathrm{~mm}$, respectively. The ranges of $J_{\mathrm{G} 1}$ and $J_{\mathrm{L} 1}$ studied in this work were $2.2-5.8 \mathrm{~m} / \mathrm{s}$ and $0.02-0.43 \mathrm{~m} / \mathrm{s}$, respectively, and inlet mass flux range of $100 \mathrm{~kg} / \mathrm{m}^{2} \mathrm{~s}$ to $600 \mathrm{~kg} / \mathrm{m}^{2} \mathrm{~s}$, while the inlet quality varied from 0.1 to 0.6 which covered stratified-wavy, annular, and intermittent flow regimes. The authors used liquid and gas separation efficiency parameters defined as:

$$
\begin{aligned}
& \eta_{\text {liq }}=F_{\mathrm{L} 2} \times 100 \% \\
& \eta_{\text {vap }}=F_{\mathrm{G} 3} \times 100 \%
\end{aligned}
$$

where 2 and 3 represent lower and upper outlets, respectively. 
The authors found that for fully open valves in outlets, as inlet mass flux and/or quality increased, that liquid separation efficiency decreased. For a particular inlet quality of 0.1 , when the inlet mass flux is increased from 100 to $400 \mathrm{~kg} / \mathrm{m}^{2} \mathrm{~s}, \eta_{\text {liq }}$ decreased by $2.5 \%$. If the mass flux is increased further to $600 \mathrm{~kg} / \mathrm{m}^{2} \mathrm{~s}$, the efficiency would decrease by a significant $20 \%$. For mass fluxes less than $200 \mathrm{~kg} / \mathrm{m}^{2} \mathrm{~s}$, $\eta$ liq remained above $95 \%$ but decreased slightly as the inlet quality increased. Furthermore, a separation efficiency of $97.5 \%$ was attained when $J_{\mathrm{G} 1}$ was kept at roughly $2.2 \mathrm{~m} / \mathrm{s}$. For the whole range of inlet qualities, $\eta_{\text {liq }}$ increased with increase in the mass extraction ratio in the bottom outlet $\left(W_{2} / W_{1}\right)$. Furthermore, if either $W_{2} / W_{1}=0.75$ or the mass flux remained less than $200 \mathrm{~kg} / \mathrm{m}^{2} \mathrm{~s}, \eta_{\text {liq }}$ could be kept within $90 \%$. Their studies concluded that the liquid separation efficiency is inversely proportional to Froude number(Fr).

In addition to the experimental work, Zheng et al. (2016) presented a model which can predict phase separation in vertical impacting tee junction based on a correlation between the fraction of liquid in the upward branch and Froude number (Fr). The model was able to predict phase separation with a deviation of $6.4 \%$ and $6.9 \%$ for annular and stratified-wavy two-phaseflows, respectively.

\subsection{Studies on Multiple Tee Junctions}

Studies on phase redistribution using tee junctions are becoming increasingly common. Researchers are now exploring new ways to achieve total phase separation using the knowledge on tee junctions. Different techniques have been implemented to achieve total phase separation, one of which was the use of multiple tee junctions. One common method used to achieve fullphase separation is by using multiple branching-type tee junction in series. On the other hand, fewer studies were done on phase separation or redistribution using multiple impacting tee junctions to the best of the author's knowledge. 
In order to achieve a desirable degree of separation at a wider range of operating conditions, multiple junctions are needed (Mohamed et al., 2012). Table 2.3 shows a summary of the currently available studies on two-phase flows through multiple tee junctions.

Table 2.3: Literature on two-phase flows through multiple tee junction systems

\begin{tabular}{|c|c|c|c|c|c|c|c|}
\hline Author(s) & $\begin{array}{l}\text { Inlet } \\
\text { Dia. } \\
(\mathbf{m m})\end{array}$ & $\begin{array}{c}\text { Test } \\
\text { Fluids }\end{array}$ & $\begin{array}{c}J_{G 1} \\
(\mathbf{m} / \mathbf{s})\end{array}$ & $\begin{array}{c}J_{L 1} \\
(\mathbf{m} / \mathbf{s})\end{array}$ & $\begin{array}{c}\text { System } \\
\text { Pressure } \\
\text { (bar) }\end{array}$ & $\begin{array}{c}\text { Number } \\
\text { and Type } \\
\text { of Tee } \\
\text { Junctions }\end{array}$ & $\begin{array}{c}\text { Inlet } \\
\text { Flow- } \\
\text { Regime }\end{array}$ \\
\hline $\begin{array}{c}\text { Wren and } \\
\text { Azzopardi } \\
(2004)\end{array}$ & 127 & $\begin{array}{c}\text { Air- } \\
\text { Water }\end{array}$ & $4-8$ & $\begin{array}{c}0.186- \\
0.31\end{array}$ & $\begin{array}{c}1-1.05 \\
\text { (abs) }\end{array}$ & $\begin{array}{c}2 \\
\text { Branching }\end{array}$ & St, S-An \\
\hline $\begin{array}{l}\text { Baker et al. } \\
\quad(2007)\end{array}$ & 38 & $\begin{array}{c}\text { Air- } \\
\text { Kerosene }\end{array}$ & $3.3-9.6$ & $\begin{array}{c}0.07- \\
0.51\end{array}$ & 6 (gauge) & $\begin{array}{c}2 \\
\text { Branching }\end{array}$ & $\mathrm{St}, \mathrm{Sl}$ \\
\hline $\begin{array}{c}\text { Yang et al. } \\
\text { (2010) }\end{array}$ & 10 & $\begin{array}{c}\text { Air- } \\
\text { Water }\end{array}$ & $\begin{array}{c}0.28- \\
0.75\end{array}$ & $\begin{array}{l}0.06- \\
0.680\end{array}$ & 2 (abs) & $\begin{array}{c}3,5,7 \\
\text { Branching }\end{array}$ & St, Pl \\
\hline $\begin{array}{l}\text { Chen et al. } \\
\text { (2012) }\end{array}$ & 40 & $\begin{array}{c}\text { Oil- } \\
\text { Water }\end{array}$ & - & - & - & $\begin{array}{c}1-7 \\
\text { Branching }\end{array}$ & St \\
\hline $\begin{array}{c}\text { Tuo and } \\
\text { Hrnjak (2014) }\end{array}$ & 8.7 & $\begin{array}{l}\text { R134a, } \\
\text { R410A }\end{array}$ & $\begin{array}{l}0.26- \\
5.46\end{array}$ & $\begin{array}{c}0.098- \\
0.5\end{array}$ & - & $\begin{array}{c}3 \\
\text { Impacting }\end{array}$ & $\begin{array}{c}\text { St, W, Ch, } \\
\text { Mt }\end{array}$ \\
\hline $\begin{array}{l}\text { Yang et al. } \\
\text { (2017) }\end{array}$ & 10 & $\begin{array}{c}\text { Air- } \\
\text { Water }\end{array}$ & $\begin{array}{c}0.275- \\
0.9\end{array}$ & $\begin{array}{c}0.056- \\
0.551\end{array}$ & 2 (abs) & $\begin{array}{c}3,5,7 \\
\text { Branching }\end{array}$ & St, Pl \\
\hline $\begin{array}{c}\text { Noor and } \\
\text { Soliman } \\
(2019) \\
\end{array}$ & 13.5 & $\begin{array}{c}\text { Air- } \\
\text { Water }\end{array}$ & $0.2-40$ & $\begin{array}{c}0.001- \\
0.34\end{array}$ & 2 (abs) & $\begin{array}{c}3 \\
\text { Impacting }\end{array}$ & $\begin{array}{c}\text { An, W, Sl, } \\
\text { Pl }\end{array}$ \\
\hline
\end{tabular}

* St - Stratified, W - Wavy, An - Annular, Sl- Slug, PI - Plug, S-An -Semi-Annular, Mt Mist, Ch - Churn

Wren and Azzopardi (2004) were among the first to use multiple branching tee junctions. In their study on phase separation of air-water two-phase flow, two large diameter (127 mm) branching tee junctions were placed in series. The branch arm of the first tee junction was placed in a vertically upward direction while for the second tee it was in a vertically downward direction. The inlet of the second junction is the run arm of the first. Accordingly, there were three outlets each having a separate valve that could be completely closed to study the separation capability of the junction with different outlet combinations. A diagram of the system is shown in Figure 2.2. For their experiments, the system was kept at room temperature and pressure. The inlet velocities $J_{\mathrm{G} 1}$ and $J_{\mathrm{L} 1}$ ranged from 4 to $8 \mathrm{~m} / \mathrm{s}$ and from 0.186 to 0.310 
$\mathrm{m} / \mathrm{s}$, respectively. These conditions corresponded to stratified and semi-annular flows. The authors studied the effects of altering the distance between the junctions from $0.5 \mathrm{~m}$ to $1.2 \mathrm{~m}$ and the consequences of decreasing the diameter of the second junction by $60 \%$.

Wren and Azzopardi defined a good separator as one that can separate liquid and gas with $10 \%$ (volume/volume \%) of the undesired phase. In comparison to single branching tee junction (with vertically downward outlet), using two tee junctions (see Figure 2.2) proved to be a better phase separator regardless of the inlet flow regime or the test section geometry. For most inlet conditions, altering the distance between the two junctions had no contribution to the performance of the dual junction system that is because no liquid was able to move up the first branch arm as almost all the liquid left through the downward arm therefore eliminating the hydraulic jump problem. The only exception was for stratified flow in the larger diameter configuration where reducing the distance between the junctions led to an increase in gas takeoff and therefore less liquid entrainment in the downward side arm. Reducing the diameter of the second tee showed better phase separation as less gas left through the downward arm and the system met the criteria of good separator according to the authors' definition as less than $10 \%$ liquid entered the gas stream.

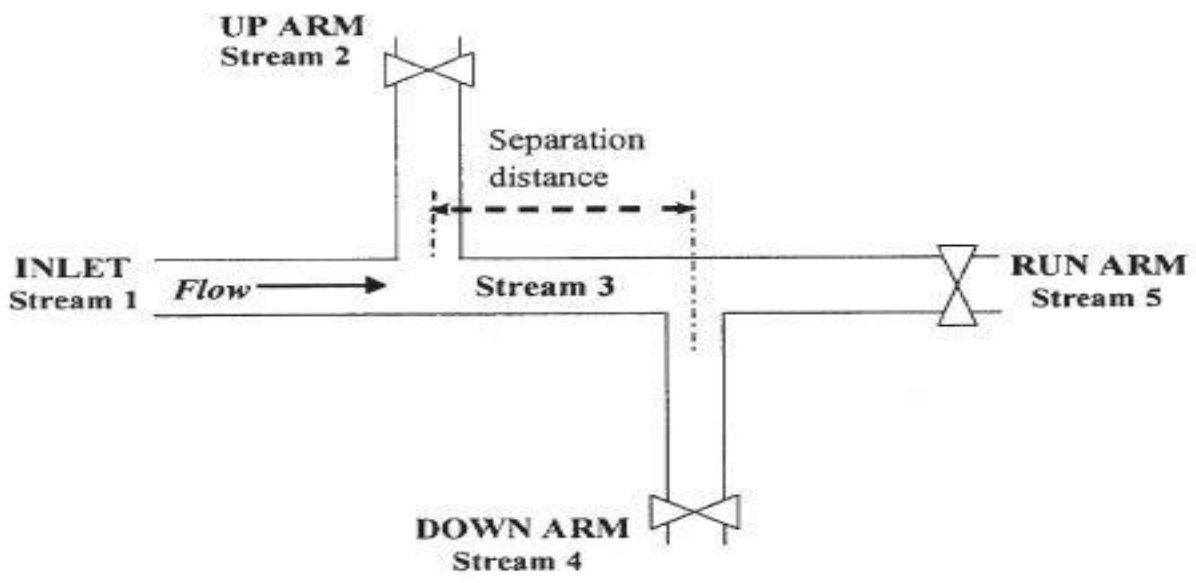

Figure 2.2: Schematic of junction layout used by Wren and Azzopardi (2004) 
Baker et al. (2007) performed an experimental study with aim of enhancing phase redistribution using multiple tee junctions in series with a fixed internal diameter of $38-\mathrm{mm}$ using a two-phase flow of air and high flash point kerosene at ambient temperature. The experimental set-up was similar to that of Wren and Azzopardi (2004) with some modifications. Air was supplied at a pressure of 6 bars. The ranges of change of inlet gas and liquid velocities were $3.3-9.6 \mathrm{~m} / \mathrm{s}$ and $0.07-0.51 \mathrm{~m} / \mathrm{s}$, respectively. These velocities corresponded to stratified and slug flow regimes. The authors added two control valves, one automatically-controlled on the downward branch arm and one manually-operated on the run arm, through which they had more control and flexibility and were able to get a gas-free liquid stream and reduce the liquid entrained in the upper branch. The authors set the same separation criterion defined by Wren and Azzopardi (2004) where the product streams would each contain less than $10 \% \mathrm{v} / \mathrm{v}$ of the unwanted phase to be considered a good separator. The authors were able to achieve a gas-free liquid stream and a gas-rich stream with less than $10 \%$ liquid by volume over a wide range of inlet conditions. Single branching junction was compared with dual junction. It was found that for stratified flow, $100 \%$ gas extraction with $8 \%$ liquid entrained was achieved in the vertically upward branch arm for the dual junction whereas the single junction had $88 \%$ gas extraction with the same level of liquid. While for slug flow at low gas take-off, liquid extraction in the gas stream could be reduced by up to $50 \%$ by using the dual junction. The downward branch acted as a liquid drain and reduced the phenomenon of hydraulic jump, and the inclusion of a liquid level control prevented any measurable gas take-off in the liquid stream. Therefore, a liquid-only stream was achieved in the downward branch arm. The authors conducted experiments while varying the control valve opening angle in the run arm to determine the optimal position for improved phase separation. The optimum angle acquired depended solely on the flow regime and not on the inlet velocities. For slug flow, the valve positions that exhibited the highest fraction of liquid recovered in the down arm 
were $54 \%$ to $60 \%$, while for stratified flow it was $20 \%$. In the vertically upward branch arm, less than $0.05 \%$ (volume/volume \%) liquid in the gas stream was achieved for stratified flow with lower gas velocities. While for slug flow, it was below 5\% v/v liquid and only for the highest liquid loading did it exceed 6\% (volume/volume \%). They were able to expand on the work of Wren and Azzopardi's (2004) by enhancing their test set-up to be capable of achieving the separation target of less than $10 \%$ v/v liquid-in-gas over a wider range of inlet conditions.

Yang et al. (2010) looked at the effect of increasing the number of branching tee junctions on the separation efficiency. The authors used 3,5 or 7 multi-tube branching tee junctions with an internal diameter of $10-\mathrm{mm}$ placed in series and compared the results with the single branching tee. The study was performed with air-water two-phase mixture at $J_{\mathrm{Gl}}$ and $J_{\mathrm{L} 1}$ ranging from 0.28 to $0.75 \mathrm{~m} / \mathrm{s}$ and from 0.06 to $0.68 \mathrm{~m} / \mathrm{s}$, respectively, which corresponded to stratified and plug flow regimes. The inlet air pressure was maintained at $0.1 \mathrm{MPa}$. The inlet pipe was horizontal, while the side arms (risers) were mounted vertically upward and connected with an upper header tube. The distance between the inlet pipe and the upper header was 60 $\mathrm{mm}$ and the distance between the two vertical side arms was $30 \mathrm{~mm}$. A diagram of their configuration with three branching junctions is shown in Figure 2.3. Subscripts 1, 2 and 3 represented the horizontal inlet, vertically upward branch arm and horizontal run arm of branching tee, respectively.

It was found that, as the number of junctions increased, separation efficiency increased. For stratified flow regime, the highest separation efficiency of $100 \%$ was achieved by 5 or more tee junctions, while the single junction achieved an efficiency of only $85 \%$. For plug flow regime, $100 \%$ separation was obtained by 5 or more junctions while $42 \%$ was reported for the single junction configuration. The effect of varying the inlet velocities on the separation efficiency was examined. For the same inlet flow regime and same number of junctions, as the inlet velocities increased, the separation efficiency decreased. The separation efficiency at each 
individual junction was not provided in the paper. Furthermore, the effect of the additional impacting tee junctions in the header created by the design of the system on the performance of the system was not mentioned.

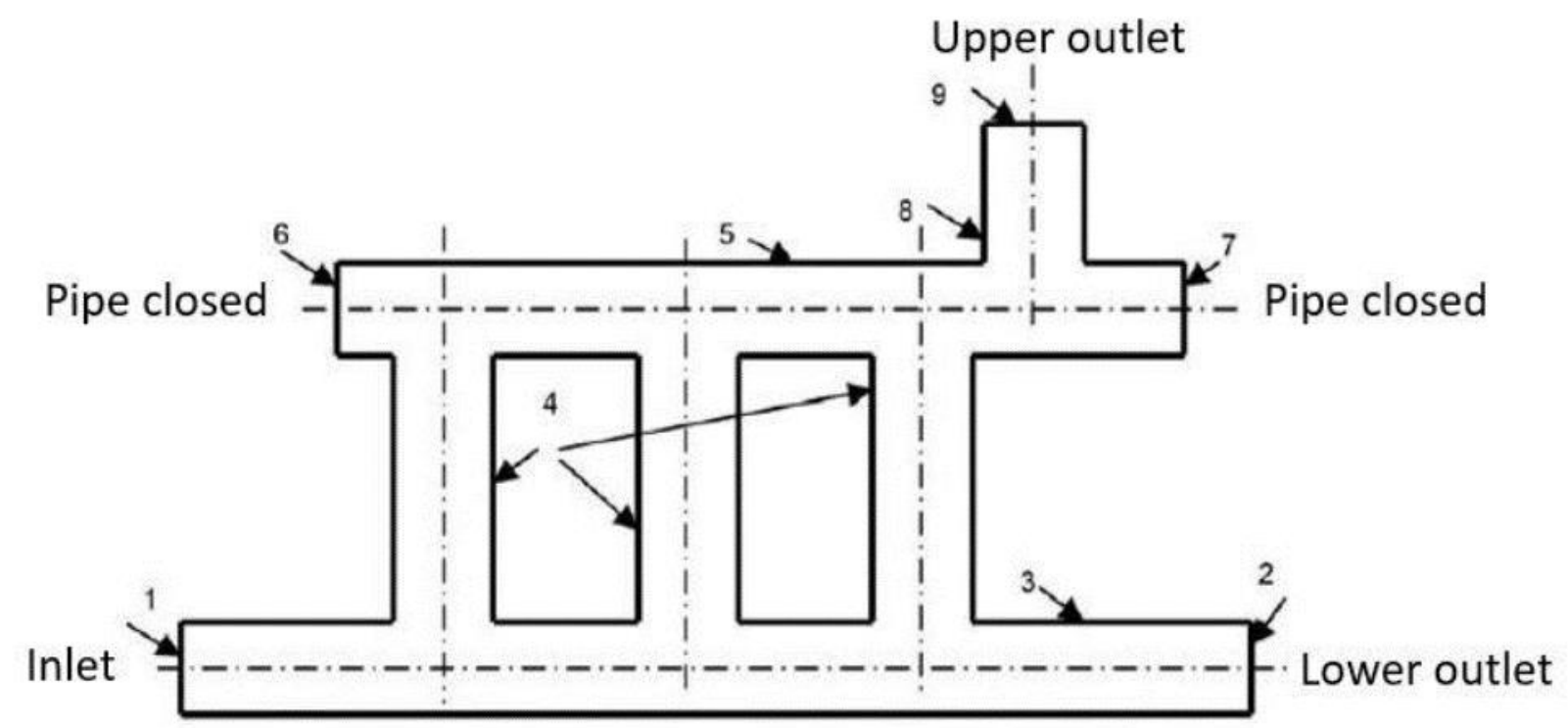

Figure 2.3: Schematic of combined-junction layout used by Yang et al. (2010)

Chen et al. (2012) used a similar set-up to Yang et al. (2010) in their numerical study with oil-water two-phase flows. The system can be seen in Figure 2.4. The authors explored the effect of varying the distance between junctions and the branch arm height on separation efficiency. The commercial CFD software Fluent was used to simulate the phase distribution characteristics in a combined tee junction and report separation efficiency using $\kappa-\varepsilon$ turbulence model and an Eulerian multi-fluid model. The authors defined separation efficiency of oil (o)water (w) two-phase flow as:

$$
\eta=\left|F_{\mathrm{o}}-F_{\mathrm{w}}\right|
$$

where, $F_{\mathrm{o}}=W_{\mathrm{o}}$ (upper) $/ W_{\mathrm{o}}$ (inlet) and $F_{\mathrm{w}}=W_{\mathrm{w}}$ (upper) $/ W_{\mathrm{w}}$ (inlet)

For the simulation, the authors studied separators with up to 7 branching tee junctions placed in series. The internal diameter of all the tubes was $40 \mathrm{~mm}$. The oil (LP-14) used had a 
density lower than water. The operation conditions were fixed for all runs. The inlet mixture velocity was $0.5 \mathrm{~m} / \mathrm{s}$, split ratio was 0.4 and oil volume fraction was $40 \%$, which corresponded to stratified flow regime. The authors varied the distance between two consecutive tee junctions from $4 \mathrm{D}, 8 \mathrm{D}$ up to $28 \mathrm{D}$ while fixing the height at $4 \mathrm{D}$. It was found that as the interval in creased, the separation efficiency increased. For higher branch intervals, the efficiency increase was slower. The branch arm height was varied from 4D, 6D up to 14D. Varying the arm height had no significant effect on the separation efficiency with $\eta$ roughly at $70 \%$ for all tested heights. However, reverse flow was seen for certain branch arm height which complicated the analysis. Their numerical results were not validated with any supporting experimental evidence.

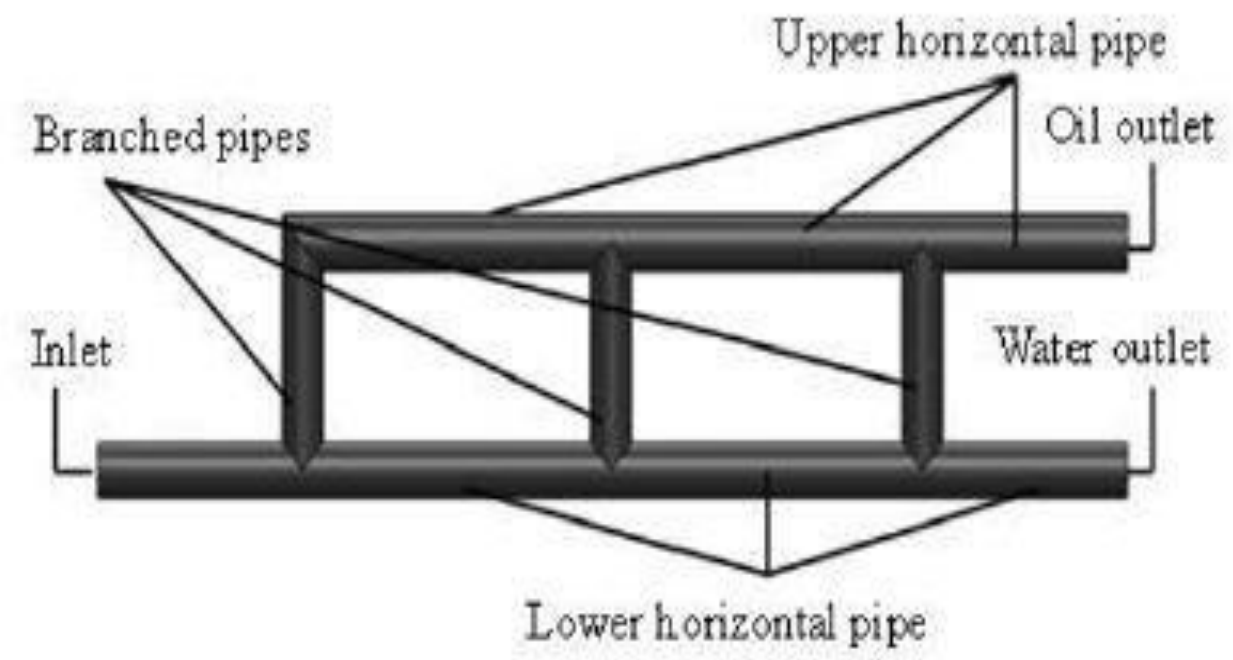

Figure 2.4: Schematic of junction layout used by Chen et al. (2012)

Tuo and Hrnjak (2014) conducted an experimental study to look at the phase separation of vapor-liquid refrigerants (R134a and R410A) in a compact vertical impacting te e-junction separator. Various design parameters were tested to select the most suitable design for a flash gas bypass (FGB) vapor compression system. These various design modifications were implemented to enhance the liquid separation. Some of these modifications included a range of inlet inclination angles $(\theta)$, dual-inlets as pre-separation, multiple inlet tube diameters, two different inlet cross-sections (rectangular and round) and varied inlet location with respect to 
the vertical tube. The relative diameters of inlet to outlet $\left(D_{\mathrm{i}} / D_{\mathrm{o}}\right)$ studied were $0.475,0.563$ and 0.656 . In their experiments, the inlet flow rate ranged from $30 \mathrm{~g} / \mathrm{s}$ to $35 \mathrm{~g} / \mathrm{s}$, and the inlet qualities tested were between 0.1 and 0.3 . The inlet velocities $J_{\mathrm{G} 1}$ and $J_{\mathrm{L} 1}$ ranged from 0.26 to $5.46 \mathrm{~m} / \mathrm{s}$ and from 0.098 to $0.5 \mathrm{~m} / \mathrm{s}$, respectively. The authors used the definitions of separation efficiencies $\eta_{1}$ and $\eta_{\mathrm{v}}$ set by Tuo and Hrnjak (2012). It was found that, as the inlet angle of inclination $(\theta)$ increased in the direction of gravity from $0^{\circ}$ (horizontal) to $45^{\circ}, \eta_{1}$ improved. Similar observation was found when the inlet diameter was increased, however the improvement was insignificant with an increase of up to $5 \%$ only. Rectangular inlet enhanced liquid separation efficiency by $8 \%$ compared to same size circular tube and $6 \%$ to the double diameter circular tube. The flat inlet had the same cross-sectional area as the smaller circular inlet and half of the larger round inlet. The tangential flat inlet aided in phase separation by inducing a swirling motion unlike the centered inlet configuration. A branching tee junction with horizontal inlet and vertically upward branch arm was added before the impacting tee junction to act as a pre-separator, consequently the flow would pass through two-stage separation in series. The inlet was inclined at an angle of $30^{\circ}$ with respect to the outlets of the second junction as shown in Figure 2.5. After the first stage of the two-stage separation, the flow was divided into a vapor-rich and liquid-rich streams by the effect of gravitational and inertial forces. Varying the mixture quality, the pre-separator alters the flow regime to be more stratified which is a desirable flow regime for separation, as demonstrated by Mohamed et al. (2012). The use of the pre-separator immensely improved the liquid separation efficiency particularly at higher flow rates $(35 \mathrm{~g} / \mathrm{s})$. 


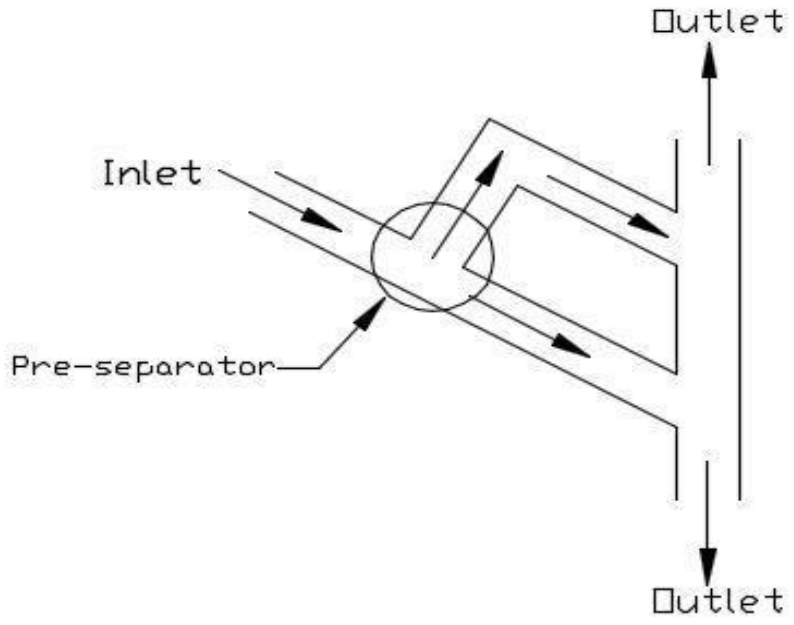

Figure 2.5: Pre-separator implemented by Tuo and Hrnjak (2014)

Yang et al. (2017) designed a multitube tee junction separator for full-phase separation of air-water two-phase flow. The separator consisted of branching tee junctions in multiple layers (two- or three-layers). The inlets gas and liquid velocities ranged from 0.275 to $0.9 \mathrm{~m} / \mathrm{s}$ and from 0.0560 to $0.551 \mathrm{~m} / \mathrm{s}$, respectively, which fell in the stratified and plug flow regimes. The inlet quality and mixture velocity varied from 0.00384 to 0.0114 and from 0.331 to 1.45 $\mathrm{m} / \mathrm{s}$, respectively. The system was supplied with air at a pressure of $0.1 \mathrm{MPa}$ (gage). The internal diameter of all the branches was $10 \mathrm{~mm}$. Two- and three-layer separators were investigated in this paper. The two-layer system (shown in Figure 2.3) is the same as the one studied by Yang et al. (2010) reviewed previously in this thesis. The three-layer separator had three branches between the first and second layers and four branches between the second and third layers. The inlet, lower outlet and upper outlet were labeled as sides 1, 2 and 3, respectively, as shown in Figure 2.6. For the two- and three-layer configurations, the distances between the inlet and the upper and lower headers were $100 \mathrm{~mm}$ and $50 \mathrm{~mm}$, respectively. The distance between two consecutive connecting tubes was $50 \mathrm{~mm}$ for both configurations. The authors adopted the separation efficiency definition used by Yang et al. (2006). In their paper, the effects of multiple parameters on phase separation were examined, such as the inlet 
velocity, flow regime, junction configuration and mixture velocity. The results were plotted on extraction ratio versus separation efficiency graphs. For the same flow regime, it was found that raising the inlet or mixture velocity had a negative effect on separation efficiency. In addition, separation efficiency increased as the number of connecting tubes increased. A $100 \%$ separation efficiency was obtained with 5 or 7 connecting tubes, for stratified flow. However, with a single branching tee junction, a maximum efficiency of $85 \%$ is achieved. Furthermore, separation efficiency decreases drastically when the flow regime changes from stratified to plug flow. However, in the two-layer system with seven connecting tubes, total phase separation was attained under certain conditions of plug flow.

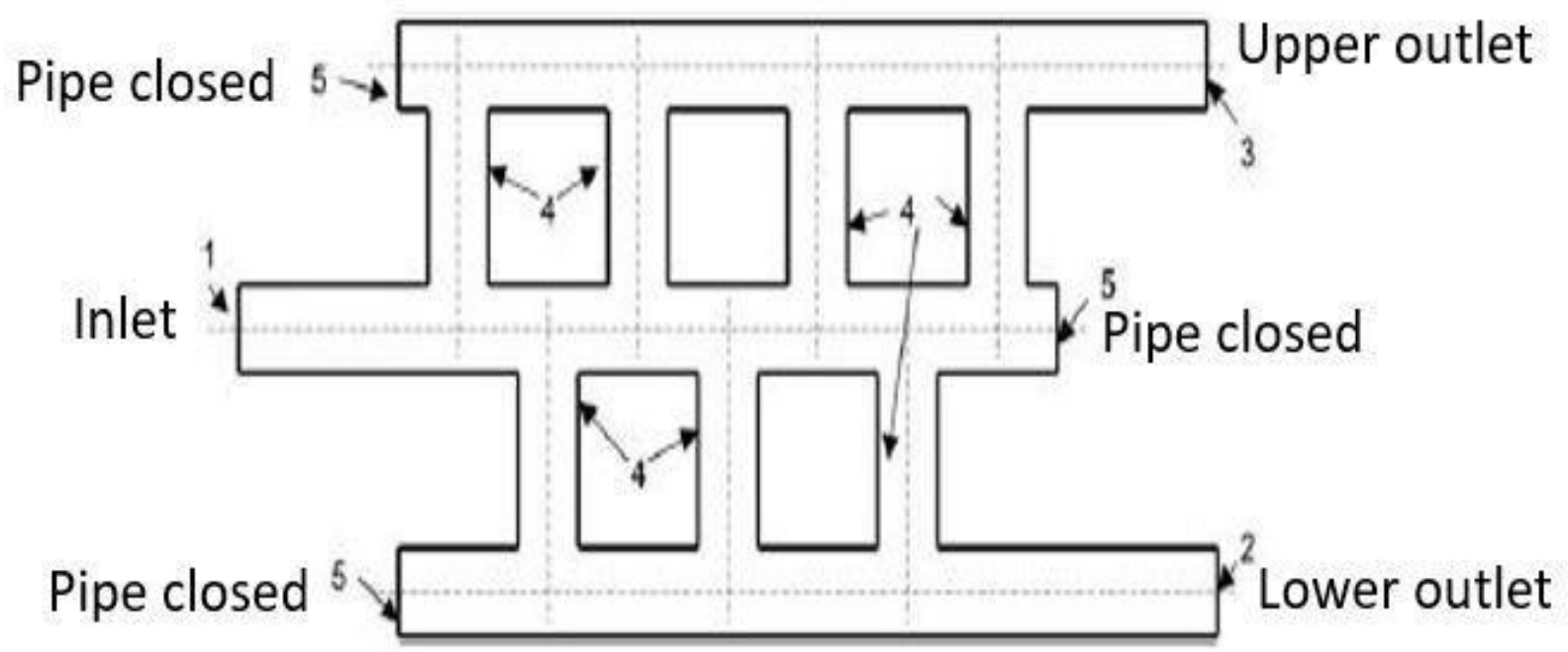

Figure 2.6: Schematic of the three-layer multitube separator unit implemented by Yang et al. (2017)

Noor and Soliman (2019) proposed a novel system of combined impacting tee junctions in order to study full- and partial-phase separation of air-water two-phase flow. The system had a single horizontal inlet and two vertical outlets as shown in Figure 2.7. The internal diameter of all the pipes was $13.5 \mathrm{~mm}$. The experiments were conducted at a pressure of $200 \mathrm{kPa}(\mathrm{abs})$ and ambient temperature. The ranges of $J_{\mathrm{G} 1}$ and $J_{\mathrm{L} 1}$ studied were $0.2-40 \mathrm{~m} / \mathrm{s}$ and $0.001-0.34$ $\mathrm{m} / \mathrm{s}$, respectively, which fell in the annular, wavy, slug and plug flow regimes. The authors 
defined a phase-separation parameter, $\eta$, to assess the effectiveness of the combined system as a phase separator, which has been defined as:

$$
\eta=\left(F_{\mathrm{G} 2}-F_{\mathrm{L} 2}\right) \times 100 \%
$$

A criterion was set for full-phase separation where $F_{\mathrm{L} 3} \geq 99 \%$ (liquid mass ex traction ratio in the bottom outlet) and $F_{\mathrm{G} 3}=0$. The authors conducted two sets of experiments with the objectives of finding the limiting conditions for full-phase separation and enhancing separation effectiveness in the partial-separation regions. It was found that the use of the combined junction considerably extended the range of $J_{\mathrm{G} 1}$ and $J_{\mathrm{L} 1}$ for which full separation can be achieved to almost double the region obtained by the single junction system reported by Mohamed et al. (2012). For slug flow, the authors were able to achieve only $99 \%$ phase separation due to the intermittent nature of slug flow. In addition, in the partial-phaseseparation region, the separation effectiveness was much higher compared to the single junction for all tested condition. The results obtained were presented in $F_{\mathrm{G} 3}$ versus $F_{\mathrm{L} 3}$ plots and compared with a single vertical impacting tee junction data at the same inlet conditions. The parameter $\eta$ for the combined junction system was almost double that of a single tee for almost all tested conditions. With the system of combined junctions, partial-phase-separation curves move in anti-clockwise direction towards the point of full-phase separation; for every $F_{\mathrm{G} 3}$, the corresponding $F_{\mathrm{L} 3}$ is higher. Furthermore, this system of combined impacting junctions proved to show full-phase separation at higher values of $J_{\mathrm{G} 1}$ and $J_{\mathrm{L} 1}$ as compared to other combined tee junctions with same number of junctions in the literature. 


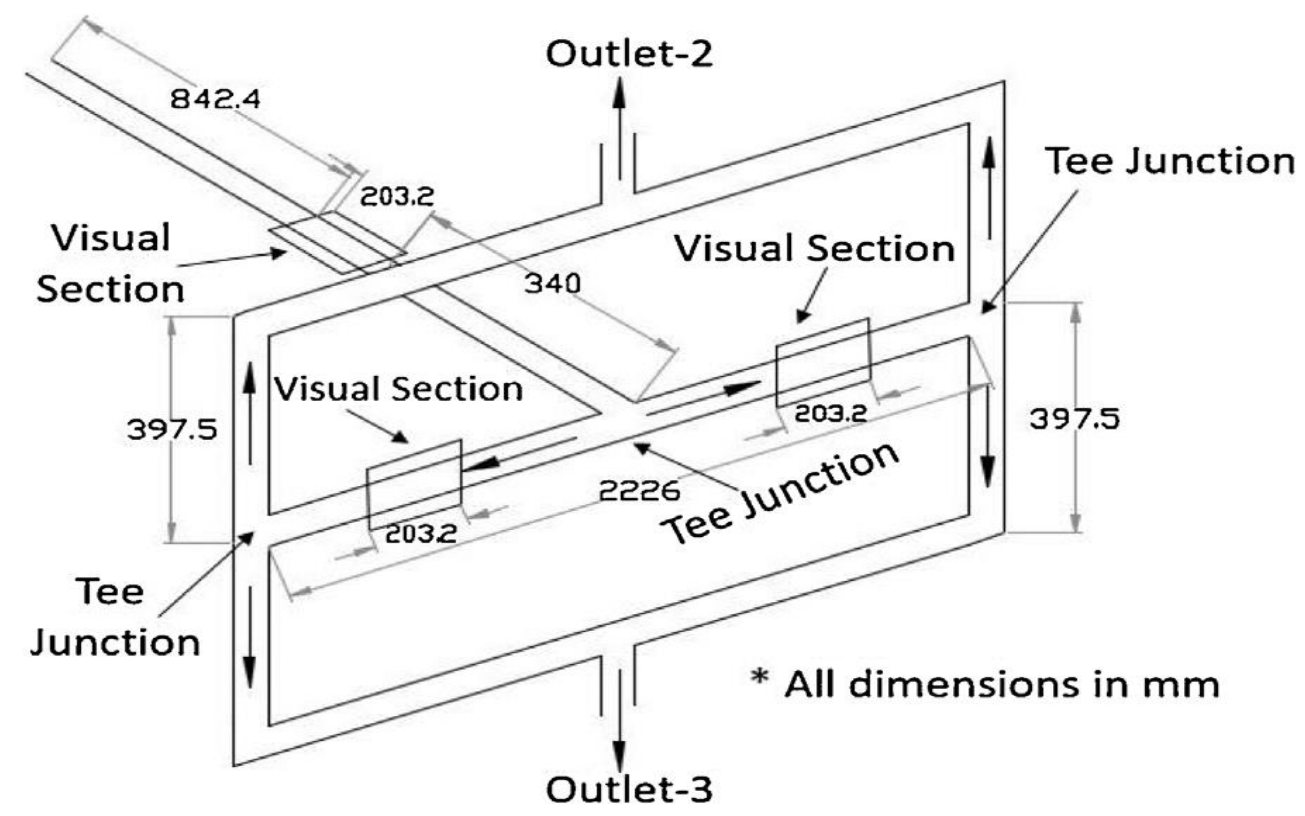

Figure 2.7: Noor and Soliman (2019) test section schematic

\subsection{Concluding Remarks}

After examining the literature, the following outcomes were reached:

1. The use of single impacting tee junction as partial-phase separators has been studied extensively in the literature.

2. By contrast, limited studies were done on utilizing impacting junctions for full-phase separation.

3. Fewer studies were done on employing multiple tee junctions as full-phase separators, most of which were performed on branching tee junctions in different arrangements.

4. To the best of the author's knowledge, no other publication on the use of multiple impacting tee junctions as complete phase separators were found in the literature, except for the work of Noor and Soliman (2019). 


\section{CHAPTER 3}

\section{TEST RIG AND EXPERIMENTAL PROCEDURE}

\subsection{Overview}

The objective of this experimental investigation was to determine the extended limiting conditions for full-phase separation and to generate partial-phase separation outside this region. The same two-phase flow test facility used by Noor and Soliman (2019) and Mohamed et al. (2012) was used for this study with some modifications. A new test section was designed and constructed to fulfil these objectives. As well, additional measuring devices (water rotameters) were added to be able to cover the extended range of flow rates. In this chapter, details of the various components and measuring devices used in the system and the experimental procedures followed are provided.

\subsection{Experimental Test Facility}

The following are the main functions of the various components in the system:

I. Accurately measure the inlet conditions of air and water such as pressure, superficial velocity, and temperature.

II. Provide a homogenous mixture of air and water into the system.

III. Separate the flow at the junctions and combine to produce two outlet streams.

IV. Separate the phases of the outlet flows in the separation tanks.

V. Accurately measure the outlet conditions of air and water.

VI. Discharge the air to the atmosphere and return the water to the reservoirs through a closed loop system. 


\subsubsection{Air-Water Loop}

A schematic diagram of the test facility retrieved from Noor and Soliman (2019) is shown in Figure 3.1. Actual pictures of various components are presented in Figures 3.2 - 3.4. Compressed air is supplied to the system from the building supply line which is then passed through an air filter and a pressure regulator to filter and ensure a constant air pressure. The air is then fed into one of three calibrated inlet air rotameters with overlapping ranges to measure the inlet air flowrate before passing through a thermocouple and a pressure gauge to measure the inlet air temperature and pressure,respectively. The air is then fed into the mixing chamber. A submersible pump in the water tank pumps distilled water through a water filter before passing through one of four water rotameters with overlapping ranges to measure and regulate the water inlet flowrate. A thermocouple and a pressure gauge measure the inlet water temperature and pressure, respectively. The water temperature in the tank is maintained using a cooling coil. The water is then fed into the mixing chamber where it is mixed with the air to form a homogenous mixture of air and water.

The mixture leaves the mixing chamber through copper tubing of $13.5-\mathrm{mm}$ inner diameter and into a visual section made of acrylic resin cube to visualize the flow and identify the flow regime. The visual section is located 62 pipe diameters away from the mix ing tee to insure fully-developedflow regime in the visual section. After a further 32 pipe diameters down from the visual section, the flow enters the test section. There are two outlets from the test section, Outlet- 2 and Outlet-3, and the flow from each outlet was directed to a respective separation tank where the air and water were separated. Each separation tank is connected to multiple air and water rotameters to measure the outlet flowrates of both air and water. Thermocouples and pressure gauges are installed at the outlets to measure the temperature and pressure of both outlets. After measurements, the air is released to the surrounding after passing 
through a muffler to minimize the noise, and the water is returned to the water reservoir in a closed loop.

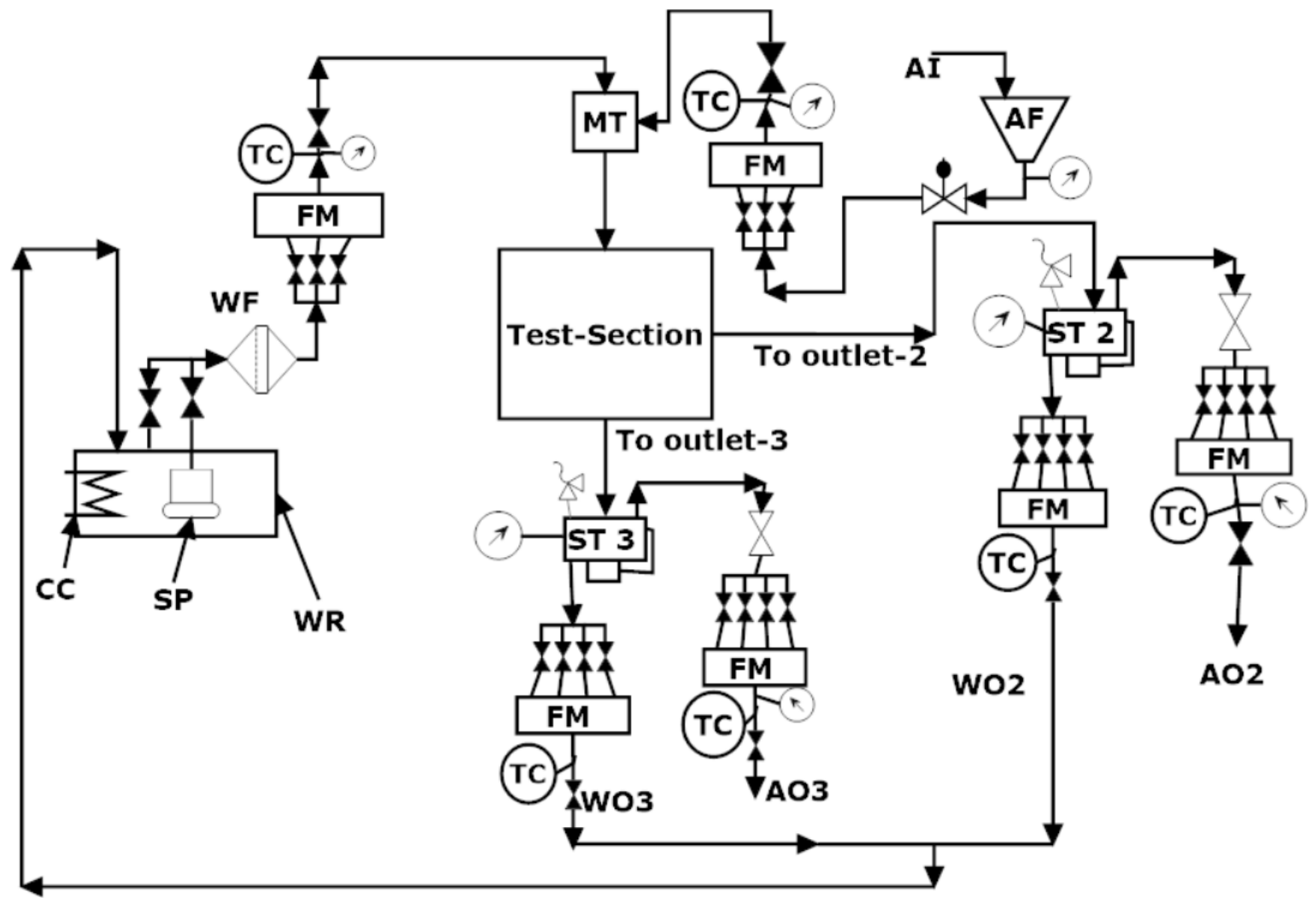

\begin{tabular}{|c|c|c|c|}
\hline Symbol & Description & Symbol & Description \\
\hline $\mathbf{A F}$ & Air filter & SP & Submersible pump \\
\hline$\overline{\mathbf{A I}}$ & Air inlet & ST & Separation Tank \\
\hline$\overline{\mathrm{AO}}$ & Air outlet & TJ & Tee junction \\
\hline $\mathrm{CC}$ & Cooling Coil & $\overline{W F}$ & Water filter \\
\hline FM & Flow meter & WO & Water outlet \\
\hline MT & Mixing tee & WR & Water reservoir \\
\hline & Control valve & & Pressure gauge \\
\hline$\rightarrow-$ & Valve & (TC) & Thermocouple \\
\hline-2 & Pressure controller & $\$$ & Safety valve \\
\hline
\end{tabular}

Figure 3.1: Schematic diagram of the test facility 
Horizontal tee

junction

Visual Section

Mixing tee

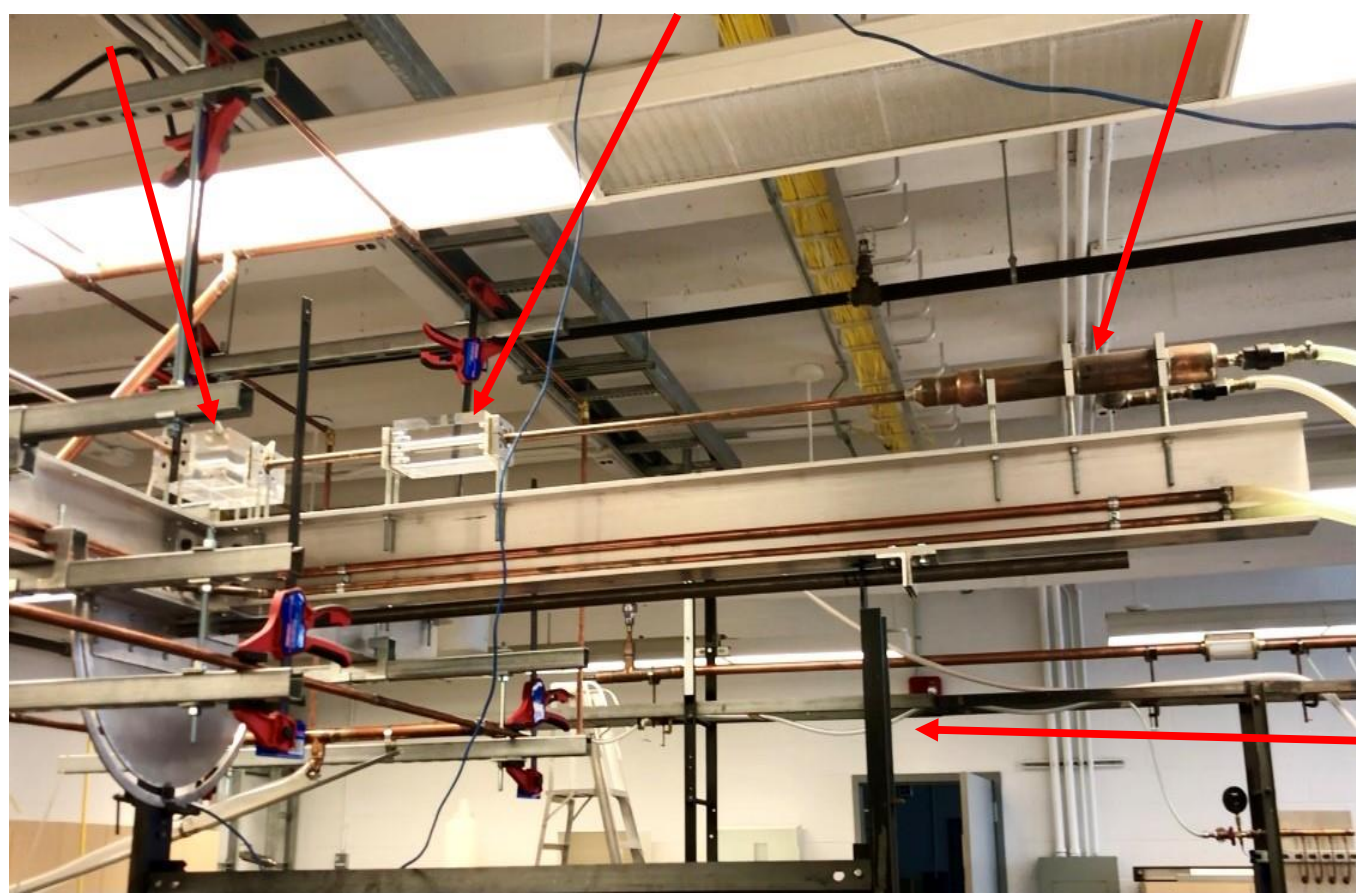

Aluminum frame

Figure 3.2: Image of the mixer and inlet

Outlet-3 air

rotameters
Outlet-2 air

rotameters
Outlet-2 water

rotameters

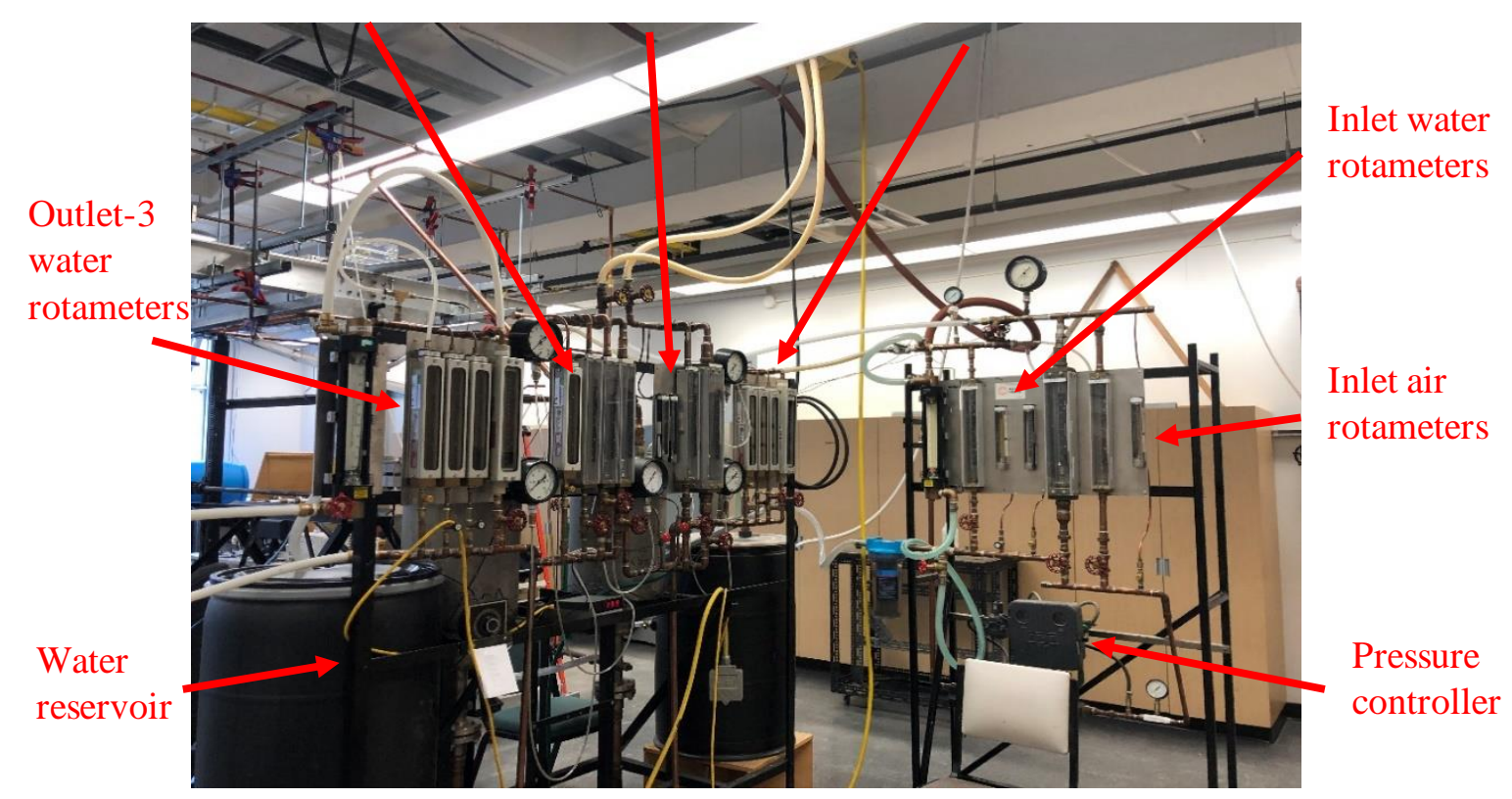

Figure 3.3: Image of inlet and outlet rotameters 


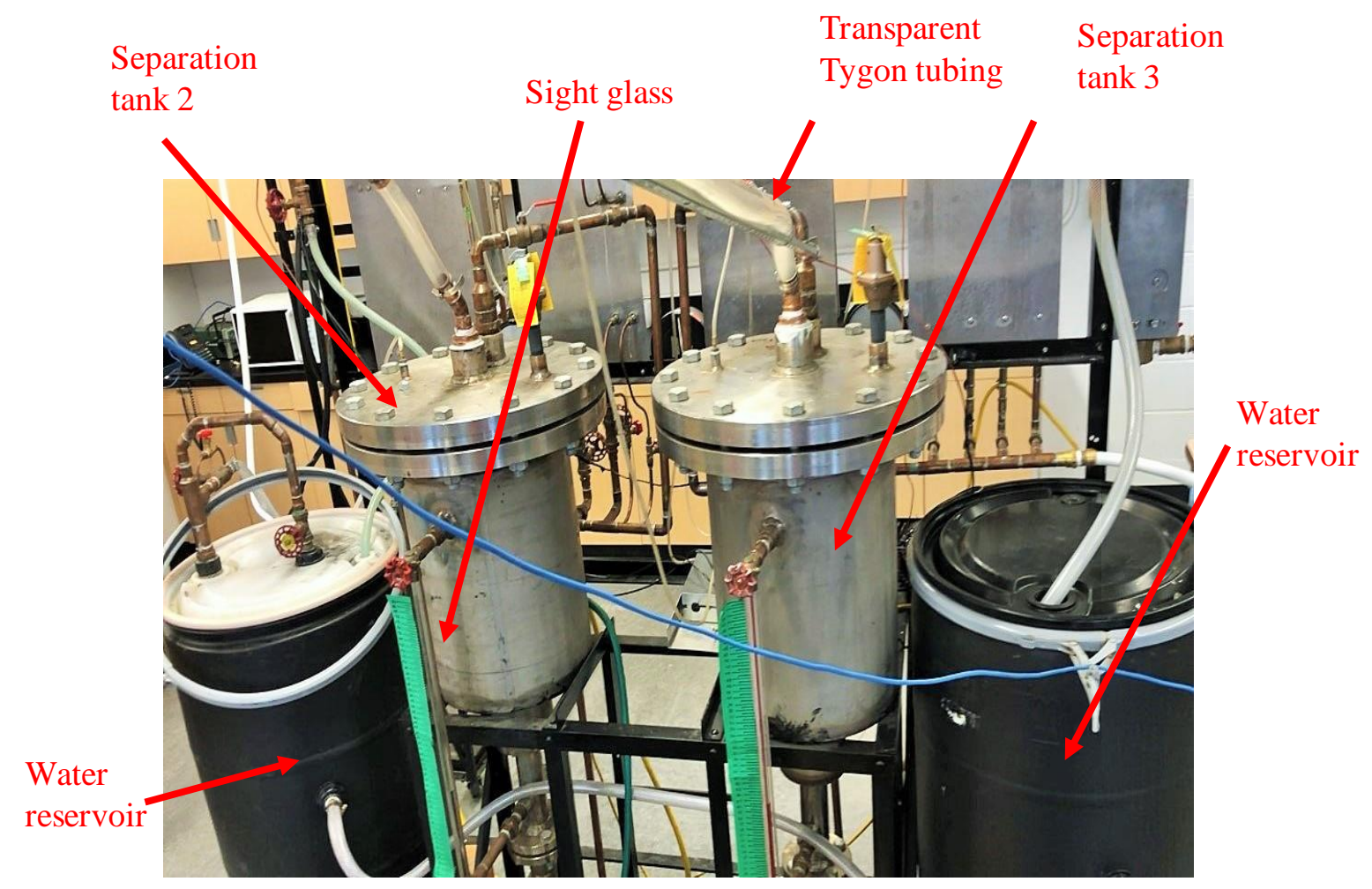

Figure 3.4: Image of the separation tanks

\subsubsection{Test Section}

The test-section consists of three horizontal and four vertical impacting junctions. A schematic diagram and an image of the test section are shown in Figures 3.5 and 3.6, respectively. All piping and connecting tees are 13.5-mm I.D. The inlet two-phase flow is divided as it enters the first tee junction which is made of acrylic resin to observe the flow separation. At the junction, a pressure gauge and a thermocouple were installed. Each outlet arm of this junction was equipped with a visual section 50 pipe diameters downstream from the junction. The two outlets of the first junction act as inlets to the two horizontal impacting junctions. The four divided flows exiting from the two horizontal junctions pass through straight piping of 29.5 pipe diameter in length before entering the four vertical impacting tees. Four upward branches of length 22.5 pipe diameters exit from these junctions, and they are combined to form a single outlet (Outlet-2). Also, the four bottom branches are combined to a single outlet (Outlet-3), and the flows from these two outlets were directed to their respective 
separation tank where the air and water are separated. Transparent Tygon tubes are used to connect the outlets to their respective separation tanks. The test section is symmetric about the inlet to ensure that inlet flow splits evenly at the first junction and therefore obtain ing two identical outlet flows. The test section, consisting of the junctions, visual sections and mixers, is mounted on a rigid aluminium frame. A survey theodolite (AN 20, Wild Heerbrugg, Lewis International Limited) was used to ensure horizontal alignment of the test section. In addition, an inclinometer was used to check both vertical and horizontal alignment of the different parts of the test section.

The first horizontal junction was made from an acrylic resin block, with dimensions $203.2 \times 179.0 \times 86.2 \mathrm{~mm}$. Details of construction of the first horizontal junction can be found in the work of Mohamed (2012). The other two horizontal junctions were brass fittings from Swagelok (Brass Swagelok Tube Fitting, Union Tee, 5/8 in. Tube OD, B-1010-3). The internal diameters of these fittings were $12.7 \mathrm{~mm}$, and they were machined to match the internal diameter of the copper tubes, at $13.5 \mathrm{~mm}$. These tees were connected to the copper tubing in the test-section by compression fitting. All four vertical junctions were brass fittings (Brass Swagelok Tube Fitting, Union Tee, 5/8 in. Tube OD, B-1010-3), identical to the ones used as horizontal junctions. These tees were also machined and connected to the copper tubing in the test-section by compression fitting.

The visual sections, mixer and separation tanks are identical to those used by Noor and Soliman (2019). Details on these can be found in the work of Noor (2018). 

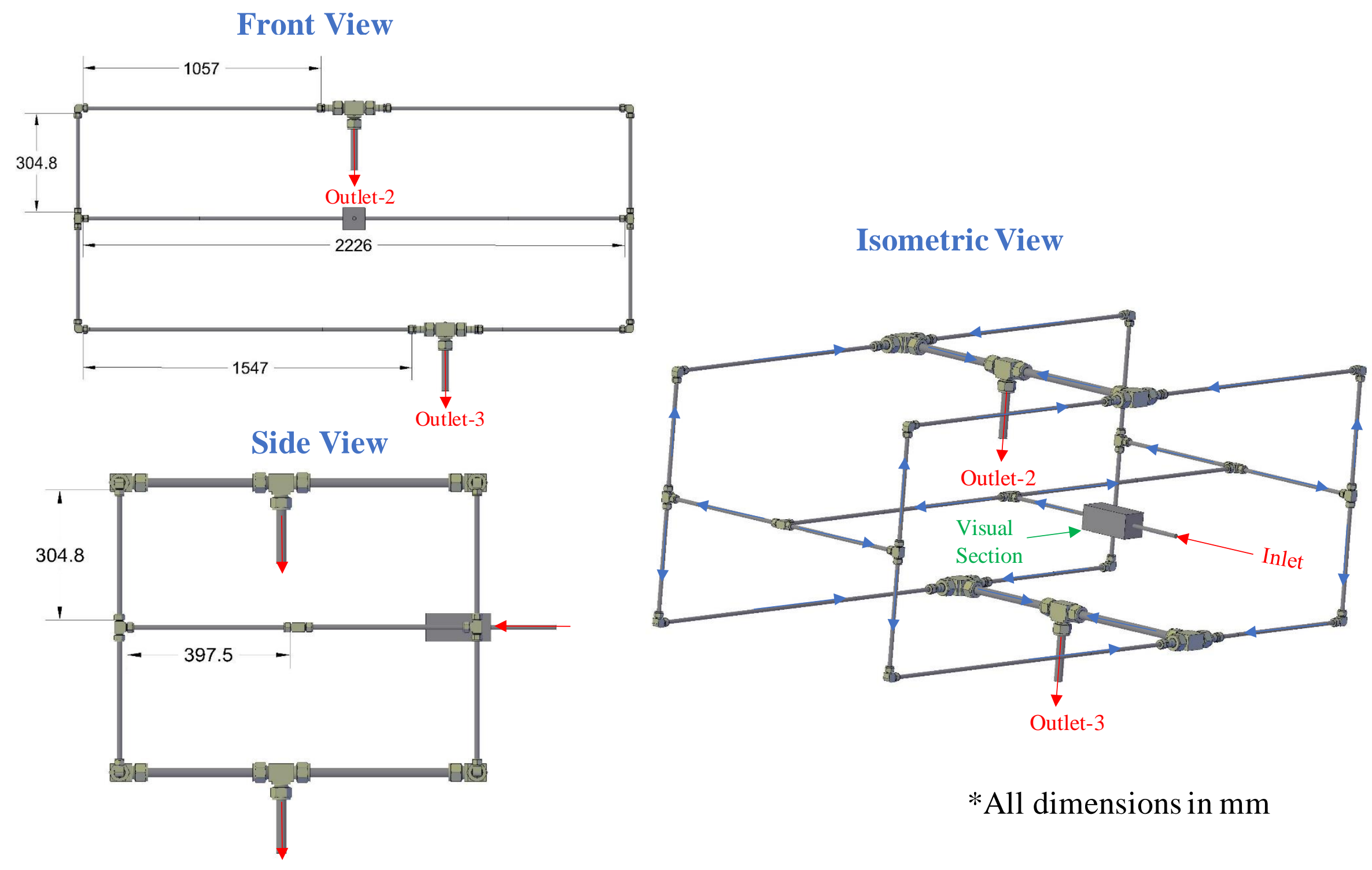

Figure 3.5: Schematic diagram of the test section 


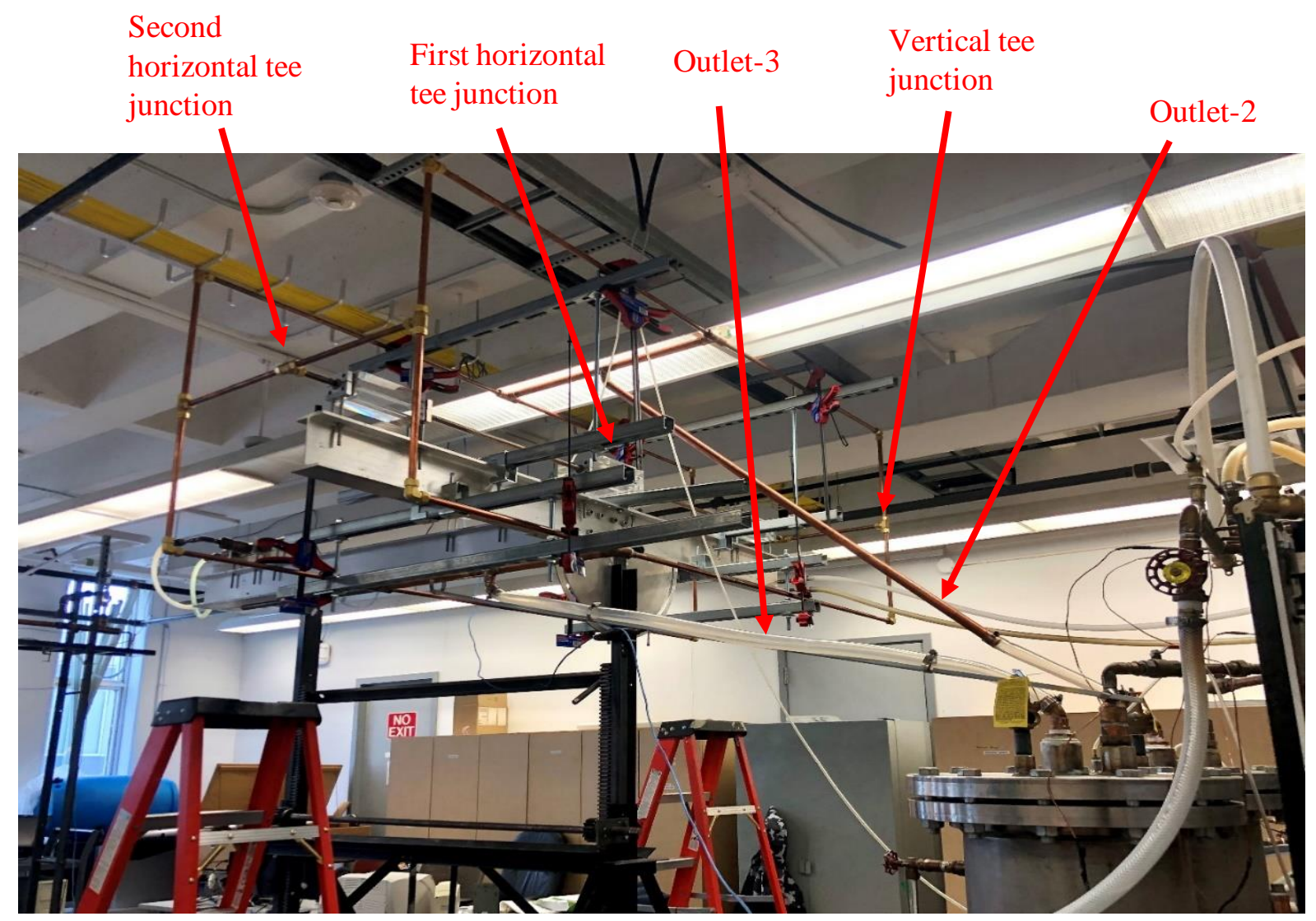

Figure 3.6: Image of the test section

\subsubsection{Measuring Devices}

Various measuring devices were used in the test section. Thermocouples, pressure gauges and rotameters were used to measure the temperature, pressure, and flowrate, respectively. In total, 24 rotameters were installed, 13 of which were used to measure the water flowrate and 11 for air. Specifications of the water and air rotameters are listed in Table 3.1 and Table 3.2, respectively. To measure the inlet flowrate of air, three rotameters with overlapping ranges were installed while for the inlet flowrate of water, four rotameters with overlapping ranges were used. In addition, each outlet had four air rotameters to measure the outlet flowrate after each separation tank. Outlet- 2 had four water rotameters and Outlet-3 had five water rotameters. 
Table 3.1: Specifications and functions of the air-flow-measurement instruments

\begin{tabular}{|c|c|c|}
\hline Rotameter & Specification & Measured variable \\
\hline IN-A-1 & $\begin{array}{c}\text { Brooks rotameter } \\
\text { Model: } 1355 \mathrm{EZ186} \\
\text { Range: } 6.47-64.7 \text { SLPM } \\
\text { Float: Ball }- \text { Stainless Steel }\end{array}$ & Inlet air flowrate \\
\hline IN-A-2 & $\begin{array}{c}\text { Brooks rotameter } \\
\text { Model: 1307EZ80 } \\
\text { Range: } 38.1-381 \text { SLPM } \\
\text { Float: Conventional - Stainless Steel }\end{array}$ & Inlet air flowrate \\
\hline IN-A-3 & $\begin{array}{c}\text { Brooks rotameter } \\
\text { Model: 1307EZ84 } \\
\text { Range: 200-2004 SLPM } \\
\text { Float: Conventional - Stainless Steel }\end{array}$ & Inlet air flowrate \\
\hline $\mathrm{O}-2-\mathrm{A}-1$ & $\begin{array}{c}\text { Brooks rotameter } \\
\text { Model: } 1355 \mathrm{EZ1} 184 \\
\text { Range: } 0.87-8.68 \text { SLPM } \\
\text { Float: Ball - Sapphire } \\
\end{array}$ & Outlet-2 air flowrate \\
\hline $\mathrm{O}-2-\mathrm{A}-2$ & $\begin{array}{c}\text { Brooks rotameter } \\
\text { Model: 1355EZ186 } \\
\text { Range: } 6.47-64.7 \text { SLPM } \\
\text { Float: Ball - Stainless Steel }\end{array}$ & Outlet-2 air flowrate \\
\hline $\mathrm{O}-2-\mathrm{A}-3$ & $\begin{array}{c}\text { Brooks rotameter } \\
\text { Model: } 1307 \mathrm{EZ80} \\
\text { Range: } 38.1-381 \text { SLPM } \\
\text { Float: Conventional - Stainless Steel }\end{array}$ & Outlet-2 air flowrate \\
\hline $\mathrm{O}-2-\mathrm{A}-4$ & $\begin{array}{c}\text { Brooks rotameter } \\
\text { Model: 1307EZ84 } \\
\text { Range: 200-2004 SLPM } \\
\text { Float: Conventional - Stainless Steel }\end{array}$ & Outlet-2 air flowrate \\
\hline O-3-A-1 & $\begin{array}{c}\text { Brooks rotameter } \\
\text { Model: 1114DG41AEHAA } \\
\text { Range: } 0.86-8.6 \text { SLPM } \\
\text { Float: Ball- Glass } \\
\end{array}$ & Outlet-3 air flowrate \\
\hline $\mathrm{O}-3-\mathrm{A}-2$ & $\begin{array}{c}\text { Brooks rotameter } \\
\text { Model: } 1307 \mathrm{EZ186} \\
\text { Range: } 4.64-46.4 \text { SLPM } \\
\text { Float: Ball }- \text { Sapphire } \\
\end{array}$ & Outlet-3 air flowrate \\
\hline $\mathrm{O}-3-\mathrm{A}-3$ & $\begin{array}{c}\text { Brooks rotameter } \\
\text { Model: 1307EZ80 } \\
\text { Range: } 38.1-381 \text { SLPM } \\
\text { Float: Conventional - Stainless Steel }\end{array}$ & Outlet-3 air flowrate \\
\hline $\mathrm{O}-3-\mathrm{A}-4$ & $\begin{array}{c}\text { Brooks rotameter } \\
\text { Model: 1307EZ79 } \\
\text { Range: 72.9-729 SLPM } \\
\text { Float: Conventional - Stainless Steel }\end{array}$ & Outlet-3 air flowrate \\
\hline
\end{tabular}


Table 3.2: Specifications and functions of the water-flow-measurement instruments

\begin{tabular}{|c|c|c|}
\hline Rotameter & Specification & Measured variable \\
\hline IN-W-1 & $\begin{array}{c}\text { Brooks rotameter, Model: } 1355 \mathrm{EZ} 183, \\
\text { Range: } 8.54-85.4 \mathrm{~cm}^{3} / \mathrm{min} \\
\text { Float: Ball }- \text { Sapphire }\end{array}$ & Inlet water flowrate \\
\hline IN-W-2 & $\begin{array}{c}\text { Brooks rotameter, Model: } 1355 \mathrm{EZ} 182, \\
\text { Range: } 49.14-491.4 \mathrm{~cm}^{3} / \mathrm{min} \\
\text { Float: Ball }- \text { Stainless Steel }\end{array}$ & Inlet water flowrate \\
\hline IN-W-3 & $\begin{array}{l}\text { Brooks rotameter, Model: 1307EZ81, } \\
\text { Range: } 250-2955 \mathrm{~cm}^{3} / \mathrm{min} \\
\text { Float: Conventional - Stainless Steel }\end{array}$ & Inlet water flowrate \\
\hline IN-W-4 & $\begin{array}{c}\text { ABB Fischer \& Porter rotameter } \\
\text { Model: FP3/4-27-G-10/55 } \\
\text { Range: } 1356-11940 \mathrm{~cm}^{3} / \mathrm{min} \\
\text { Float: Conventional - Stainless Steel }\end{array}$ & Inlet water flowrate \\
\hline O-2-W-1 & $\begin{array}{c}\text { Brooks rotameter, Model: 1114DC91BDHAA } \\
\text { Range: } 1.0-10.0 \mathrm{~cm}^{3} / \mathrm{min} \\
\text { Float: Ball - Sapphire }\end{array}$ & Outlet- 2 water flowrate \\
\hline $\mathrm{O}-2-\mathrm{W}-2$ & $\begin{array}{c}\text { Brooks rotameter, Model: } 1114 \text { DC71BDHAA } \\
\text { Range: } 7.45-74.5 \mathrm{~cm}^{3} / \mathrm{min} \\
\text { Float: Ball - sapphire } \\
\end{array}$ & Outlet- 2 water flowrate \\
\hline $\mathrm{O}-2-\mathrm{W}-3$ & $\begin{array}{c}\text { Brooks rotameter, Model:1114DG41BDHAA } \\
\text { Range: } 48.5-485 \mathrm{~cm}^{3} / \mathrm{min} \\
\text { Float: Ball - Stainless Steel }\end{array}$ & Outlet- 2 water flowrate \\
\hline O-2-W-4 & $\begin{array}{c}\text { Brooks rotameter, Model: 1114DJ41BDHAA } \\
\text { Range: } 295-2950 \mathrm{~cm}^{3} / \mathrm{min} \\
\text { Float: Conventional - Stainless Steel }\end{array}$ & Outlet- 2 water flowrate \\
\hline $\mathrm{O}-3-\mathrm{W}-1$ & $\begin{array}{c}\text { Brooks rotameter } \\
\text { Model: } 1114 \mathrm{DC} 91 \mathrm{BDHAA} \\
\text { Range: } 1.0-10.0 \mathrm{~cm}^{3} / \mathrm{min} \\
\text { Float: Ball }- \text { Sapphire } \\
\end{array}$ & Outlet-3 water flowrate \\
\hline $\mathrm{O}-3-\mathrm{W}-2$ & $\begin{array}{c}\text { Brooks rotameter } \\
\text { Model: } 1114 \mathrm{DC} 71 \mathrm{BDHAA} \\
\text { Range: } 7.45-74.5 \mathrm{~cm}^{3} / \mathrm{min} \\
\text { Float: Ball }- \text { Sapphire } \\
\end{array}$ & Outlet-3 water flowrate \\
\hline $\mathrm{O}-3-\mathrm{W}-3$ & $\begin{array}{c}\text { Brooks rotameter } \\
\text { Model: } 1114 \mathrm{DG} 41 \mathrm{BDHAA} \\
\text { Range: } 48.5-485 \mathrm{~cm}^{3} / \mathrm{min} \\
\text { Float: Ball }- \text { Stainless Steel }\end{array}$ & Outlet-3 water flowrate \\
\hline $\mathrm{O}-3-\mathrm{W}-4$ & $\begin{array}{c}\text { Brooks rotameter: } \\
\text { Model: } 1114 \mathrm{DJ} 41 \mathrm{BDHAA} \\
\text { Range: } 295-2950 \mathrm{~cm}^{3} / \mathrm{min} \\
\text { Float: Conventional - Stainless Steel }\end{array}$ & Outlet-3 water flowrate \\
\hline $\mathrm{O}-3-\mathrm{W}-5$ & $\begin{array}{l}\text { ABB Fischer \& Porter rotameter: } \\
\text { Model: FP3/4-27-G-10/55 } \\
\text { Range: } 1230-12060 \mathrm{~cm}^{3} / \mathrm{min} \\
\text { Float: Conventional - Stainless Steel }\end{array}$ & Outlet-3 water flowrate \\
\hline
\end{tabular}


Calibration data reported by Mohamed (2012) were used for the calculations since it is within $\pm 2 \%$ and $\pm 3 \%$ of manufacturer's values for air and water rotameters, respectively. Linear interpolation was used to calculate flowrates for both air and water rotameter which lie between any two consecutive points. Full calibration data are available in the work of Mohamed (2012) and the spot checks for all rotameters are given in Table A.1 and Table A.2.

Pressure gauges were installed to measure the pressure at the air inlet, water inlet, testsection, air outlet-2, air outlet-3, separation tank 2 and separation tank 3 . A feedback pressure controller (Fisher $4160 \mathrm{~K}$ series) and a pressure regulator were used to regulate inlet air pressure from the supply line. Pressure gauges were placed upstream and downstream of the pressure controller. Calibration data for the pressure gauges are presented in the work by Mohamed (2012). Specifications of the pressure gauges used in the test rig are listed in Table 3.3. The temperatures of both air and water were measured using six iron-constantan thermocouples (JType Omega).

Table 3.3: Specifications and functions of the pressure-measurement instruments

\begin{tabular}{|c|c|c|}
\hline Instrument & Specification & Location \\
\hline Pressure gauge 1 & $\begin{array}{c}\text { Marshall town Bourdon gauge } \\
\text { Range: 0 - 689.8 kPa (0 - 100 psi) }\end{array}$ & Before pressure controller \\
\hline Pressure gauge 2 & $\begin{array}{c}\text { USG Bourdon gauge } \\
\text { Range: 0 - 1100 kPa (0 - 160 psi) }\end{array}$ & After pressure controller \\
\hline Pressure gauge 3 & $\begin{array}{c}\text { USG Bourdon gauge } \\
\text { Range: 0 - 689.8 kPa (0 - } 100 \mathrm{psi})\end{array}$ & Air inlet \\
\hline Pressure gauge 4 & Ashcroft gauge & Water inlet \\
\hline Pressure gauge 5 & $\begin{array}{c}\text { Wika Bourdon gauge } \\
\text { Range: 0 - 413.9 kPa (0 - 60 psi) }\end{array}$ & Inlet of the combined tee junction \\
\hline Pressure gauge 6 & $\begin{array}{c}\text { Marshall town Bourdon gauge } \\
\text { Range: 0 - 413.9 kPa (0 - 60 psi) }\end{array}$ & Separation tank 2 \\
\hline Pressure gauge 7 & $\begin{array}{c}\text { Marshall town Bourdon gauge } \\
\text { Range: 0 - 413.9 kPa (0 - 60 psi) }\end{array}$ & Separation tank 3 \\
\hline Pressure gauge 8 & $\begin{array}{c}\text { USG Bourdon gauge } \\
\text { Range: 0 - 689.8 kPa (0 - } 100 \mathrm{psi})\end{array}$ & Air Outlet 2 \\
\hline Pressure gauge 9 & $\begin{array}{c}\text { USG Bourdon gauge } \\
\text { Range: 0 - 689.8 kPa (0 - } 100 \mathrm{psi})\end{array}$ & Air Outlet 3 \\
\hline
\end{tabular}




\subsection{Experimental Procedure}

\subsubsection{Partial-Phase-Separation Experiments}

For the ten partial-phase-separation data points in the annular and slug flow regimes the following numbered steps were followed in performing the tests:

1. Atmospheric pressure and ambient temperature were recorded.

2. Inlet and discharge valves of the separation tanks were left fully opened.

3. The outlet pressure of the pressure controller was set at $207 \mathrm{KPa}$ (gauge).

4. The air supply line was fully opened.

5. The control valve after the inlet air rotameters was kept fully open. The control valve upstream of the desired air rotameter was adjusted to provide the required air inlet flow rate (for a fixed $J_{\mathrm{G} 1}$ ). The float of the rotameter was constantly monitored to ensure that it has stayed in the same location throughout the experiment.

6. The appropriate air outlet rotameters in sides 2 and 3 were adjusted simultaneously to obtain the desired $F_{\mathrm{G} 2}$ and $F_{\mathrm{G} 3}$ and to maintain the test-section pressure at $2.0 \mathrm{bar}$ (abs). This was done by continuously adjusting the control valves located before the rotameters. The control valves after the rotameters were kept opened to the atmosphere.

7. The cooling water line for the water storage tank was turned on and the bypass valve was kept fully opened. The submersible pump was then turned on.

8. The control valve downstream of the inlet water rotameters was kept fully opened. The valve upstream of the appropriate water rotameter was adjusted for the desired inlet water flow rate (for a fixed $J_{\mathrm{L} 1}$ ).

9. The control valves above and below of the appropriate outlet water rotameters were activated for both Outlets-2 and -3 , while monitoring the water level in the separation tanks for any change in level (at a level where it could be monitored easily) and the outlet water rotameters were adjusted accordingly. 
10. After 15 mins of steady-state operation (steady water levels in the tanks and fixed test section pressure), the following readings were taken:

- Pressures of the inlet air and water, air outlets, separation tanks and test section.

- Temperatures of air and water at the inlet and outlets.

- Volume flowrates of air and water at the inlet and outlet from rotameters $\left(V_{\mathrm{G} 1}, V_{\mathrm{G} 2}\right.$, $\left.V_{\mathrm{G} 3}, V_{\mathrm{L} 1}, V_{\mathrm{L} 2}, V_{\mathrm{L} 3}\right)$.

At a particular inletcondition (fixed set of $J_{\mathrm{G} 1}$ and $J_{\mathrm{L} 1}$ ), steps 1 to 10 were repeated for different values of $\mathrm{F}_{\mathrm{G} 3}$, until $F_{\mathrm{L} 3}=1$ was reached.

\subsubsection{Full-Phase-Separation Experiments}

The objective of the full-phase-separation experiments was to determine the limiting inlet conditions for which the present system of combined junction is able to fully separate the phases. The full-phase-separation experiments were divided into two segments. For $J_{\mathrm{G} 1}<30$ $\mathrm{m} / \mathrm{s}, J_{\mathrm{G} 1}$ was fixed and $J_{\mathrm{L} 1}$ was increased until the limiting conditions were reached. For $J_{\mathrm{G} 1}>$ $30 \mathrm{~m} / \mathrm{s} J_{\mathrm{L} 1}$ was fixed while $J_{\mathrm{G} 1}$ was increased. All full-phase-separation experiments were conducted at a constant test-section pressure of $200 \mathrm{kPa}$ (abs) and ambient temperature. Between each data run, the system was completely dried by pushing air through the inlet and discharging it through the outlet air rotameters for a duration of time. Limiting conditions of full-phase separation were established when the liquid is entrained in the upward gas stream which was visually observed in the form of continuous flow of a liquid stream or liquid drops in the clear Tygon tubing connecting Outlet-2 with its separation tank.

\subsubsection{Full-Phase-Separation Experiments for $J_{\mathrm{G} 1}<30 \mathrm{~m} / \mathrm{s}$}

For a fixed $J_{\mathrm{G} 1}<30 \mathrm{~m} / \mathrm{s}$, the following procedure was followed for all full-phase-separation experiments:

1. Atmospheric pressure and ambient temperature were recorded. 
2. Inlet and discharge valves of the separation tanks were left fully opened.

3. The outlet pressure of the pressure controller was set at $207 \mathrm{KPa}$ (gauge).

4. The air supply line was fully opened.

5. The control valve after the inlet air rotameters was kept fully open. The control valve upstream of the desired air rotameter was adjusted to provide the required air inlet flow rate (for a fixed $J_{\mathrm{G} 1}$ ). The float of the rotameter was constantly monitored to ensure that it has stayed in the same location throughout the experiment.

6. The air rotameters for Outlet-3 were kept completely closed to force all the inlet air to exit through the top outlet, i.e., Outlet-2. The control valve downstream of the bank of Outlet-2 air rotameters was kept fully opened to the atmosphere. The control valve of the appropriate air rotameter for Outlet- 2 was adjusted to maintain the test section at a pressure of $200 \mathrm{kPa}(\mathrm{abs})$.

7. The cooling water line for the water storage tank was turned on and the bypass valve was kept fully opened. The submersible pump was then turned on.

8. The control valve downstream of the inlet water rotameters was kept fully opened. The valve upstream of the appropriate water rotameter was adjusted for the desired inlet water flow rate.

9. The control valves above and below of the appropriate outlet water rotameter were activated for Outlet-3, while monitoring the water level in the separation tank for any change in level (at a level where it could be monitored easily) and the outlet water rotameter was adjusted accordingly.

10. After 10 mins of steady-state operation (steady water levels in the tanks, fixed test section pressure and no liquid observed in the transparent Tygon tube for Outlet-2), the inlet water flowrate was increased slightly by adjusting the inlet water rotameter, while 
keeping the settings of the inlet and outlet air rotameters fixed. Step 9 was then repeated for the new inlet water flowrate or $J_{\mathrm{L} 1}$.

11. Step 10 was repeated iteratively with increasing $J_{\mathrm{L} 1}$ until liquid is observed exiting through the top outlet. The value of $J_{\mathrm{L} 1}$ at this point was considered the limiting value for full-phase separation at the chosen $J_{\mathrm{G} 1}$. the following readings were then taken:

a) Pressures of the inlet air and water, air outlets, separation tanks and test section.

b) Temperatures of air and water at the inlet and outlets.

Volume flowrates of air and water at the inlet and outlet from rotameters ( $V_{\mathrm{G} 1}, V_{\mathrm{G} 2}, V_{\mathrm{G} 3}, V_{\mathrm{L} 1}$, $\left.V_{\mathrm{L} 2}, V_{\mathrm{L} 3}\right)$

\subsubsection{Full-Phase-Separation Experiments for $J_{G 1}>30 \mathrm{~m} / \mathrm{s}$}

For $J_{\mathrm{G} 1}>30 \mathrm{~m} / \mathrm{s}$, a procedure similar to the one described in section 3.3.2.1 was followed but instead of varying $J_{\mathrm{L} 1}$ at a fixed $J_{\mathrm{G} 1}, J_{\mathrm{L} 1}$ was fixed while $J_{\mathrm{G} 1}$ was increased gradually until limiting conditions of full-phase separation were reached. For these cases, air inlet flowrate is gradually increased and consequently the air flowrate for Outlet- 2 is increased to maintain the test section pressure at $200 \mathrm{kPa}(\mathrm{abs})$. A wait time of 10 minutes between each iteration was implemented to ensure steady-state conditions. Once liquid is observed exiting through Outlet-2, the value of $J_{\mathrm{G} 1}$ at this point was considered to be the limiting value for fullphase separation at the chosen $J_{\mathrm{L} 1}$. If no liquid is observed, the inlet air flowrate is increased slightly while keeping $J_{\mathrm{L} 1}$ fixed.

\subsection{Data Reduction}

The equations used for calculating various parameters from the collected experimental data are shown below:

The gas density at any point in the test section was calculated by:

$$
\rho_{G}=\frac{P}{R T}
$$


Where the gas constant for air, $R=0.287 \mathrm{KJ} / \mathrm{kg}$. The standard density, $\rho_{\mathrm{STD}}$, was calculated using Equation (3.1), with values of $P$ and $T$ at $101.3 \mathrm{kPa}$ and $294.1 \mathrm{~K}$, respectively.

The water density at any location in the loop was calculated using linear interpolation of the values of water densities at various temperatures $(\mathrm{K})$ collected from thermodynamic property tables of water.

The gas mass flowrates at the inlet and outlets, $W_{\mathrm{G}}$, were calculated using the equation:

$$
W_{\mathrm{G}}=V_{\mathrm{G}} \times \rho_{\mathrm{STD}} \times \sqrt{\left(\rho_{\mathrm{G}} / \rho_{\mathrm{STD}}\right)}
$$

The liquid mass flowrates at the inlet and outlets, $W_{\mathrm{L}}$, were calculated using the equation:

$$
W_{L}=V_{L} \times \rho_{L}
$$

The equations used to calculate other parameters such as $W_{1}, W_{2}, W_{3}, W_{\mathrm{R}}, F_{\mathrm{G} 2}, F_{\mathrm{G} 3}, F_{\mathrm{L} 2}$, $F_{\mathrm{L} 3}, J_{\mathrm{L} 1}$, and $J_{\mathrm{G} 1}$ have been included in section 1.3. 


\section{CHAPTER 4}

\section{RESULTS AND DISCUSSION}

\subsection{Data Range}

Two sets of experiments were performed: partial- and full-phase-separation experiments. Nine data points in the annular flow regime region and one data point in the slug flow regime region were examined for the partial-phase-separation experiments. Each data point was conducted at a fixed combination of liquid and gas velocities, nominal test section pressure of $200 \mathrm{kPa}(\mathrm{abs})$, and ambient temperature. For each partial-phase-separation data point, several runs at various mass-split ratios $\left(W_{3} / W_{1}\right)$ ranging between 0 and 1 were performed. To obtain the full-phase-separation curve, 20 data points were collected. The data collected were within $J_{\mathrm{G} 1}=0.2-39 \mathrm{~m} / \mathrm{s}$ and $J_{\mathrm{L} 1}=0.0009-0.72 \mathrm{~m} / \mathrm{s}$, which fell in the annular, slug and plug flow regimes.

Air and water mass balance calculations were performed for every data point. Mass balance was defined as the percentage deviation between the flow rate in the inlet of a specific phase and the sum of the flow rates in the two outlets. A positive mass balance indicates a sum of the two outlet flowrates lower than the inlet flowrate. For all collected data, the air mass balances were within $\pm 5 \%$ and the water mass balances were within $\pm 3 \%$.

Table 4.1 and Table 4.2 summarise the ranges of operating conditions for the full- and partial-phase-separation experiments, respectively. The complete set of data for full-and partial-phase separation can be found in Appendix B. The partial-phase-separation data points are shown on the flow regime map constructed by Mandhane et al. (1974) in Figure 4.1. 
Table 4.1: Range of operating conditions for full-phase-separation data

\begin{tabular}{|c|c|}
\hline Number of data points & 20 \\
\hline Inlet flow regime & Annular, Slug, Plug \\
\hline Inlet gas superficial velocity $\boldsymbol{J}_{\mathbf{G} \mathbf{1}} \mathbf{( \mathbf { m } / \mathbf { s } )}$ & $0.2-39$ \\
\hline Inlet liquid superficial velocity $\left.\boldsymbol{J}_{\mathbf{L} 1} \mathbf{( m} / \mathbf{s}\right)$ & $0.0009-0.72$ \\
\hline Temperature, $\mathbf{T}\left({ }^{\mathbf{0}}\right)$ & $20 \pm 1$ \\
\hline Test section pressure $\boldsymbol{P}_{\mathbf{s}}(\mathbf{k P a})$ & $200 \pm 3$ \\
\hline Air mass balance $(\boldsymbol{\%})$ & Within \pm 5.0 \\
\hline Water mass balance $(\boldsymbol{\%})$ & Within \pm 3.0 \\
\hline
\end{tabular}

Table 4.2: Range of operating condition s for partial-phase-separation data

\begin{tabular}{|c|c|}
\hline Number of data points & 49 \\
\hline Inlet flow regime & Annular, Slug \\
\hline Inlet gas superficial velocity $\boldsymbol{J}_{\mathbf{G} 1}$ & $10-41$ \\
\hline Inlet liquid superficial velocity $\boldsymbol{J}_{\mathbf{L} 1}$ & $0.01-0.6$ \\
\hline Temperature, $\mathbf{T}\left({ }^{\mathbf{0}} \mathbf{)}\right.$ & $19.7 \pm 1$ \\
\hline Test section pressure $\boldsymbol{P}_{\mathbf{s}}(\mathbf{k P a})$ & $200 \pm 2.5$ \\
\hline Air mass balance $(\boldsymbol{\%})$ & Within \pm 2.0 \\
\hline Water mass balance $(\%)$ & Within \pm 2.0 \\
\hline
\end{tabular}

Values of $J_{\mathrm{G} 1}$ and $J_{\mathrm{L} 1}$ were kept within $\pm 3 \%$ and $\pm 1 \%$, respectively, of the nominal values during the experimental investigation for partial-phase separation. The observed inlet flow regimes were in good agreement with the flow regimes predicted by Mandhane et al. (1974) flow-regime map. For full-phase-separation curve, limiting conditions of $J_{\mathrm{G} 1}$ and $J_{\mathrm{L} 1}$ were experimentally determined when water starts to flow through the top outlet (Outlet-2). 


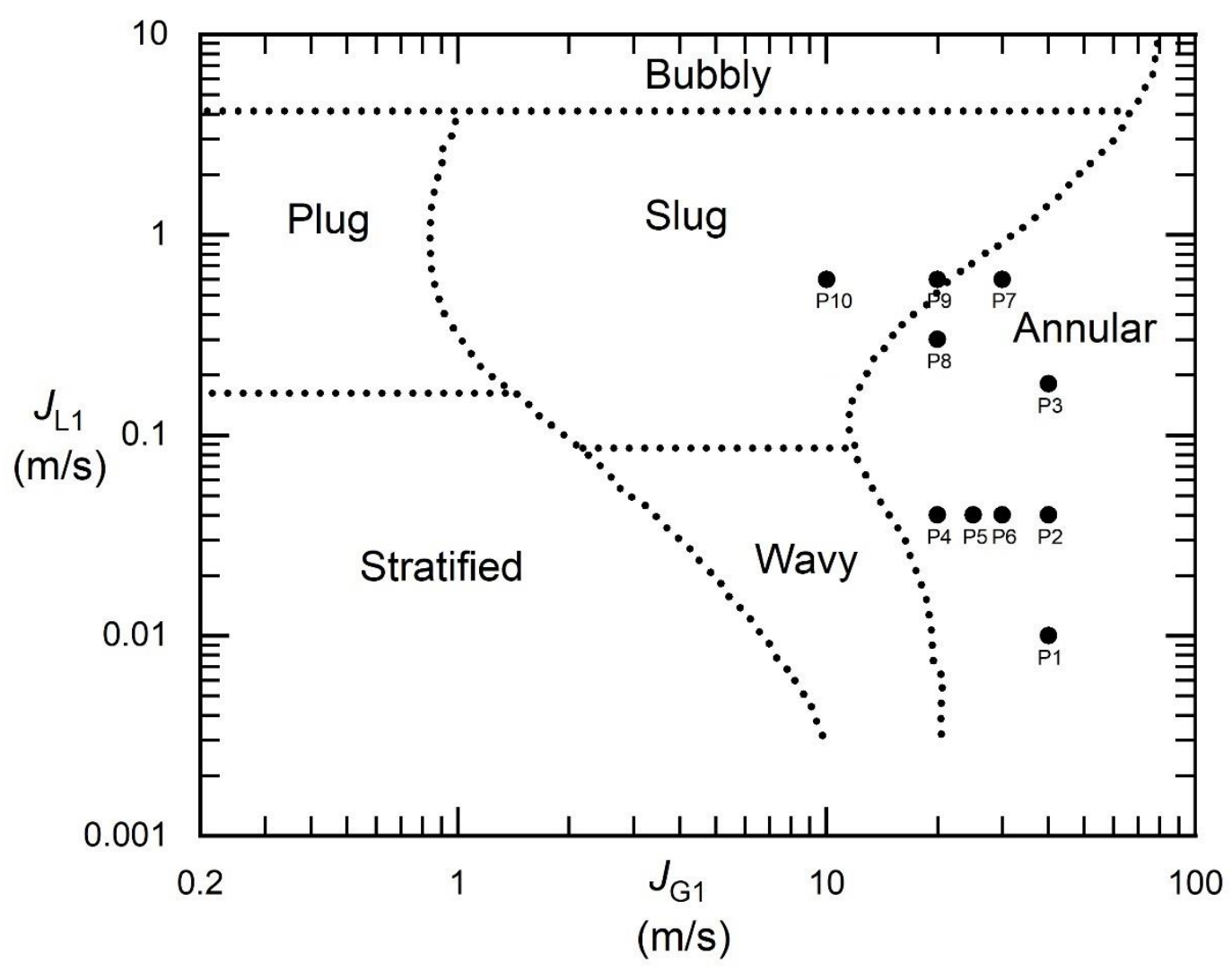

Figure 4.1: Inlet conditions for partial-phase-separation experiments plotted on Mandhane et al. (1974) flow-regime map

\subsection{Measurement Uncertainty}

Uncertainty analysis was performed on both full- and partial-phase-separation data to account for uncertainties in measuring instruments, inaccuracy in calibration devices and errors in experimental procedure. Fixed error margins were pre-set for the various measuring instruments; these error margins are tabulated in Table 4.3.

The uncertainty analysis technique used was the numerical method of sequential perturbation. The analysis was performed on both partial- and full-phase-separation data for inlet parameters $W_{\mathrm{G} 1}, W_{\mathrm{L} 1}, J_{\mathrm{G} 1}, J_{\mathrm{L} 1}$ and for outlet parameters $W_{\mathrm{G} 2}, W_{\mathrm{G} 3}, W_{\mathrm{L} 2}, W_{\mathrm{L} 3}, F_{\mathrm{G} 3}$ and $F_{\mathrm{L} 3}$. A summary of the analysis is tabulated in Table 4.4. A complete set of results is provided in Appendix C. 
Table 4.3: Fixed uncertainties for partial- and full-phase-separation experiments

\begin{tabular}{|c|c|}
\hline Pressure Gauges & $\pm 1.8 \%$ \\
\hline Thermocouples & $\pm 0.2^{\circ} \mathrm{C}$ \\
\hline Air Rotameters & $\pm 2 \%$ of reading \\
\hline Water Rotameters & $\pm 3 \%$ of reading \\
\hline Diameter & $\pm 1.5 \%$ \\
\hline
\end{tabular}

Table 4.4: Summary of uncertainty analysis for phase-separation experiments

\begin{tabular}{|c|c|c|c|c|c|c|c|c|c|c|}
\hline \multirow{2}{*}{$\begin{array}{c}\text { Phase } \\
\text { Separation }\end{array}$} & $J_{\mathrm{G} 1}$ & $J_{\mathrm{L} 1}$ & $W_{\mathrm{G} 1}$ & $W_{\text {G2 }}$ & $W_{\text {G3 }}$ & $W_{\mathrm{L} 1}$ & $W_{\mathrm{L} 2}$ & $W_{\mathbf{L} 3}$ & $F_{\mathrm{G} 3}$ & $F_{\mathrm{L} 3}$ \\
\hline & $(\%)$ & $(\%)$ & $(\%)$ & $(\%)$ & $(\%)$ & $(\%)$ & $(\%)$ & $(\%)$ & $(\%)$ & $(\%)$ \\
\hline Full & \pm 3.8 & \pm 4.2 & \pm 2.1 & \pm 2.1 & $\mathrm{NA}$ & \pm 3.0 & NA & \pm 3.0 & NA & \pm 5.4 \\
\hline Partial & \pm 3.8 & \pm 4.2 & \pm 2.1 & \pm 2.0 & \pm 1.4 & \pm 3.0 & \pm 3.0 & \pm 3.0 & \pm 4.1 & \pm 4.5 \\
\hline
\end{tabular}

\subsection{Reliability and Symmetry of the Test Section}

To ensure reliability, two partial-phase-separation data points reported by Noor and Soliman (2019) were reproduced in the annular flow regime region. Data were generated over the full range of mass-split ratios. The experiments were conducted with the combined impacting system consisting of three impacting tees used by Noor and Soliman at the same operating conditions; thus, it is sensible/reasonable to compare the results.

Figure 4.2 illustrates partial-phase-separation data at $J_{\mathrm{G} 1}=40 \mathrm{~m} / \mathrm{s}$ and two different $J_{\mathrm{L} 1}$. The rectangular symbols represent data obtained by Noor and Soliman (2019) while the circular symbols represent present data. The present data obtained was in good agreement with those of Noor and Soliman for the entire range of mass extraction ratios. The deviation between the two data sets can be explained by procedural uncertainties and operational difference s but the results are still within the limits of experimental accuracy. 
After construction of the new test section, the loop had to be tested for symmetry and ability to reproduce data under similar conditions. To test the symmetry of the test loop, singlephase air is passed through the loop at four different inlet flowrates $(3,10,20,40 \mathrm{~m} / \mathrm{s})$. The test section was maintained at $200 \mathrm{kPa}(\mathrm{abs})$ and ambient temperature. For each run, the pressures of the two air outlets and the two separation tanks were kept at the same value relative to each other. Under these conditions, it is expected to get equal air outlet flowrates from each outlet; the flowrates obtained were within $3 \%$ of each other as shown in Table 4.5 .

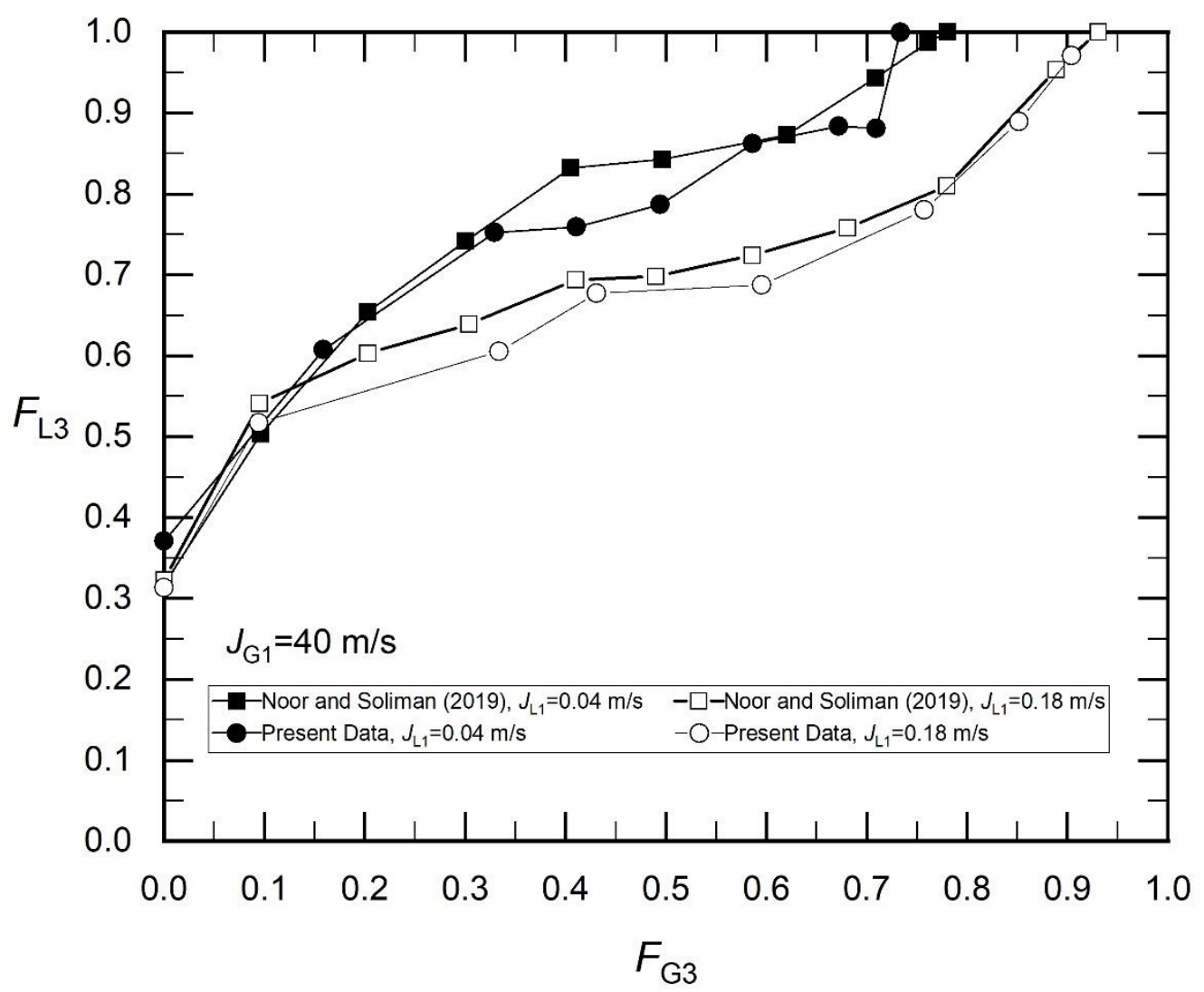

Figure 4.2: Comparison of data with Noor and Soliman (2019) at identical test conditions 
Table 4.5: Test loop symmetry data

\begin{tabular}{|c|c|c|c|c|}
\hline$J_{\mathbf{G} 1}$ & $\boldsymbol{W}_{\mathbf{G} 1}$ & $\boldsymbol{W}_{\mathbf{G} 2}$ & $\boldsymbol{W}_{\mathbf{G 3}}$ & $\begin{array}{c}\text { Percentage } \\
\text { Difference }\end{array}$ \\
\hline$(\mathbf{m} / \mathbf{s})$ & $\mathbf{( k g / h r})$ & $\mathbf{( k g / h r})$ & $\mathbf{( k g / h r})$ & $(\%)$ \\
\hline 3 & 3.70 & 1.87 & 1.82 & $2.94 \%$ \\
\hline 10 & 12.2 & 6.14 & 6.08 & $1.05 \%$ \\
\hline 20 & 23.5 & 11.7 & 11.7 & $0.02 \%$ \\
\hline 40 & 48.6 & 24.2 & 24.2 & $0.11 \%$ \\
\hline
\end{tabular}

\subsection{Data Repeatability}

Few data points were repeated to ensure repeatability of collected data. Table 4.6 shows the results of some of the full-phase-separation experiments that were repeated. The data points are exact/almost identical and thus validate the system and procedure.

Table 4.6: Repeatability of full-phase-separation data

\begin{tabular}{|c|c|c|c|}
\hline $\boldsymbol{J}_{\mathbf{G} 1}$ & $\boldsymbol{J}_{\mathbf{L} 1}$ & $\boldsymbol{F}_{\mathbf{G 3}}$ & $\boldsymbol{F}_{\mathbf{L 3}}$ \\
\hline $\mathbf{( m / \mathbf { s } )}$ & $\mathbf{( m / \mathbf { s } )}$ & 0 & 1 \\
\hline 2.75 & 0.42 & 0 & 1 \\
\hline 2.73 & 0.41 & 0 & 1 \\
\hline 34.18 & 0.0184 & 0 & 1 \\
\hline 34.89 & 0.0184 & 0 & 1 \\
\hline 36.42 & 0.0089 & 0 & 1 \\
\hline
\end{tabular}




\subsection{Full Phase Separation}

\subsubsection{Shape of the Full-Phase-Separation Curve}

The full-phase-separation curve defines the limiting conditions of inlet superficial velocities, $J_{\mathrm{G} 1}$ and $J_{\mathrm{L} 1}$, for which full separation of phases can be obtained. The area under the curve corresponds to inlet conditions for which full separation is attainable, while only partial separation is possible above the data curve as demonstrated in Figure 4.3 plotted on the flow regime map of Mandhane et al. (1974).

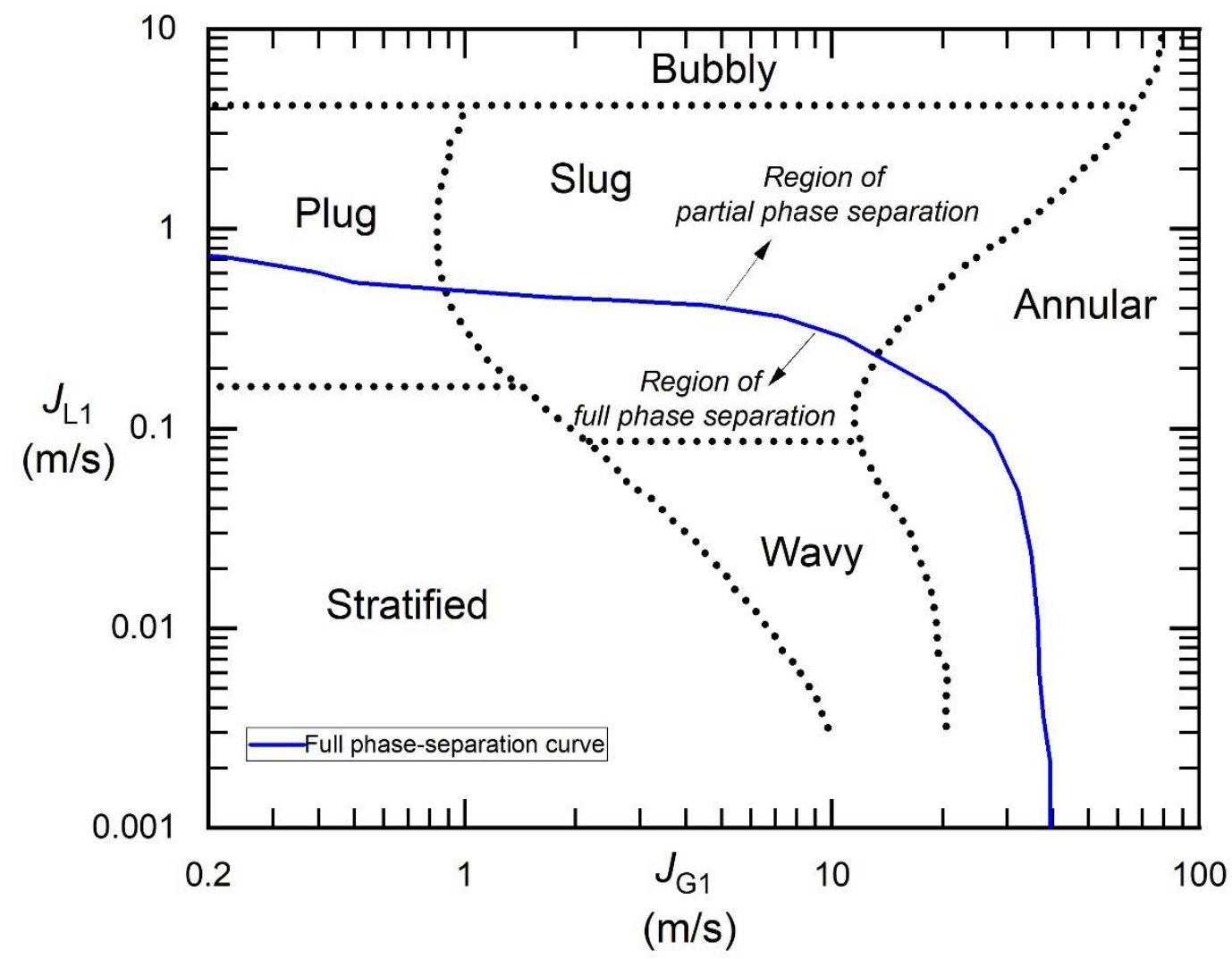

Figure 4.3: Full-phase-separation curve 


\subsubsection{Full-Phase-Separation Data}

The present full-phase-separation curve with data points plotted on Mandhane et al. (1974) flow-regime map is shown in Figure 4.4. The curve represents limiting conditions for full-phase separation whereby liquid started to flow from Outlet-2. The curve obtained almost coincide with the theoretical curve representing double the limiting conditions of full-phase separation obtained by Noor and Soliman (2019), which means that the present system of combined junctions consisting of seven impacting tees has limiting conditions of $J_{\mathrm{G} 1}$ and $J_{\mathrm{L} 1}$ for full separation of phase that are almost twice those obtained by the system of combined junctions consisting of three impacting tees by Noor and Soliman (2019).

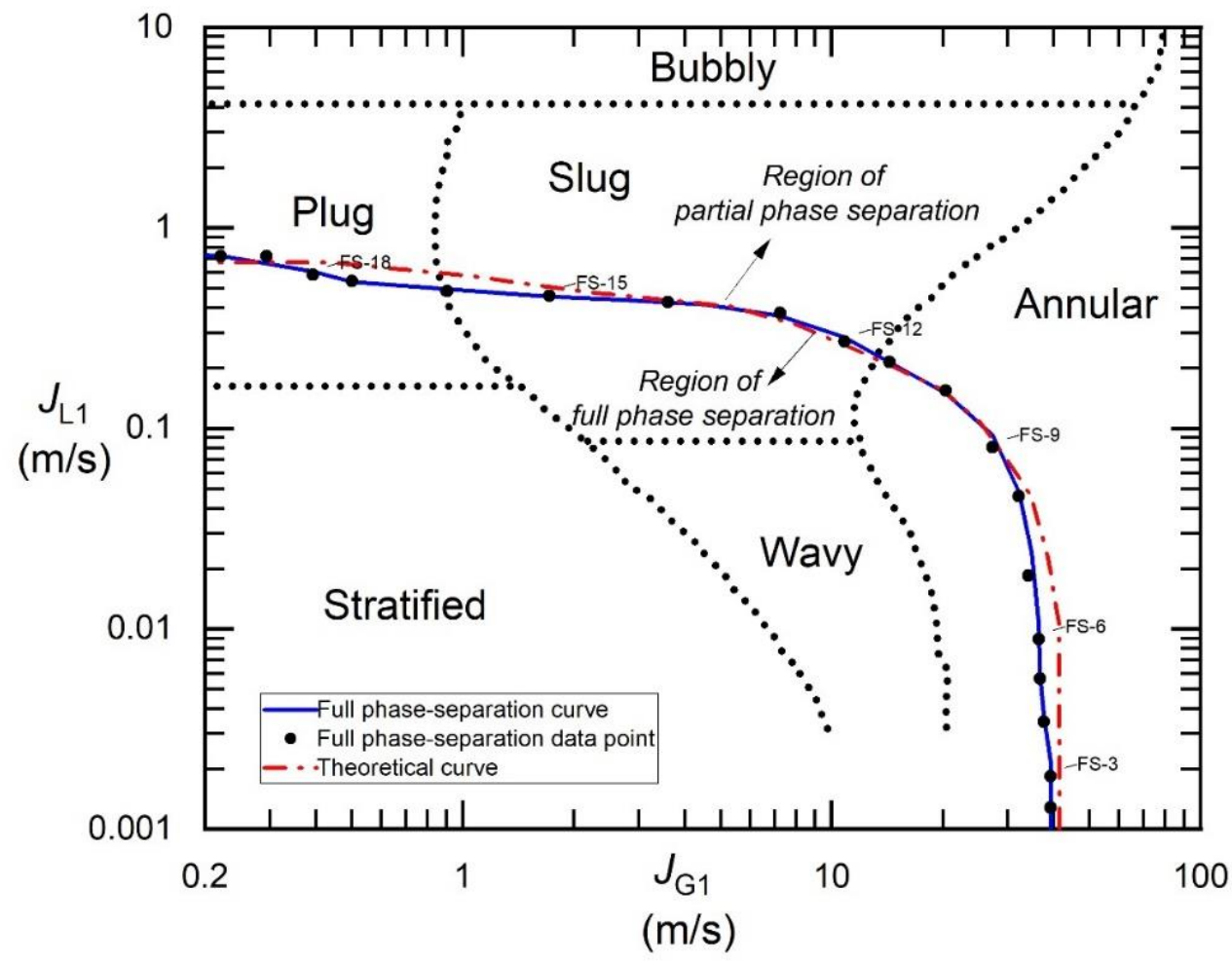

Figure 4.4: Limiting conditions of full phase separation plotted on Mandhane et al. (1974) flow-regime map

This could be explained by the design of the test section. At the first horizontal impacting junction, the inlet flow is split equally in terms of quantity and quality i.e., $J_{\mathrm{G} 1}$ and 
$J_{\mathrm{L} 1}$ should be half of the inlet values, owing to the symmetry of the loop. At the second junction the flow is halved again. Therefore, each of the four vertical lines, where the phase separation occurs, receive one quarter of the inlet flow. Thus, theoretically, the present combined junction can perform full separation for inlet flows that are four times those of a single impacting tee (Mohamed et al., 2012) and two times those of a combined junction with three impacting tees (Noor and Soliman, 2019). Figure 4.5 compares the present system with the two systems mentioned above. The present data is represented by closed circular symbols. The dashed curve presents the limiting condition obtained by Noor and Soliman (2019) with a system of three impacting junctions. The dotted curve is the curve obtained by Mohamed et al. (2012) with a single tee-junction system. As demonstrated in the figure, the new system further ex tends the region for which full-phase separation is attainable.

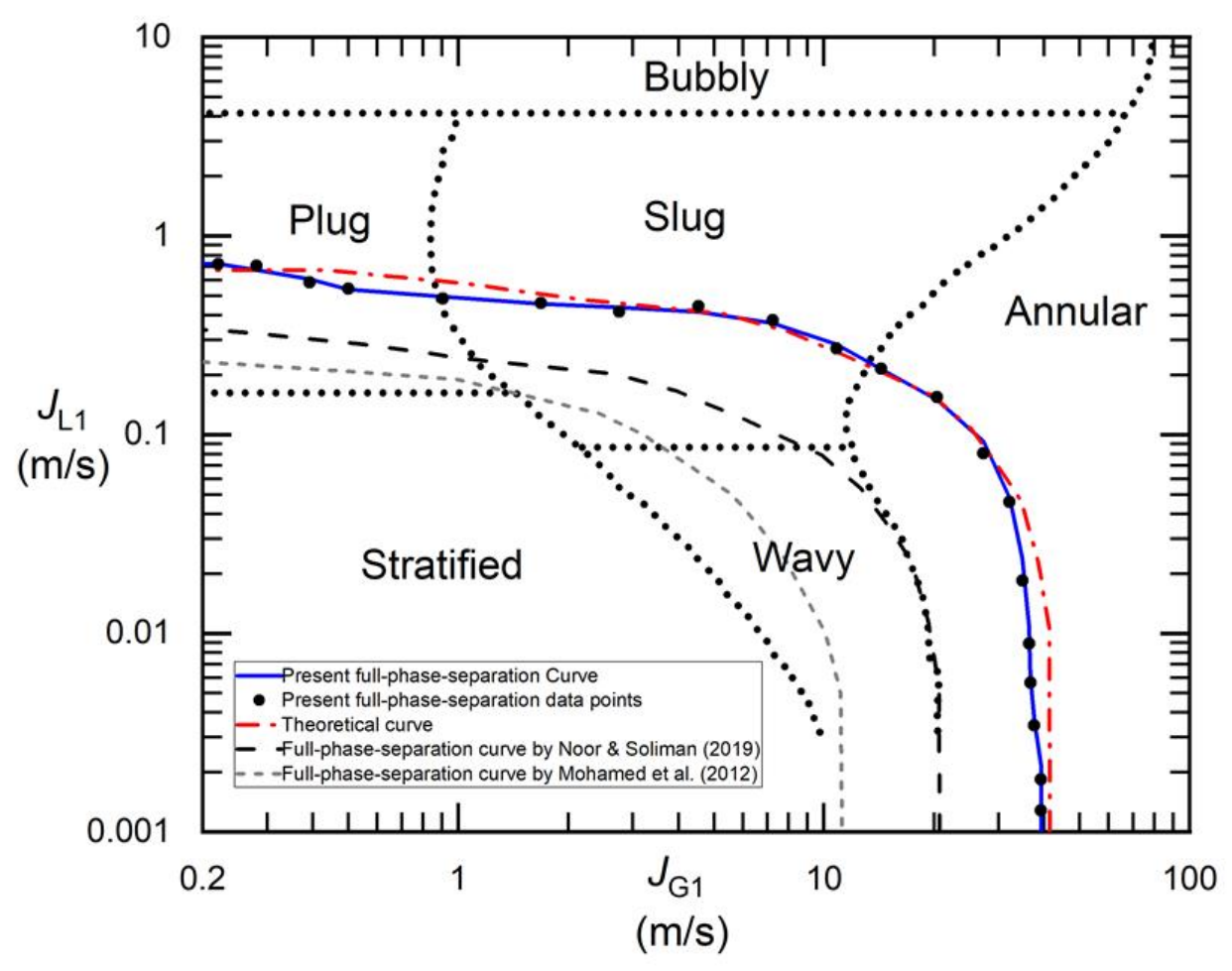

Figure 4.5: Full-phase-separation curves from literature 


\subsection{Partial Phase Separation}

\subsubsection{Data Points}

Ten data points were selected to study partial-phase separation in the region beyond the full-phase-separation curve, as illu strated in Figure 4.6. The data points were in the annular and slug flow regimes. Six of which (P1-P6) were studied by Noor and Soliman (2019). Three of these points (P4, P5, and P6) are obviously inside the full-separation region with the present system. Four additional points (P7-P10) were also examined. The purpose of this section of the thesis is to compare the performance of the present system against previous systems when full separation was not achieved. In this section, the results are presented in $F_{\mathrm{G} 3}$ versus $F_{\mathrm{L} 3}$ plots to display the phase redistribution in the two outlets, when full-phase separation cannot be achieved. Each data point corresponds to a fixed combination of $J_{\mathrm{G} 1}$ and $J_{\mathrm{L} 1}$. For every point, the mass flow rate of gas in the bottom outlet, $W_{\mathrm{G} 3}$, is increased gradually from 0 , up to the point where all the liquid leaves from the bottom outlet, i.e., $F_{\mathrm{L} 3}=1$.

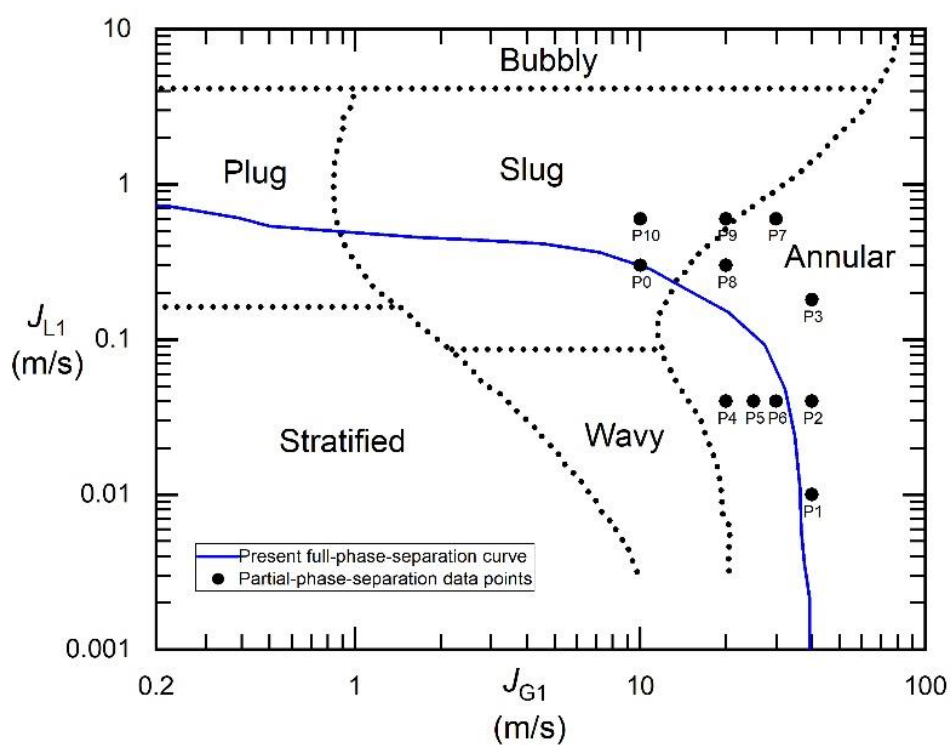

Figure 4.6: Inlet conditions for partial-phase-separation experiments plotted on Mandhane et al. (1974) flow-regime map. 


\subsubsection{Partial-Phase-Separation Data at Fixed $J_{\mathrm{L} 1}$}

The effect of altering the inlet gas superficial velocity, $J_{\mathrm{G} 1}$, at fixed inlet liquid superficial velocity, $J_{\mathrm{L} 1}$, on phase separation is presented in Figures 4.7 and 4.8. In Figure 4.7, three inlet gas velocities $(10,20$ and $30 \mathrm{~m} / \mathrm{s})$ at a fixed inlet liquid velocity of $0.6 \mathrm{~m} / \mathrm{s}$ were studied; these corresponded to the points P10, P9, and P7, respectively. In Figure 4.8, two inlet gas velocities (10 and $20 \mathrm{~m} / \mathrm{s}$ ) at a fixed inlet liquid velocity of $0.3 \mathrm{~m} / \mathrm{s}$ were studied; these corresponded to the points $\mathrm{P} 0$ and $\mathrm{P} 8$, respectively.

It is clear from these figures that as $J_{\mathrm{G} 1}$ decreases, the phase-redistribution curve shifts in the counter-clockwise direction closer to the point of full-phase separation, i.e., point $(0,1)$ on the $F_{\mathrm{G} 3}$ versus $F_{\mathrm{L} 3}$ plot, which means higher fraction of liquid enters the bottom outlet at the same fraction of gas. This observation is caused by two factors; the natural tendency of liquids to exit through bottom outlets because of gravity represented by $\rho_{L} g \sin (\theta)$ which acts to push the liquid down and gas inertia force which is defined as the ability of gas to entrain liquid with it as it exits through the top outlet given by $\rho_{\mathrm{G}} J_{\mathrm{G}}{ }^{2}$ which acts to pull the liquid up. Increasing $J_{\mathrm{G} 1}$, which in turn increases the gas inertia force, causes more liquid to leave through the top outlet, thus, increasing $F_{\mathrm{L} 2}$ and consequently, reducing $F_{\mathrm{L} 3}$. Increasing $F_{\mathrm{G} 3}$ causes less gas to leave through the top outlet, thus, decreasing liquid entrainment, subsequently, $F_{\mathrm{L} 3}$ is increased. Increasing $F_{\mathrm{G} 3}$ further, results in a drop in gas inertia force until it can no longer hold any liquid and all the liquid leaves through the bottom outlet, i.e., $F_{\mathrm{L} 3}=1$. At lower $J_{\mathrm{G} 1}$, the point of $F_{\mathrm{L} 3}$ $=1$ occurs sooner as a result of lower gas inertia force. 


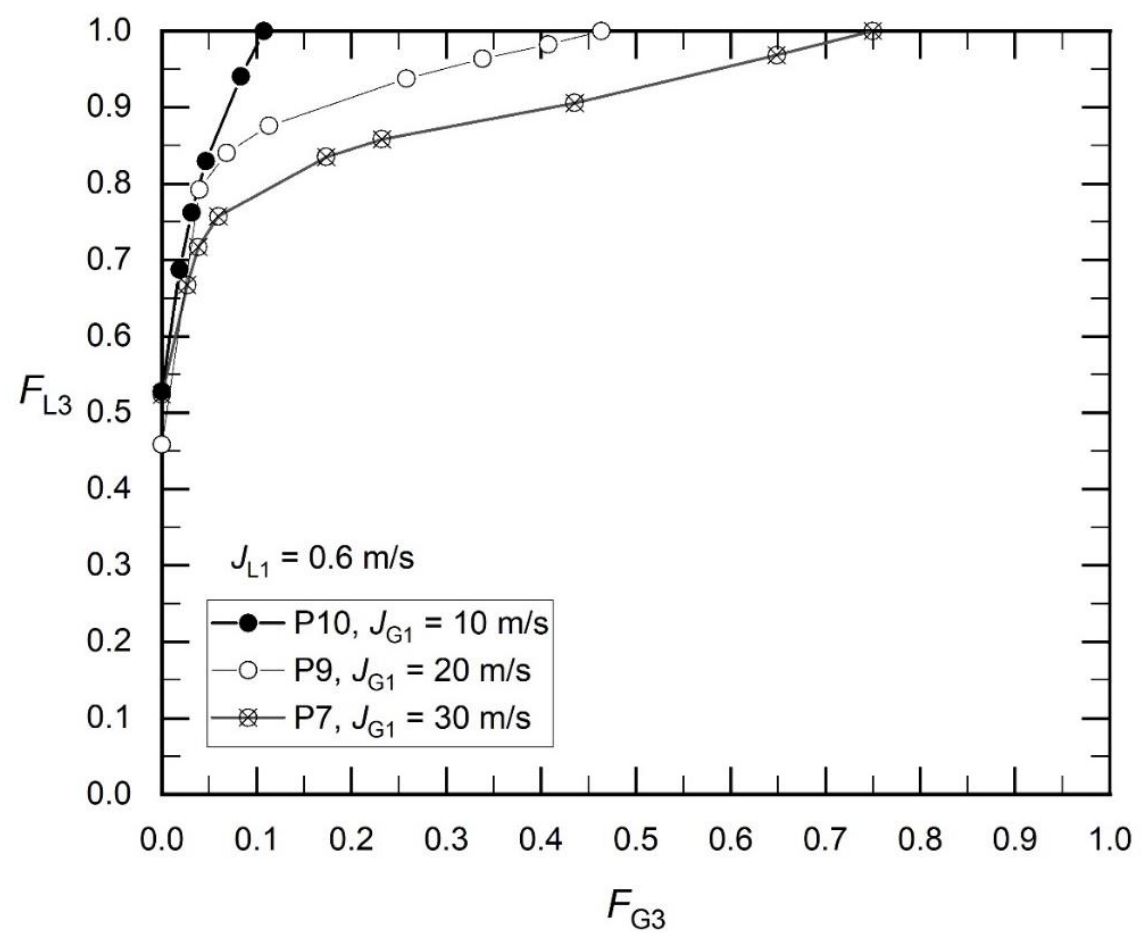

Figure 4.7: Partial-phase-separation data at fixed $J_{\mathrm{L} 1}=0.6 \mathrm{~m} / \mathrm{s}$

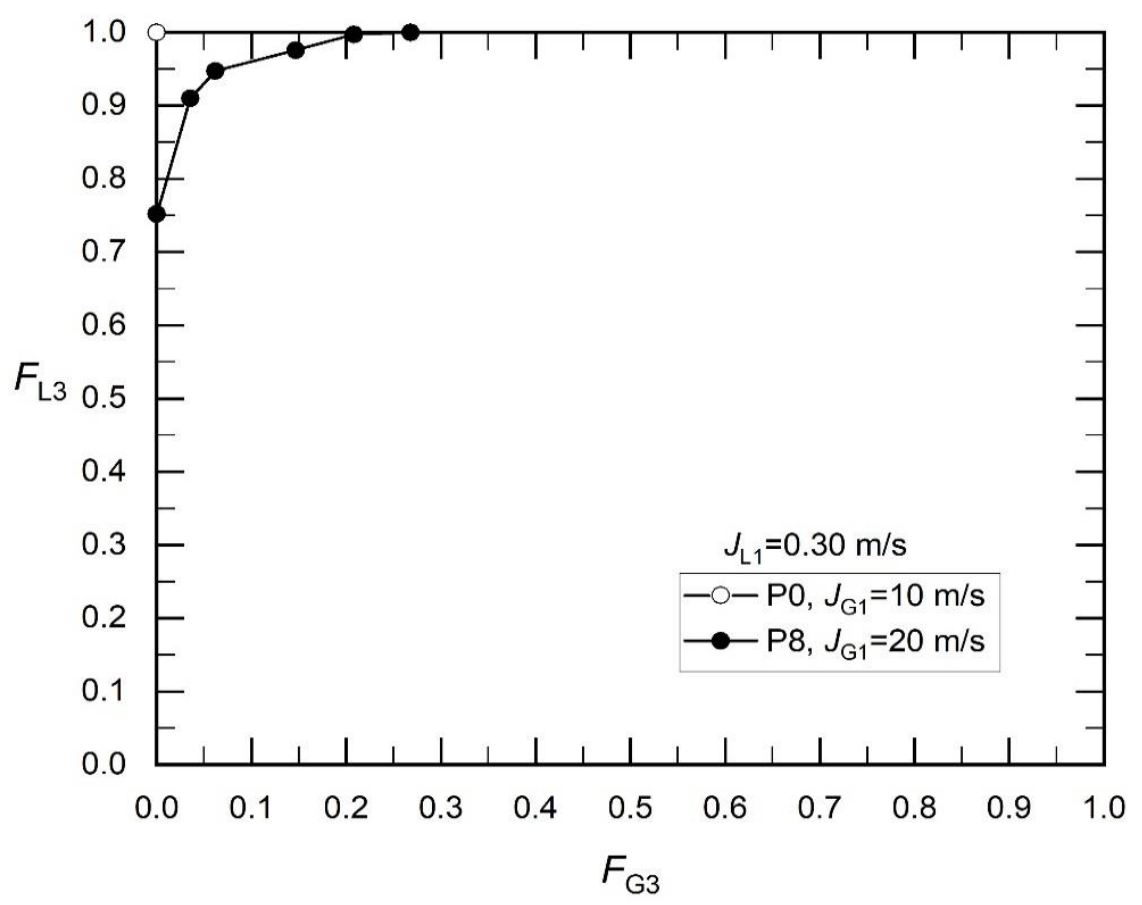

Figure 4.8: Partial-phase-separation data at fixed $J_{\mathrm{L} 1}=0.3 \mathrm{~m} / \mathrm{s}$ 


\subsubsection{Partial-Phase-Separation Data at Fixed $J_{\mathrm{G} 1}$}

The effect of varying the inlet liquid superficial velocity, $J_{\mathrm{L} 1}$, at fixed inlet gas superficial velocity, $J_{\mathrm{G} 1}$, on phase separation is presented in Figure 4.9. Three inlet liquid velocities $(0.01,0.04$ and $0.18 \mathrm{~m} / \mathrm{s})$ at a fixed inlet gas velocity of $40 \mathrm{~m} / \mathrm{s}$ were studied, these corresponded to the points $\mathrm{P} 1, \mathrm{P} 2$, and $\mathrm{P} 3$, respectively. The effect of $J_{\mathrm{L} 1}$ on phase separation is less pronounced than the effect of $J_{\mathrm{G} 1}$ shown earlier. No clear trend can be deduced from the figure until after $F_{\mathrm{G} 3}=0.2$; this irregularity was also observed by Noor and Soliman (2019) and Mohamed et al. (2012). The partial-phase-separation curves move in counter-clockwise direction towards the point of full-phase separation with decreasing $J_{\mathrm{L} 1}$ as larger volumes of liquid leave through the bottom outlet. This observation is hard to explain but it could be attributed to the balance between gas inertia and liquid gravity forces.

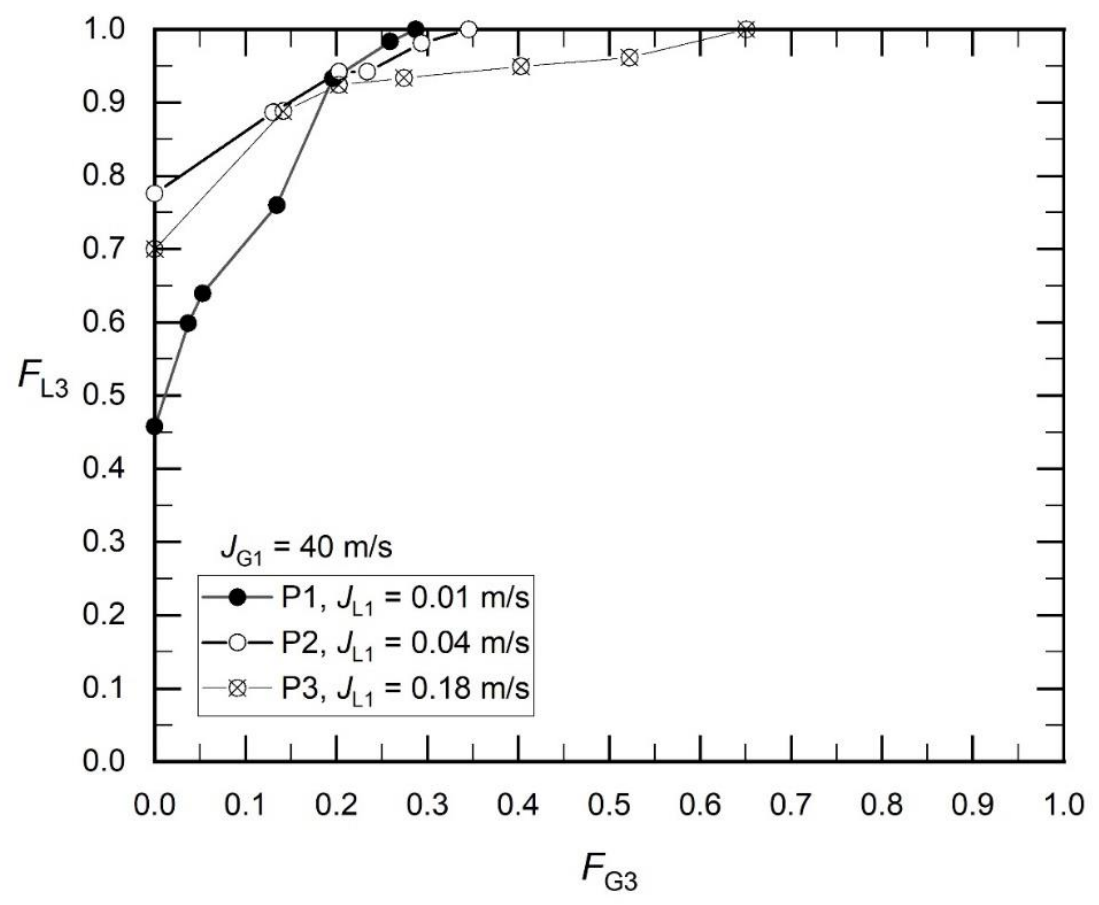

Figure 4.9: Partial-phase-separation data at fixed $J_{\mathrm{G} 1}=40 \mathrm{~m} / \mathrm{s}$ 


\subsection{Phase-Separation Parameter}

\subsubsection{Definition}

To evaluate the system's effectiveness in separating the phases, a 'phase-separation parameter' proposed by Noor and Soliman (2019) was implemented. The phase-separation parameter is defined as:

$$
\eta=\left(F_{\mathrm{G} 2}-F_{\mathrm{L} 2}\right) \times 100 \%
$$

The parameter quantifies the distribution of phases in the two outlets by considering the fractions of both inlet liquid and gas entering the same outlet. Maximum effectiveness is reported when all the inlet gas leaves through the top outlet (Outlet-2), i.e., $F_{\mathrm{G} 2}=1$, and all the inlet liquid exits through the bottom outlet (Outlet-3), i.e., $F_{\mathrm{L} 2}=0$. The relation between the phase-separation parameter, $\eta$, and $F_{\mathrm{G} 3}$ is shown in Figure 4.10. All data points should appear between the two lines marked $F_{\mathrm{L} 3}=0$ and $F_{\mathrm{L} 3}=1$ on Figure 4.10; no data can exist outside these lines. There are four main limiting points: $(0,0),(0,100),(1,0)$ and $(1,-100)$, on the plot. The interpretation of each is as follows:

Point $(\mathbf{0 , 0})$ : This point is equivalent to point $(0,0)$ in the partial-phase-separation $\left(F_{\mathrm{G} 3} \mathrm{Vs} . F_{\mathrm{L} 3}\right)$ graph. At this point, the phase-separation effectiveness is zero which occurs when all the inlet liquid and gas exit through the top outlet.

Point $(\mathbf{0 , 1 0 0})$ : At this point the phase-separation effectiveness is $100 \%$, which represents the point of full-phase separation where all the gas leaves through Outlet-2 and all the liquid leaves through Outlet-3.

Point $(\mathbf{1 , 0})$ : This point equivalent to point $(1,1)$ in the partial-phase-separation $\left(F_{\mathrm{G} 3}\right.$ Vs. $\left.F_{\mathrm{L} 3}\right)$ graph. At this point, the phase-separation effectiveness is zero; all the inlet liquid and gas exit through the bottom outlet (Outlet-3). 
Point $(1,-100)$ : This point equivalent to point $(1,0)$ in the partial-phase-separation $\left(F_{\mathrm{G} 3} \mathrm{Vs}\right.$. $\left.F_{\mathrm{L} 3}\right)$ graph. At this point, all the gas leaves through Outlet-3 and all the liquid leaves through Outlet-2, which is a highly unlikely scenario.

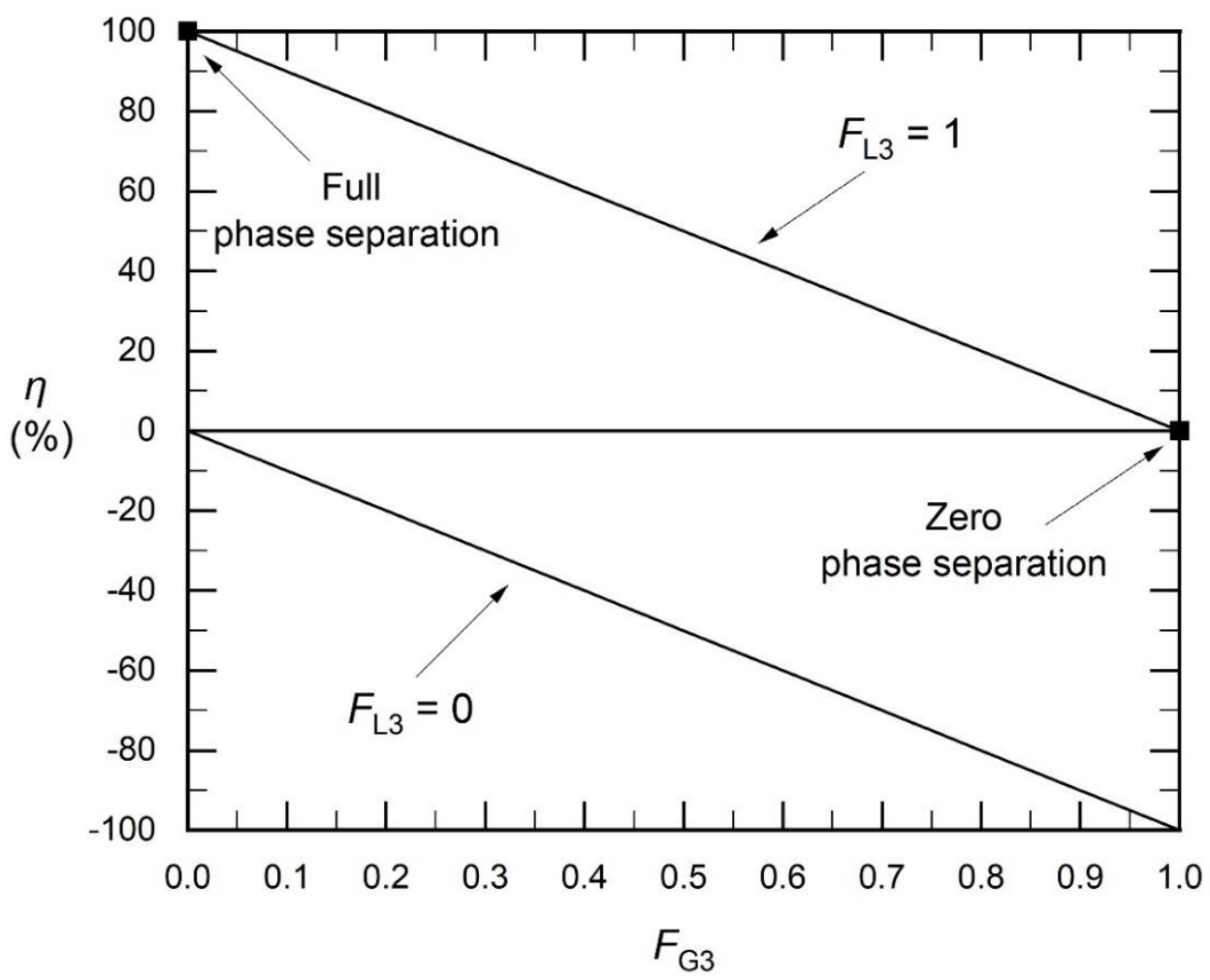

Figure 4.10: Plot of phase-separation parameter, $\eta$, as a function of $F_{\mathrm{G} 3}$

\subsubsection{Phase-Separation Parameter at Fixed $J_{\mathrm{L} 1}$}

The effect of $J_{\mathrm{G} 1}$, on the phase-separation parameter, $\eta$, is shown in Figure 4.11 for three points: P7, P9, and P10 at fixed $J_{\mathrm{L} 1}=0.60 \mathrm{~m} / \mathrm{s}$ and in Figure 4.12 for the points $\mathrm{P} 0$ and P8 at fixed $J_{\mathrm{L} 1}=0.30 \mathrm{~m} / \mathrm{s}$. As observed from the figures, for increasing values of $J_{\mathrm{G} 1}, \eta$ decreases for every corresponding $F_{\mathrm{G} 3}$. The same trend was noted by Noor and Soliman (2019). The point where $F_{\mathrm{L} 3}=1$, corresponding to all liquid leaving through the bottom outlet, gets closer to the full-phase-separation point with decreasing $J_{\mathrm{G} 1}$. The separation effectiveness, $\eta$, is higher for all $F_{\mathrm{G} 3}$, as $J_{\mathrm{G} 1}$ is decreased. 


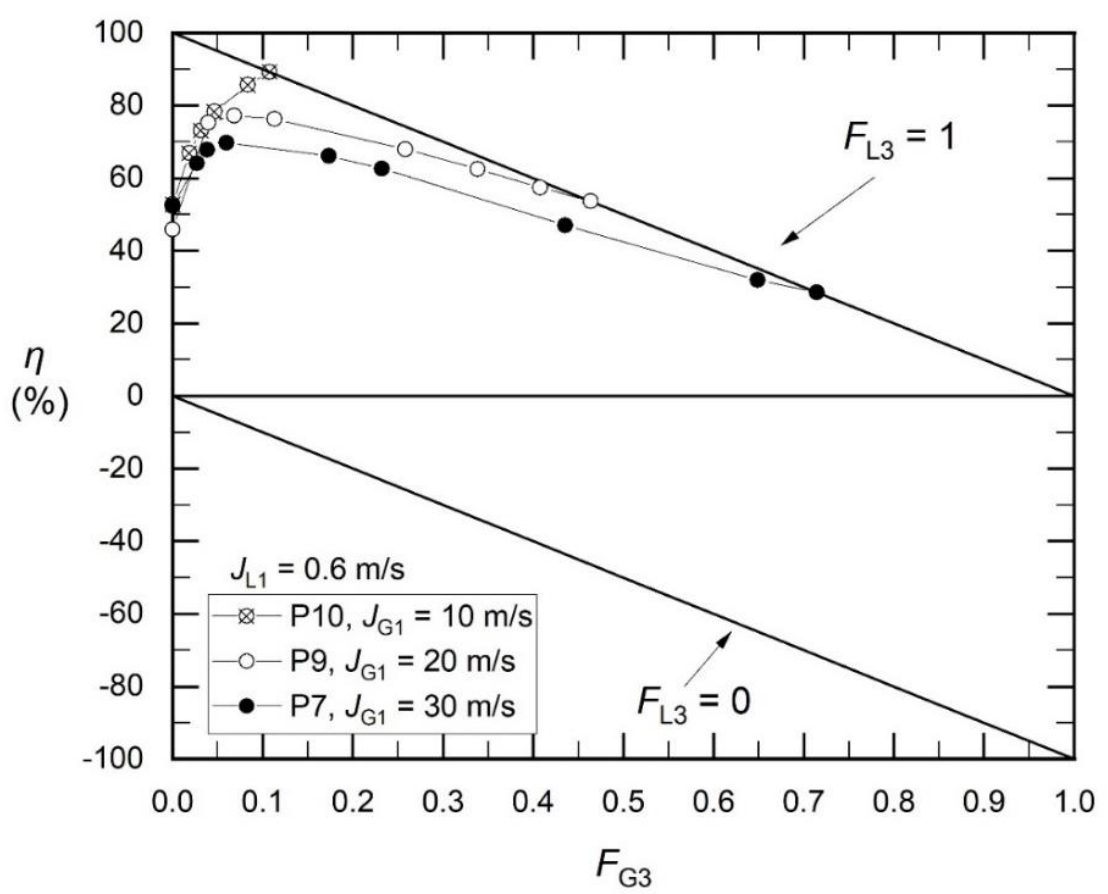

Figure 4.11: Phase-separation parameter, $\eta$, at fixed $J_{\mathrm{L} 1}=0.60 \mathrm{~m} / \mathrm{s}$

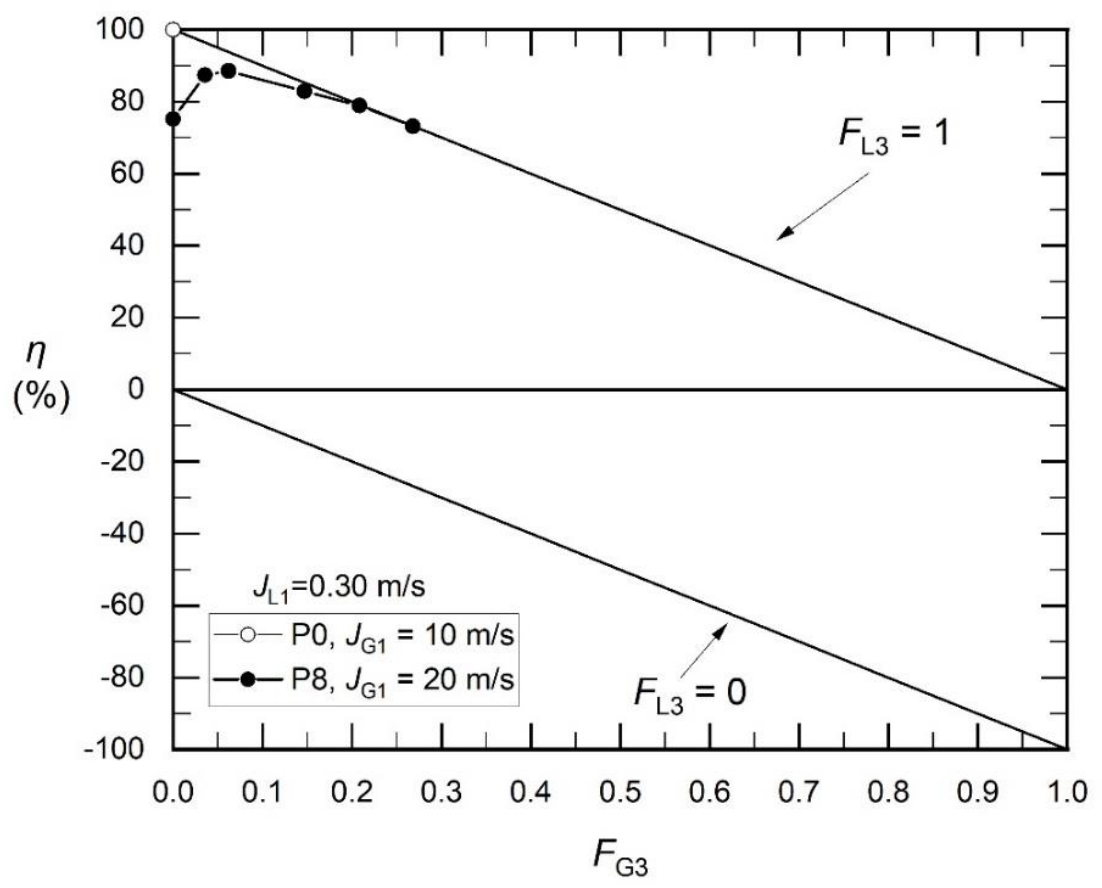

Figure 4.12: Phase-separation parameter, $\eta$, at fixed $J_{\mathrm{L} 1}=0.30 \mathrm{~m} / \mathrm{s}$ 


\subsubsection{Phase-Separation Parameter at Fixed $J_{\mathrm{G} 1}$}

Figure 4.13 presents the curves of phase-separation parameter, $\eta$, as a function of $F_{\mathrm{G} 3}$ for the three annular points $\mathrm{P} 1, \mathrm{P} 2$ and $\mathrm{P} 3$, all of which have a $J_{\mathrm{G} 1}=40 \mathrm{~m} / \mathrm{s}$ and a different $J_{\mathrm{L} 1}$. A similar trend to that observed by Noor and Soliman (2019) can be seen in the figure. There is a change of trend pivoted at $F_{\mathrm{G} 3}=0.2$. For $F_{\mathrm{G} 3}<0.2$, there is no fixed trend. For $F_{\mathrm{G} 3}>0.2$, decreasing $J_{\mathrm{L} 1}$ helps achieve a higher phase-separation effectiveness for all $F_{\mathrm{G} 3}$. The point where $F_{\mathrm{L} 3}=1$, gets closer to full-phase-separation point $(0,100)$ with decreasing $J_{\mathrm{L} 1}$, which is an indicator of enhanced phase-separation effectiveness.

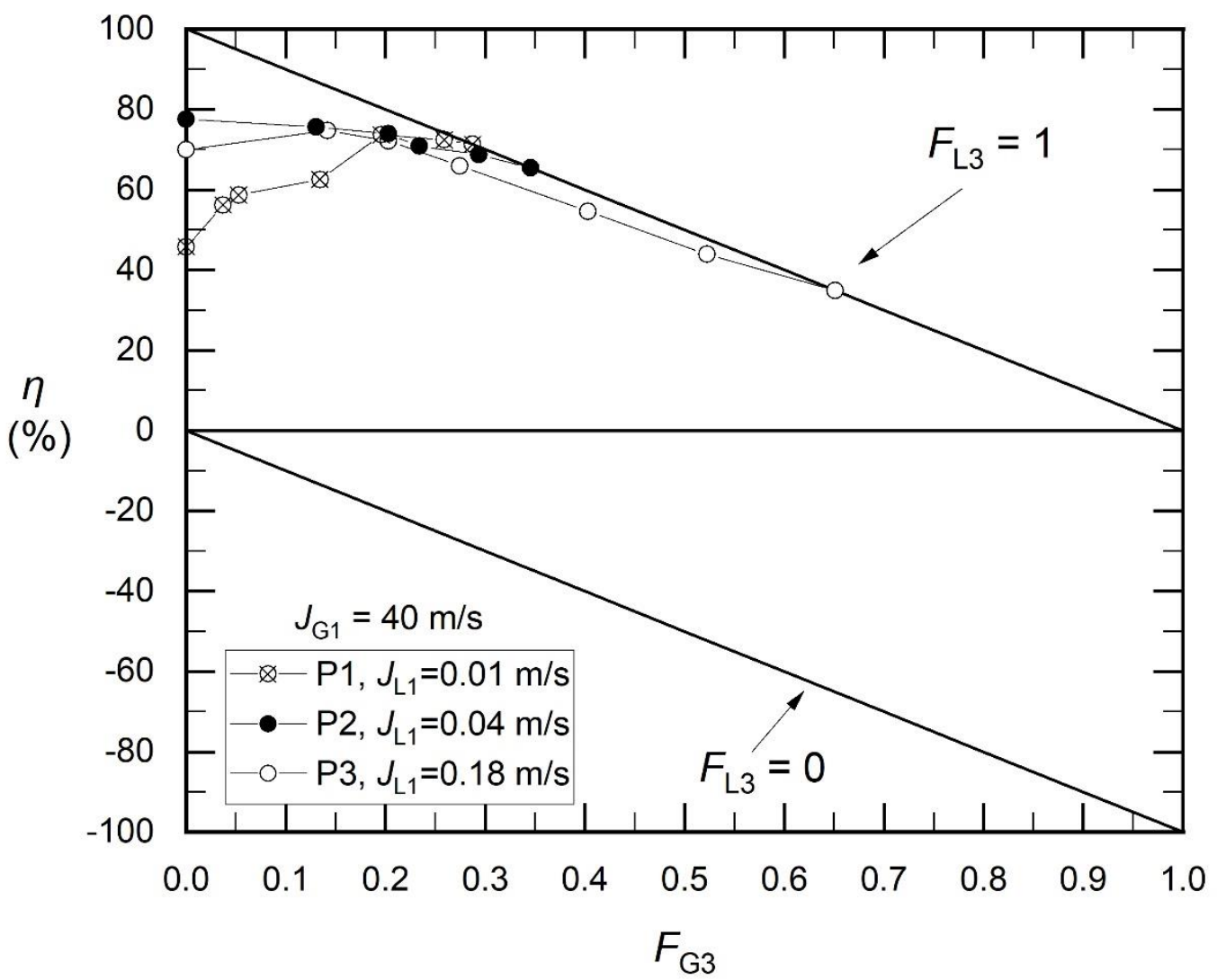

Figure 4.13: Phase-separation parameter, $\eta$, at fixed $J_{\mathrm{G} 1}=40 \mathrm{~m} / \mathrm{s}$ 


\subsection{Comparison of Partial-Separation Data Points}

\subsubsection{Overview}

Data collected with the present system have been compared to data obtained by other systems in the literature. The comparison is based on partial-phase-separation data and the separation parameter, $\eta$, to highlight the enhancement in phase-separation effectiveness when the present system of combined junctions is used. Noor and Soliman (2019) have reported partial-phase-separation data for the points 1-6 with a system of combined junctions under identical testconditions to those used in the present study. Similar partial-phase-separation data for points P2 and P3 using the combined junction system used by Noor and Soliman have been collected by the author of this thesis as illustrated earlier in Figure 4.2. For all the studied data points, phase-separation parameter, $\eta$, has been calculated and compared in this section.

\subsubsection{Partial-Phase-Separation Data}

A comparison in partial-phase-separation data between the present system of seven impacting tees, a system of three impacting tees and a system of a single impacting tee is shown in Figures $4.14-4.16$. These figures each present three sets of data for P1, P2 and P3 data points. In all these figures, circular symbols represent the data for the present system.

It is clear from the figures that the phase-separation effectiveness improves with increased number of tee junctions in a system. Furthermore, the partial-phase-separation curves move in counter-clockwise direction closer to the point of full-phase separation for the present system when $J_{\mathrm{L} 1}$ is decreased. 


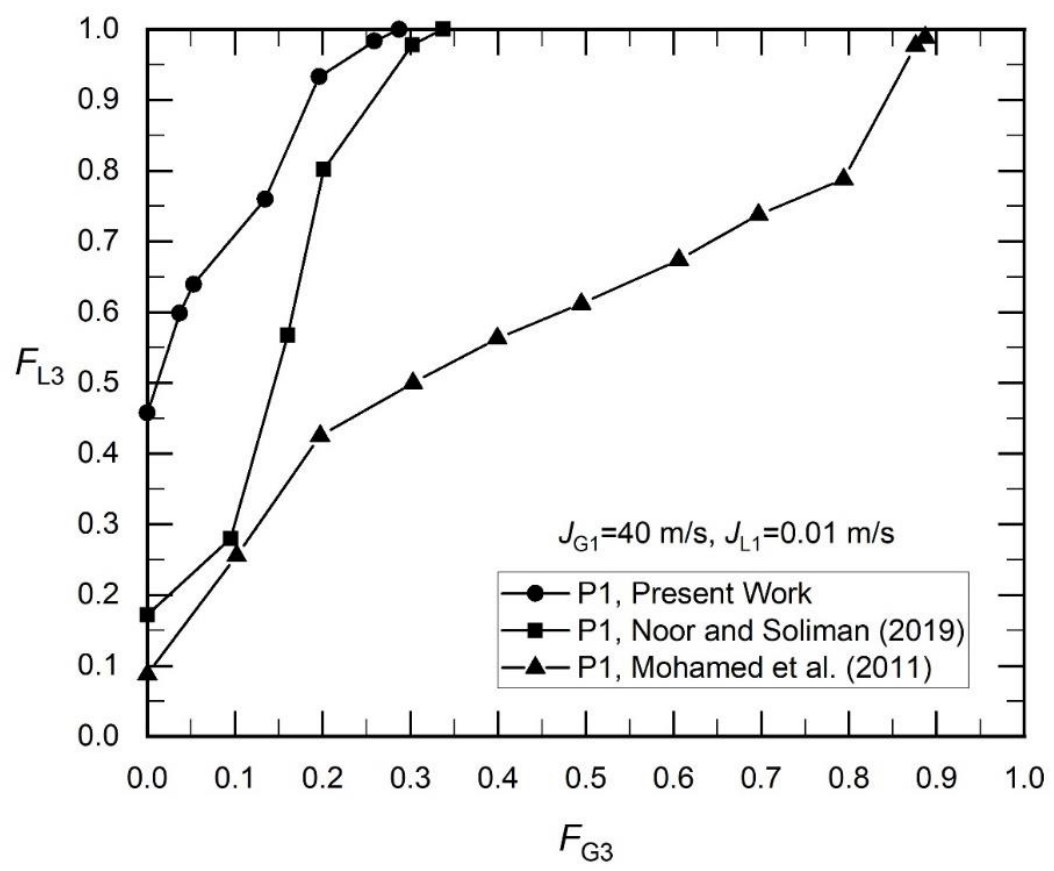

Figure 4.14: Comparison of partial-phase-separation data for P1 data point

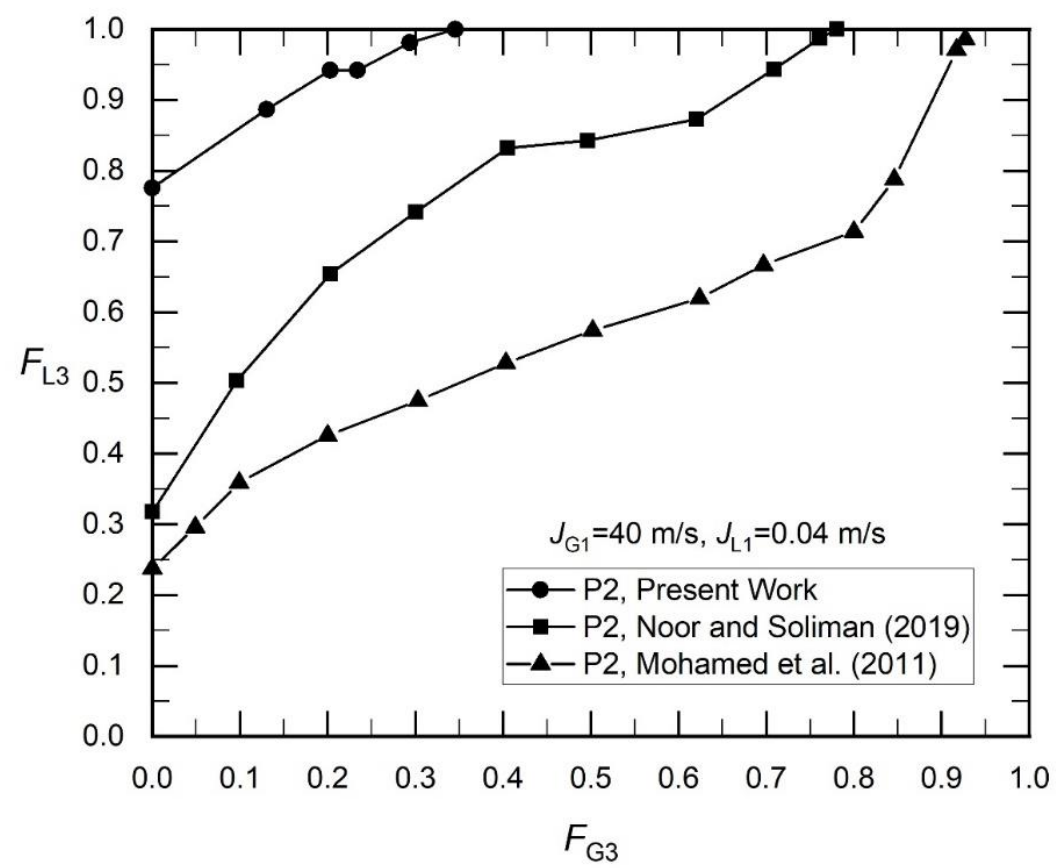

Figure 4.15: Comparison of partial-phase-separation data for P2 data point 


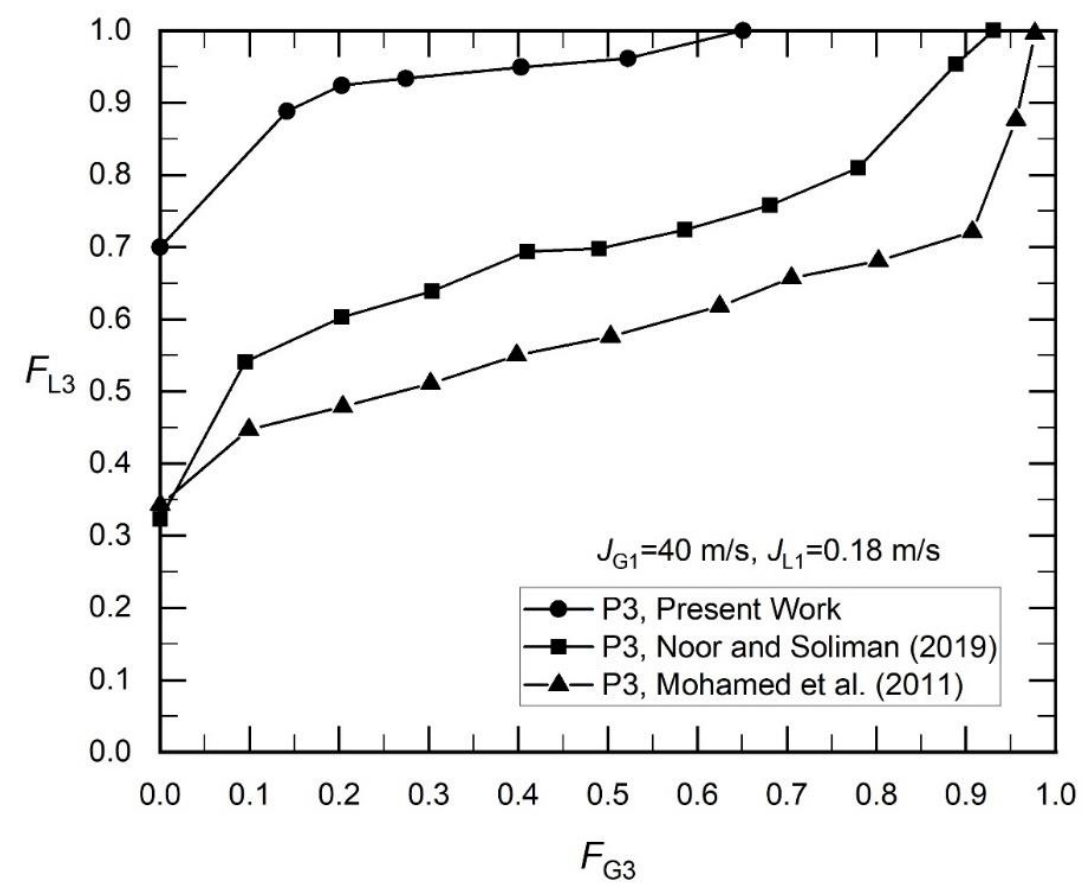

Figure 4.16: Comparison of partial-phase-separation data for P3 data point

\subsubsection{Comparison Based on the Phase-Separation Parameter}

A comparison of phase-separation parameter, $\eta$, as a function of $F_{\mathrm{G} 3}$ between the present system, a system of three combined tees and a system of a single tee junction of the same kind is shown in Figures 4.17 - 4.19, for data points P1, P2 and P3, respectively, where the present system data is represented by circular symbols.

It is apparent from the figures that the phase-separation parameter, $\eta$, is higher for every $F_{\mathrm{G} 3}$ with the present system. It is therefore safe to conclude that phase-separation effectiveness is increased with increased number of tee junctions in the system. This is consistent with the results obtained by Noor and Soliman (2019). 


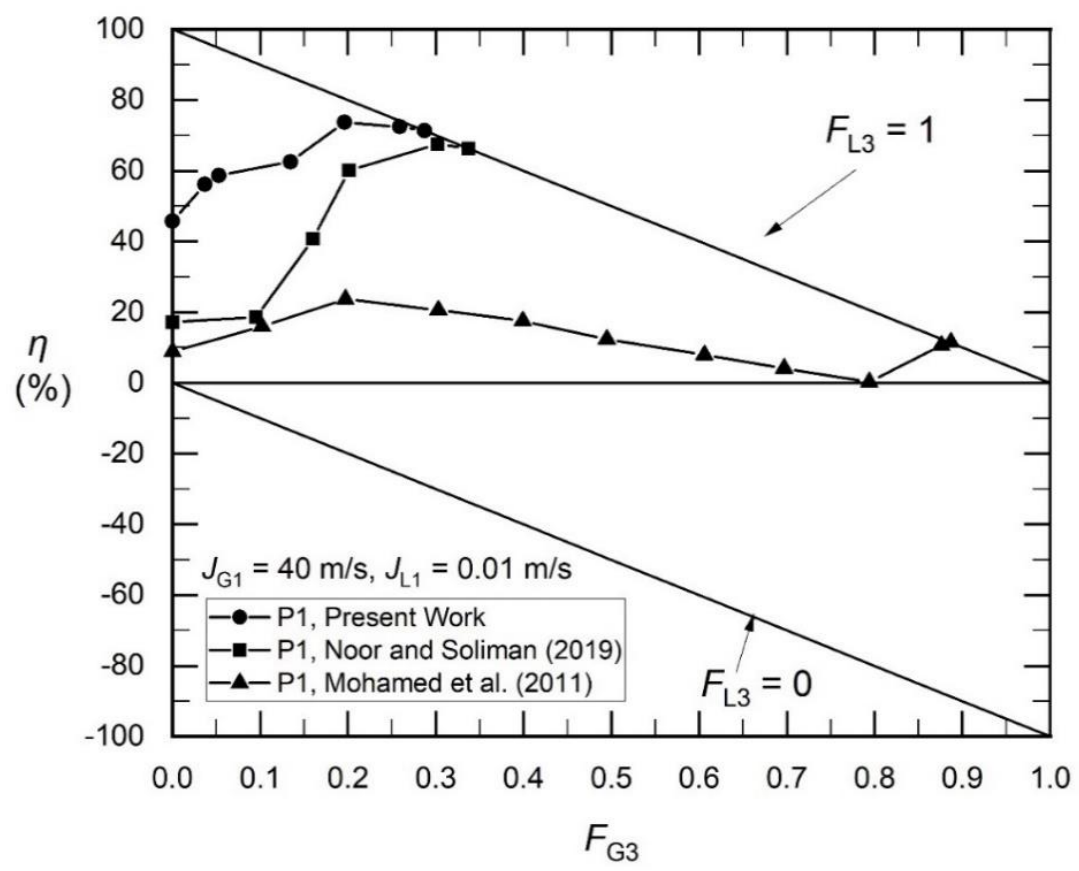

Figure 4.17: Comparison of phase-separation parameter of the present system with literature P1 data point

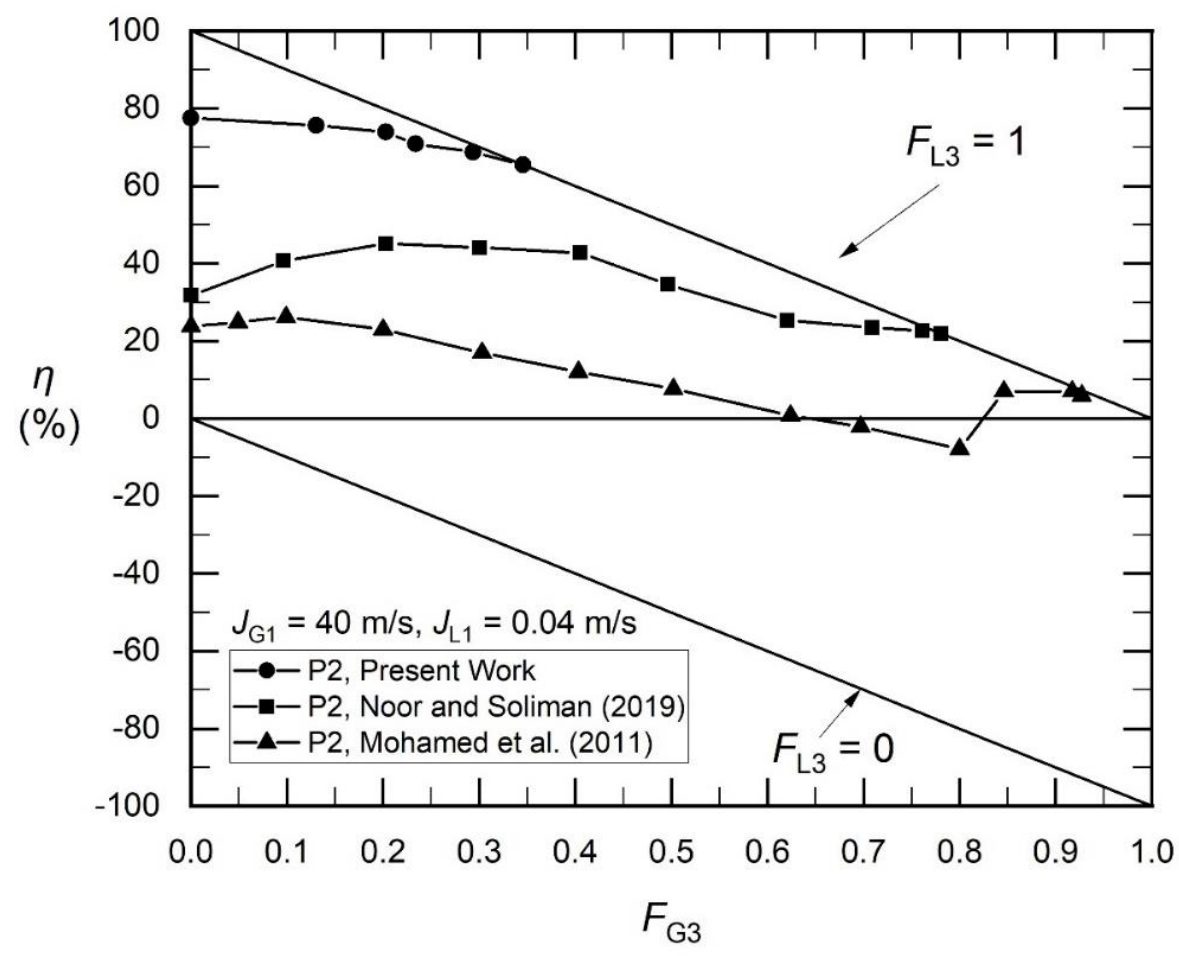

Figure 4.18: Comparison of phase-separation parameter of the present system with literature P2 data point 


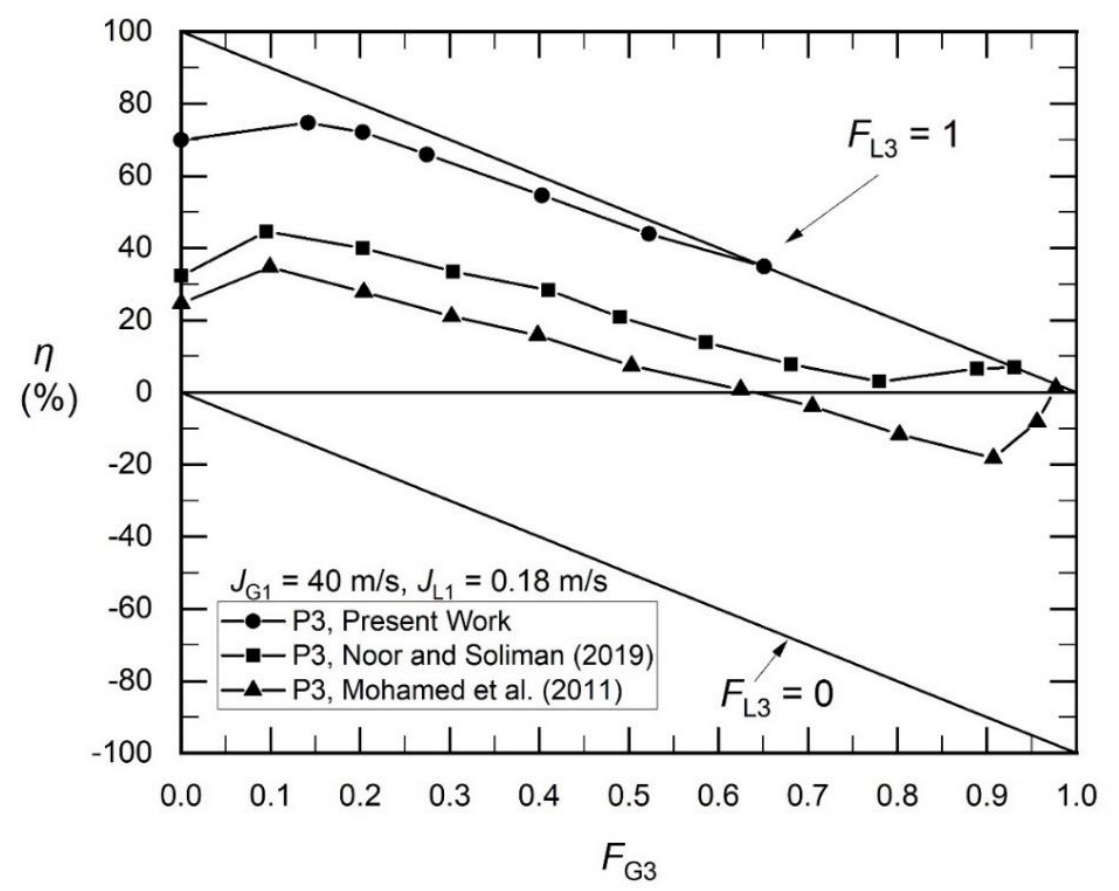

Figure 4.19: Comparison of phase-separation parameter of the present system with literature P3 data point

\subsection{Comparison with Other Systems Based on the Maximum Separation Parameter}

Phase-separation data collected with the present system of combined impacting tees were compared to phase-separation data of other systems of combined impacting tees from the literature. For the comparison to be valid, the studied fluids and data ranges had to match with the present study. It was found that the present system shows better phase-separation effectiveness when compared to other combined junctions reported in the literature.

\subsubsection{Comparison with Yang et al. (2017)}

The phase-separation data from the present system were compared with data from a two- and three-layer systems of combined branching tees. The two-layer system consisted of 3,5 or 7 connecting tubes or dividing tees of the branching type. Schematic diagram of this system is shown in Figure 2.3. The three-layer system had four upwards and three downwards connecting tubes or 7 branching tees in total as shown in Figure 2.6. Eight data points collected 
by Yang et al. (2017) in the plug flow regime are shown in Figure 4.20. The solid line in this figure is the full-phase-separation curve obtained with the present system.

All eight data points studied by Yang et al. (2017) lie below the full-phase-separation curve obtained with the present system, which means the present system is able to fully separate the two phases at these points. For the two closest data points to the full-phase-separation curve; $\mathrm{Y} 6$ and $\mathrm{Y} 8$, the authors reported $\eta_{\max }=88 \%$ and $98 \%$, respectively, when the three-layer system was used. Table 4.7 gives the separation effectiveness data reported by Yang et al. (2017) and data obtained with the present system.

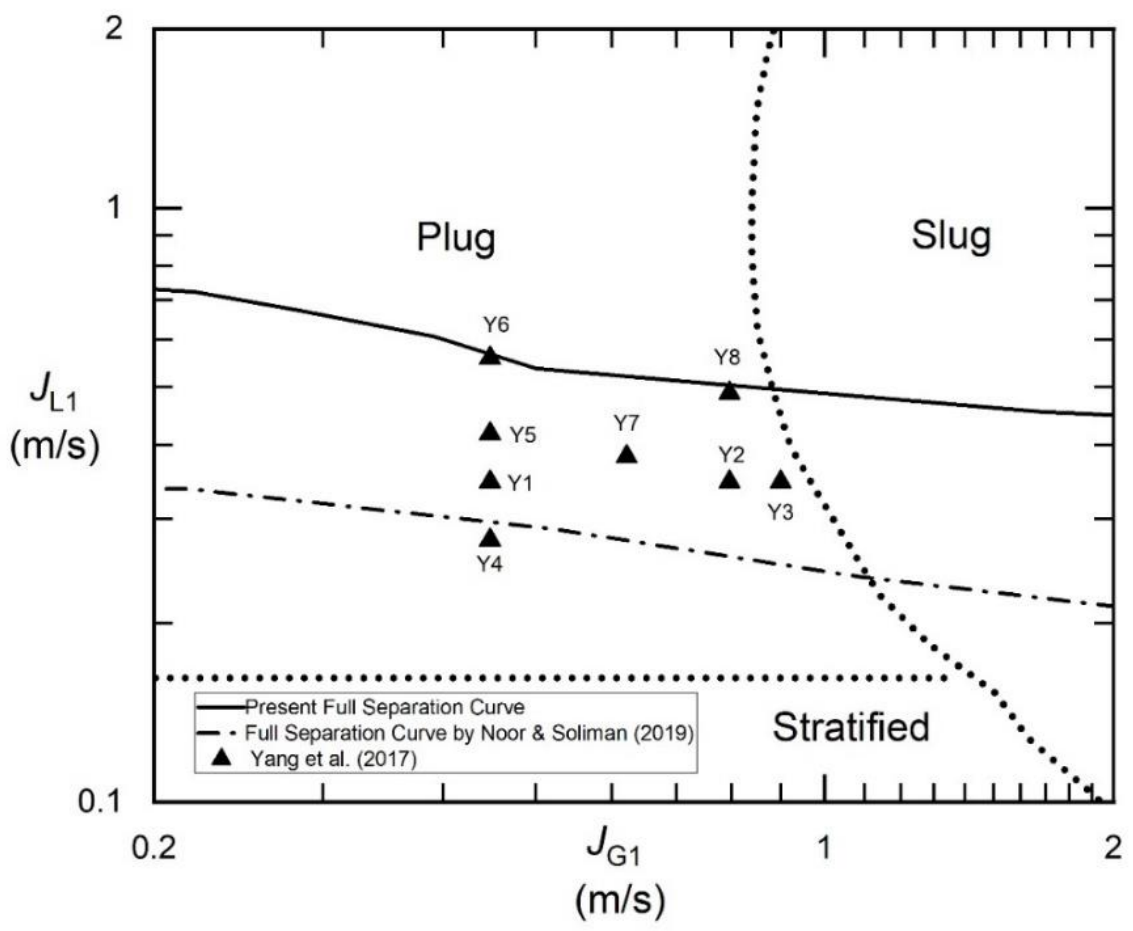

Figure 4.20: Inlet conditions for the data reported by Yang et al. (2017) 
Table 4.7: Comparison between the present system and Yang et al. (2017)

\begin{tabular}{|c|c|c|c|c|c|}
\hline \multirow{2}{*}{$\begin{array}{c}\text { Point } \\
\text { Number }\end{array}$} & \multirow{2}{*}{$\begin{array}{c}J_{\mathrm{G} 1} \\
(\mathrm{~m} / \mathbf{s})\end{array}$} & \multirow{2}{*}{$\begin{array}{c}J_{\mathrm{L} 1} \\
(\mathrm{~m} / \mathrm{s})\end{array}$} & \multirow{2}{*}{ Separator Design } & \multicolumn{2}{|c|}{ Maximum Effectiveness } \\
\hline & & & & Yang et al. (2017) & Present \\
\hline Y1 & 0.448 & 0.346 & $\begin{array}{l}\text { 2-layer multi-tube tee with } 7 \\
\text { connecting tubes }\end{array}$ & 100 & 100 \\
\hline $\mathrm{Y} 2$ & 0.796 & 0.346 & 3-layer multi-tube tee & 96 & 100 \\
\hline Y3 & 0.9 & 0.346 & $\begin{array}{l}\text { 2-layer multi-tube tee with } 3 \\
\text { connecting tubes }\end{array}$ & 90 & 100 \\
\hline Y4 & 0.448 & 0.276 & $\begin{array}{l}\text { 2-layer multi-tube tee with } 5 \\
\text { connecting tubes }\end{array}$ & 100 & 100 \\
\hline Y5 & 0.448 & 0.417 & $\begin{array}{l}\text { 2-layer multi-tube tee with } 7 \\
\text { connecting tubes }\end{array}$ & 100 & 100 \\
\hline Y6 & 0.448 & 0.559 & 3-layer multi-tube tee & 88 & 100 \\
\hline Y7 & 0.622 & 0.382 & 3-layer multi-tube tee & 100 & 100 \\
\hline Y8 & 0.796 & 0.488 & 3-layer multi-tube tee & 98 & 100 \\
\hline
\end{tabular}

Examining the data in Table 4.7, it is fair to conclude that the present system shows better phase-separation effectiveness than the systems by Yang et al. (2017). As observed by Yang et al. (2017), increasing $J_{\mathrm{G} 1}$ or $J_{\mathrm{L} 1}$ has an adverse effect on phase-separation effectiveness while increasing number of tee junctions can improve phase-separation effectiveness.

\subsubsection{Comparison with Noor and Soliman (2019)}

The phase-separation data obtained with the present system were compared with data from a system of combined impacting junctions by Noor and Soliman (2019). The system consisted of one horizontal and two vertical equal-sided impacting tee junctions. A schematic diagram of this system is shown in Figure 2.7. Partial-phase-separation data points collected by Noor and Soliman (2019) in the annular flow regimes are shown in Figure 4.21. The solid line in this figure is the full-phase-separation curve obtained with the present system.

Points P4, P5 and P6 in the annular flow regime in Figure 4.21 lie below the full-phaseseparation curve generated in this study with a system of seven impacting tees. Noor and 
Soliman (2019) reported maximum phase-separation efficiencies $\left(\eta_{\max }\right)$ of $87 \%, 71 \%$ and $62 \%$, respectively, for these three points. This observation is in line with the author's predictions. Points P1, P2 and P3 lie outside the present full-phase-separation curve, which means that full separation of phases could not be reached for these points with the present system. Noor and Soliman (2019) reported maximum phase-separation efficiency $\left(\eta_{\max }\right)$ of $68 \%, 45 \%$ and $45 \%$, respectively. The present system was able to achieve $\eta_{\max }=74 \%, 78 \%$ and $75 \%$ for these three data points, respectively. Table 4.8 presents a summary of this comparison.

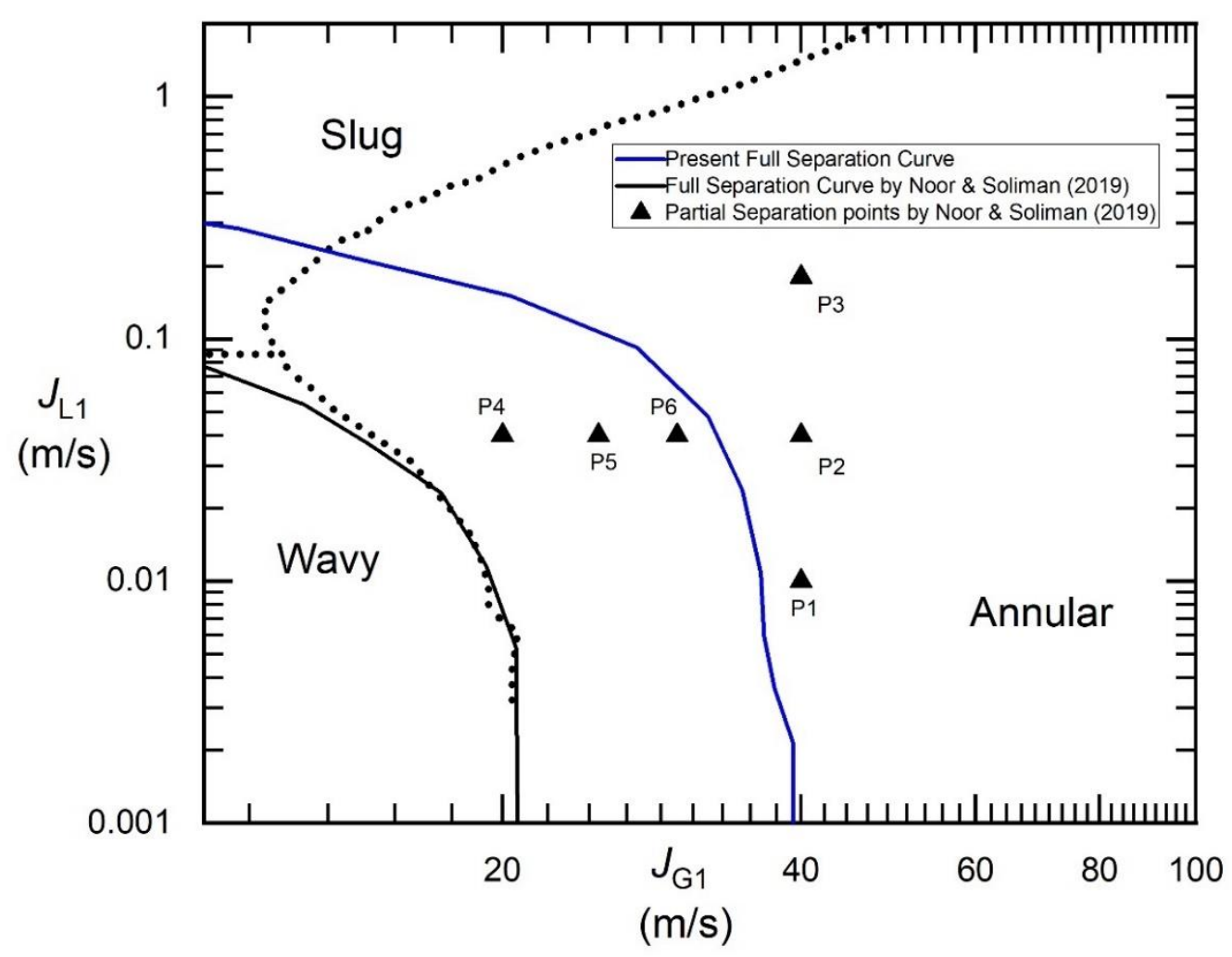

Figure 4.21: Inlet conditions for the data reported by Noor and Soliman (2019) 
Table 4.8: Comparison of partial-phase-separation data with Noor and Soliman (2019)

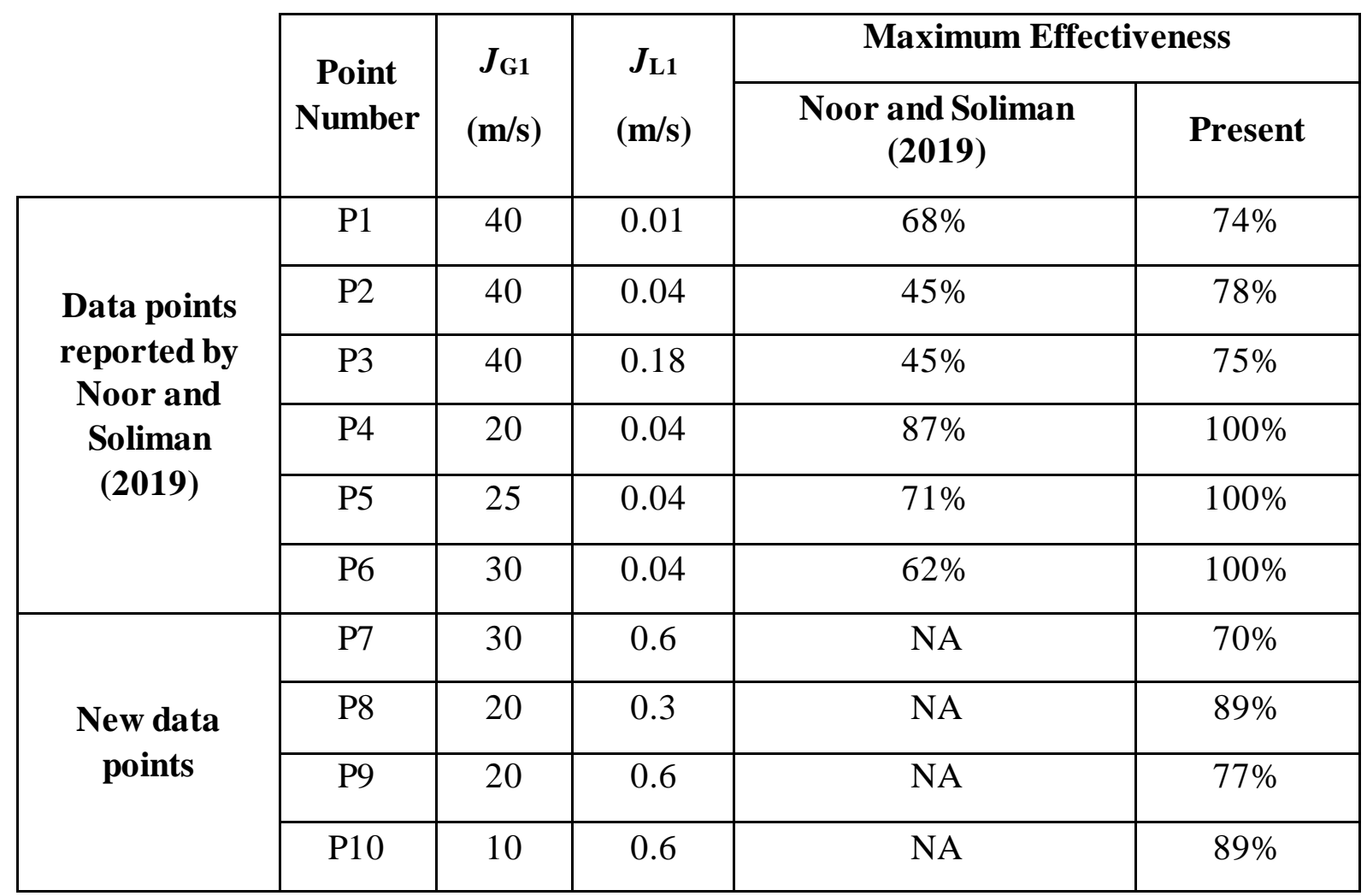




\section{CHAPTER 5}

\section{CONCLUSIONS AND RECOMMENDATIONS}

\subsection{Conclusions}

In this study, limiting conditions (liquid and gas superficial velocities, $J_{\mathrm{G} 1}$ and $J_{\mathrm{L} 1}$ ) for full phase separation of air-water two phase flow were determined experimentally for a system of combined junctions having a diameter of $13.5 \mathrm{~mm}$ at a nominal pressure of $200 \mathrm{kPa}$ (abs). Ten data points outside the full-phase-separation region in the annular and slug flow regimes were chosen to study the phase separation capabilities of the system. A 'phase separation parameter' defined by Noor and Soliman (2019) was used in the analysis to quantify the effectiveness of the combined system as a phase separator. Based on the present results from the full- and partial-phase-separation experiments, the following conclusions can be drawn:

\section{Full-Phase-Separation Experiments:}

1. In comparison to other combined junction systems in the literature, the present system has an extended region for which full phase separation of air-water two phase flow is attainable.

2. The limiting conditions for full separation of phases with the present system is almost double that of a three impacting junction system and quadruple that of a single vertical tee junction.

\section{Partial-Phase-Separation Experiments:}

1. At a fixed $J_{\mathrm{L} 1}$, and within the same flow regime, as $J_{\mathrm{G} 1}$ decreases, the value of $F_{\mathrm{L} 3}$ increases at any given $F_{\mathrm{G} 3}$, which shifts the partial-phase-separation curves towards the point of full phase-separation $(0,1)$ in counter-clockwise direction in the $F_{\mathrm{G} 3}$ versus $F_{\mathrm{L} 3}$ plot. This means higher fractions of inlet liquid leaving through the bottom outlet with 
the same fraction of gas. Full separation of phases can be achieved when $J_{\mathrm{G} 1}$ is decreased further.

2. Partial-phase-separation curves did not follow a consistent trend when varying $J_{\mathrm{L} 1}$ while keeping $J_{\mathrm{G} 1}$ fixed. Decreasing $J_{\mathrm{L} 1}$ resulted in lower fraction of liquid leaving through the bottom outlet with same gas fraction until a particular $F_{\mathrm{G} 3}$, after which, the partial-phase-separation curves shift in anti-clockwise direction towards the point of full phase separation with decreasing $J_{\mathrm{L} 1}$.

3. At a fixed $J_{\mathrm{L} 1}$, and within the same flow regime, as $J_{\mathrm{G} 1}$ decreases, the phase-separation parameter, $\eta$, increases for every corresponding value of $F_{\mathrm{G} 3}$. A $100 \%$ phase-separation effectiveness is attainable with the studied system when $J_{\mathrm{G} 1}$ is decreased further.

4. At a fixed $J_{\mathrm{G} 1}$, the phase separation effectiveness curves did not follow a consistent trend when varying $J_{\mathrm{L} 1}$ until a particular $F_{\mathrm{G} 3}$. For $F_{\mathrm{G} 3}>0.20$, phase-separation parameter, $\eta$, increases for corresponding $F_{\mathrm{G} 3}$ with decreasing $J_{\mathrm{L} 1}$.

5. In comparison to a system of three impacting junctions and a system of a single vertical junction, the partial-phase-separation curves generated with the present system are closer to the full-phase-separation point, and for every $F_{\mathrm{G} 3}$, the corresponding $F_{\mathrm{L} 3}$ is higher.

6. In comparison to other combined junction systems in the literature, the present system shows a higher phase separation effectiveness at all values of $J_{\mathrm{G} 1}$ and $J_{\mathrm{L} 1}$.

\subsection{Recommendations for Future Work}

This experimental study expanded on the idea of developing phase separators using just impacting type tee junctions and provided more data to support the viability of such separators. Nevertheless, recommendations for future research in this area can be made:

1. Conduct experiments at different operating conditions (temperature and pressure) to study the effect of operating conditions on phase separation. 
2. Conduct experiments with industrial and biomedical junction dimensions and inlet flowrates $\left(J_{\mathrm{G} 1}\right.$ and $\left.J_{\mathrm{L} 1}\right)$ to provide more data on the possibility of using junction-based separators in different applications.

3. Study phase separation in a combined system with different types of fluids.

4. Collect more partial-phase-separation data at higher values of $J_{\mathrm{G} 1}$ and $J_{\mathrm{L} 1}$ and from all flow regimes.

5. Model the phase separation in a system of combined junction to develop an empirical correlation to predict the phase separation for different inlet conditions and geometries. 


\section{REFERENCES}

Azzopardi, B.J., Whalley, P.B., 1982. The effect of flow patterns on two-phase flow in a T junction. International Journal of Multiphase Flow 8, 491-507.

Azzopardi, B.J., Colman, D.A., Nicholson, D., 2002. Plant application of a T-junction as a partial phase separator. Chemical Engineering Research and Design 80, 87-96.

Azzopardi, B.J., Purvis, A., Govan, A.H., 1986a. Two phase flow split at an impacting T. UKAEA Report, Atomic Energy Research Establishment, AERE-R-12179.

Azzopardi, B.J., Purvis, A., Govan, A. H, 1986b. Flow split of churn flow at a vertical impacting T. Atomic Energy Research Establishment Harwell (England), AERE-R-12440.

Baker, G., Clark, W.W., Azzopardi, B.J., Wilson, J. A, 2007. Controlling the phase separation of gas-liquid flows at horizontal T-junctions. AIChE Journal 53 (8), 1908-1915.

Chien, S., Rubel, M.T., 1992. Phase splitting of wet steam in annular flow through a horizontal impacting tee junction. SPE production engineering 7 (04), 368-374.

Chen, J., He, L., Luo, X., Bai, H., Wei, Y., 2012. Simulation of oil-water two phase flow and separation behaviors in combined T junctions. Journal of Hydrodynamics 24 (6), 848-857.

Chen, J., Wang, S., Ke, H., Zhou, M., Li, X., 2014. Experimental investigation of annular twophase flow splitting at a microimpacting T-junction. Chemical Engineering Science 118, 154-163.

Chen, J, Wang, S., Zhang, X., Ke, H., Li, X., 2015. Experimental investigation of two-phase slug flow splitting at a micro impacting T-junction. International Journal of Heat and Mass Transfer 81, 939-948. 
Elazhary, A.M., Soliman, H. M., 2012. Two-phase flow in a horizontal mini-size impacting Tjunction with a rectangular cross-section. International journal of multiphase flow 42, $104-$ 114.

El-Shaboury, A.M. F., Soliman, H.M., Sims, G. E., 2007. Two-phase flow in a horizontal equal-sided impacting tee junction. International journal of multiphase flow 33 (4), $411-431$.

Fujii, T., Takenaka, N., Nakazawa, T., Asano, H., 1995. The phase separation characteristics of a gas-liquid two-phase flow in the impacting T-junction. Proc. 2nd Int. Conf. on Multiphase Flow, Kyoto, Japan, pp. 627-632.

Fujii, T., Asano, H., Takenaka, N., Sakoda, K., 1996. "Phase separation characteristics of gasliquid two-phase flow in T-junction (effects of the geometry of junctions)", Proceeding of the 15th Multiphase Flow Symposium, Fukui, Japan, pp. 61-64.

Hong, K.C., 1978. Two-phase flow splitting at a pipe tee. Journal of Petroleum Technology 30 (02), 290-296.

Hong, K.C., Griston, S., 1995. Two-phase flow splitting at an impacting tee. SPE Production \& Facilities 10 (03), 184-190.

Hwang, S.T., Soliman, H.M., Lahey Jr., R.T., 1989. Phase separation in impacting wyes and tees. International Journal of Multiphase Flow 15 (6), 965-975.

Mandhane, J.M., Gregory, G.A., Aziz, K., 1974. A flow pattern map for gas-liquid flow in horizontal pipes. International Journal of Multiphase Flow 1 (4), 537-553.

Mohamed, M.A., Soliman, H.M., Sims, G.E., 2011. Experimental investigation of two-phase flow splitting in an equal-sided impacting tee junction with inclined outlets. Experimental Thermal and Fluid Science 35 (6), 1193-1201. 
Mohamed, M.A., Soliman, H.M., Sims, G.E., 2012. Conditions for complete phase separation in an impacting tee junction at various inclinations of the outlet arms. International Journal of Multiphase Flow 47, 66-72.

Mohamed, M.A., 2012. Phase redistribution and separation of gas-liquid flows in an equalsided impacting tee junction with a horizontal inlet and inclined outlets. Ph.D. Thesis, University of Manitoba, Canada.

Mohamed, M.A., Soliman, H.M., Sims, G.E., 2014. Effects of pipe size and system pressure on the phase redistribution in horizontal impacting tee junctions. Experimental Thermal and Fluid Science 54, 219-224.

Noor, S., 2018. Design and assessment of a new device for gas-liquid separation. M.Sc. Thesis, University of Manitoba, Canada.

Noor, S., Soliman, H.M., 2019. Experimental assessment of a new device for gas-liquid separation. Chemical Engineering Research and Design, 149, 45-51.

Sun, W., Liu, Y., He, K., Wang, S., 2018. The phase distribution of gas-liquid two-phase flow in microimpacting $\mathrm{T}$-junctions with different branch channel diameters. Chemical Engineering Journal 333, 34-42.

Tuo, H., Hrnjak, P., 2012. Experimental study of refrigerant two phase separation in a compact vertical T-junction. ASHRAE Transactions $118(1)$.

Tuo, H., Hrnjak, P., 2014. Enhancement of vapor-liquid separation in vertical impact Tjunctions for vapor compression systems with flash gas bypass. International Journal of Refrigeration 40, 43-50.

Wren, E., Azzopardi, B.J., 2004. The phase separation capabilities of two T-junctions placed in series. Chemical Engineering Research and Design 82 (3), 364-371. 
Yang, L., Azzopardi, B.J., Belghazi, A., Nakanishi, S., 2006. Phase separation of liquid-liquid two-phase flow at a T-junction. AIChE Journal 52 (1), 141-149.

Yang, L., Zhao, Z., Qi, P., Zhao, L., Azzopardi, B.J., 2010. Phase separation of gas-liquid twophase flows in multi-tube T-junction separators. Proceedings of the Second China Energy Scientist Forum, pp. 241-245.

Yang, L, Wang, J., Zhao, Z., Xu, S., Azzopardi, B.J., Wang, H., 2017. Phase separation of gasliquid two-phase stratified and plugflows in multitube T-junction separators. AIChE Journal $63(6), 2285-2292$.

Zheng, N., Zhao, L., Hwang, Y., Zhang, J., Yang, X., 2016. Experimental study on two-phase separation performance of impacting T-junction. International Journal of Multiphase Flow $83,172-182$. 


\section{APPENDIX A \\ CALIBRATION OF ROTAMETERS}

The test facility used for this study is the same as the one used by Noor and Soliman (2019). The system was tested for reliability in section 4.3 and the data were in good agreement with those reported by Noor and Soliman (2019). Therefore, the calibration tables used by Noor (2018) were used for this analysis. Noor (2018) conducted spot checks at three points for each rotameter used in the test facility and the results were compared with the calibration data reported by Mohamed (2012) for the same rotameters. The results of these spot checks matched closely with those reported by Mohamed(2012).

Two new water rotameters, IN-W-4 and O-3-W-5, were added to the existing test facility. Calibration was performed on these rotameters and the calibration data collected was used in the calculations. Linear interpolation was used to calculate flowrates for both air and water rotameter which lie between any two consecutive points.

\section{A.1 Calibration of Air Rotameters}

For the air rotameters, calibration was done by Mohamed (2012) and confirmed by Noor (2018) using either wet test meters or venturis, depending on their capacity. The two wet test meters used were Elster-Handel GmbH with calibration ranges of 1 - 10 SLPM and 2.5 250 SLPM. The two venturis used in calibrations were from FOX Valve Development Corp. Details of the procedure can be found in the work of Mohamed (2012) and Noor (2018). Manufacturer flow rates, measured flow rates by Mohamed (2012), and results of spot checks by Noor (2018) for the tested points for each air rotameter are listed in Table A.1. 
Table A.1: Calibration data of air rotameters

\begin{tabular}{|c|c|c|c|c|}
\hline Rotameter & $\begin{array}{c}\text { Reading } \\
(\%)\end{array}$ & $\begin{array}{l}\text { Manufacturer } \\
\text { Flow Rate } \\
\text { (SLPM) }\end{array}$ & $\begin{array}{l}\text { Flow Rate from } \\
\text { Mohamed (2012) } \\
\text { (SLPM) }\end{array}$ & $\begin{array}{c}\text { Flow Rate from } \\
\text { Noor (2018) } \\
\text { (SLPM) }\end{array}$ \\
\hline \multirow{3}{*}{ IN-A-1 } & 20 & 10.5 & 10.25 & 11.1 \\
\hline & 50 & 28.5 & 28.3 & 29.5 \\
\hline & 80 & 49.2 & 49.3 & 53.3 \\
\hline \multirow[t]{3}{*}{ IN-A-2 } & 20 & 82 & 83 & 85.8 \\
\hline & 50 & 192 & 192 & 190.5 \\
\hline & 80 & 297 & 293 & 290 \\
\hline \multirow[t]{3}{*}{ IN-A-3 } & 20 & 375 & 375 & 363 \\
\hline & 30 & 560 & 560 & 567.2 \\
\hline & 40 & 740 & 745 & 760.3 \\
\hline \multirow[t]{3}{*}{ O-2-A-1 } & 20 & 1.72 & 1.66 & 1.8 \\
\hline & 50 & 4.3 & 4.18 & 4.4 \\
\hline & 80 & 6.88 & 6.82 & 7.4 \\
\hline \multirow[t]{3}{*}{ O-2-A-2 } & 20 & 12.3 & 12.9 & 11.2 \\
\hline & 50 & 26.6 & 25.5 & 24 \\
\hline & 80 & 39.5 & 39.5 & 38.2 \\
\hline \multirow[t]{3}{*}{ O-2-A-3 } & 20 & 87 & 88 & 86.9 \\
\hline & 50 & 195 & 195 & 195.1 \\
\hline & 80 & 305 & 306 & 315.8 \\
\hline \multirow[t]{3}{*}{ O-2-A-4 } & 20 & 146 & 143 & 149.2 \\
\hline & 50 & 365 & 346 & 345.5 \\
\hline & 80 & 584 & 580 & 565.6 \\
\hline \multirow[t]{3}{*}{ O-3-A-1 } & 20 & 1.55 & 1.52 & 1.7 \\
\hline & 50 & 4.2 & 4.2 & 4.7 \\
\hline & 80 & 6.9 & 7.1 & 7.2 \\
\hline \multirow[t]{3}{*}{ O-3-A-2 } & 20 & 10.5 & 10.75 & 11.6 \\
\hline & 50 & 29 & 30.4 & 32.4 \\
\hline & 80 & 49.5 & 51 & 53 \\
\hline \multirow[t]{3}{*}{ O-3-A-3 } & 20 & 87 & 89 & 89.4 \\
\hline & 50 & 195 & 195 & 195.7 \\
\hline & 80 & 305 & 306 & 300.5 \\
\hline \multirow[t]{3}{*}{ O-3-A-4 } & 20 & 375 & 378 & 390.5 \\
\hline & 50 & 560 & 565 & 589.3 \\
\hline & 80 & 740 & 755 & 747.6 \\
\hline
\end{tabular}




\section{A.2 Calibration of Water Rotameters}

Two new water rotameters were added to the existing test facility. Calibration was performed on these rotameters and the data collected was used in the calculations. Calibration data for the rotameters IN-W-4 and O-3-W-5 can be found in Tables A.2 and A.3, respectively. The new water rotameters were calibrated using a weight and time method. The scale used in the calibration, Signum series, model number "SIWADCP-1-35-S", has a maximum capacity of $35 \mathrm{~kg}$ with an accuracy of $0.5 \mathrm{~g}$. The timer used was Lab-chron 1402 with accuracy of onetenth of a second. Manufacturer flow rate,s measured flow rates by Mohamed (2012), and results of spot checks by Noor (2018) for the tested points for each water rotameter are tabulated in Table A.2.

Table A.2: Calibration data of water inlet rotameter, IN-W-4

$\begin{array}{cc}\text { Reading (\%) } & \begin{array}{c}\text { Measured Flow } \\ \text { Rate (cc/min) }\end{array} \\ 20 & 2657.8 \\ 30 & 4091.3 \\ 40 & 5491.9 \\ 50 & 6783.0 \\ 60 & 6783.0 \\ 70 & 8152.4 \\ 80 & 9460.0 \\ 90 & 10731.6 \\ 100 & 13461.4\end{array}$

Table A.3: Calibration data of water outlet rotameter, O-3-W-5

$\begin{array}{cc}\text { Reading (\%) } & \begin{array}{c}\text { Measured Flow } \\ \text { Rate (cc/min) }\end{array} \\ 20 & 2644.0 \\ 30 & 3981.3 \\ 40 & 5367.8 \\ 50 & 6701.3 \\ 60 & 7982.6 \\ 70 & 9272.9 \\ 80 & 10544.2 \\ 90 & 11905.7 \\ 100 & 13302.3\end{array}$


Table A.2: Calibration data of water rotameters

\begin{tabular}{|c|c|c|c|c|}
\hline Rotameter & $\begin{array}{c}\text { Reading } \\
(\%)\end{array}$ & $\begin{array}{l}\text { Manufacturer } \\
\text { Flow Rate } \\
\text { (cc/min) }\end{array}$ & $\begin{array}{l}\text { Flow Rate from } \\
\text { Mohamed (2012) } \\
\text { (cc/min) }\end{array}$ & $\begin{array}{c}\text { Flow Rate from } \\
\text { Noor (2018) } \\
\text { (cc/min) }\end{array}$ \\
\hline \multirow{3}{*}{ IN-W-1 } & 20 & 10.5 & 11 & 11.77 \\
\hline & 50 & 38.75 & 39.6 & 41.49 \\
\hline & 80 & 66 & 65.5 & 66.89 \\
\hline \multirow[t]{3}{*}{ IN-W-2 } & 20 & 87 & 89 & 96.35 \\
\hline & 50 & 240 & 246 & 229.71 \\
\hline & 80 & 393 & 388 & 387.99 \\
\hline \multirow[t]{3}{*}{ IN-W-3 } & 20 & 660 & 675 & 626.4 \\
\hline & 50 & 1455 & 1470 & 1437.2 \\
\hline & 80 & 2320 & 2340 & 2344.1 \\
\hline \multirow[t]{3}{*}{ O-2-W-1 } & 20 & 2 & 1.5 & 1.3 \\
\hline & 50 & 5 & 4.5 & 4.61 \\
\hline & 80 & 8 & 7.2 & 7.41 \\
\hline \multirow[t]{3}{*}{ O-2-W-2 } & 20 & 15 & 14.5 & 14.13 \\
\hline & 50 & 37.5 & 36.75 & 37.53 \\
\hline & 80 & 60 & 60 & 60.53 \\
\hline \multirow[t]{3}{*}{$0-2-W-3$} & 20 & 96 & 95 & 91.03 \\
\hline & 50 & 240 & 240 & 230.11 \\
\hline & 80 & 384 & 392 & 372.53 \\
\hline \multirow[t]{3}{*}{ O-2-W-4 } & 20 & 583 & 573 & 565.96 \\
\hline & 50 & 1457 & 1433 & 1450.8 \\
\hline & 80 & 2332 & 2312 & 2303.5 \\
\hline \multirow[t]{3}{*}{ O-3-W-1 } & 20 & 2 & 1.5 & 1.3 \\
\hline & 50 & 5 & 4.1 & 4.3 \\
\hline & 80 & 8 & 7.2 & 7.21 \\
\hline \multirow[t]{3}{*}{$0-3-W-2$} & 20 & 15 & 14.5 & 13.43 \\
\hline & 50 & 37.5 & 37.2 & 35.27 \\
\hline & 80 & 60 & 59.5 & 57.62 \\
\hline \multirow[t]{3}{*}{$0-3-W-3$} & 20 & 96 & 92.5 & 92.95 \\
\hline & 50 & 240 & 240 & 236.92 \\
\hline & 80 & 384 & 377 & 375.33 \\
\hline \multirow[t]{3}{*}{$0-3-W-4$} & 20 & 583 & 548 & 545.41 \\
\hline & 50 & 1457 & 1456 & 1466.7 \\
\hline & 80 & 2332 & 2312 & 2317.1 \\
\hline
\end{tabular}




\section{APPENDIX B \\ EXPERIMENTAL DATA}

This appendix contains data for both full- and partial-phase-separation experiments. Tables B.1 and B.2 provide a listing of the operating conditions and phase-separation data for all data points. Tables B.3 and B.4 contain the mass flow rates of air and water for all data points. For data points with $J_{\mathrm{G} 1}<0.5 \mathrm{~m} / \mathrm{s}$ or $J_{\mathrm{L} 1}<0.005 \mathrm{~m} / \mathrm{s}$, the mass-balance errors were not recorded as they are too small to be measured within the acceptable range of the smallest rotameter.

\section{Legend}

$J_{\mathrm{G} 1}$ Inlet superficial gas velocity, $\mathrm{m} / \mathrm{s}$

$J_{\mathrm{L} 1}$ Inlet superficial liquid velocity, $\mathrm{m} / \mathrm{s}$

$P_{\mathrm{TS}}$ Test-section pressure, $\mathrm{kPa}$

$T_{\mathrm{G} 1}$ Temperature of inlet gas, $\mathrm{K}$

$F_{\mathrm{G} 3}$ Fraction of inlet gas leaving through Outlet-3

$F_{\mathrm{L} 3}$ Fraction of inlet liquid leaving through Outlet-3

$M B_{\mathrm{G}}$ Gas mass-balance error, $(\%)$

$M B_{\mathrm{L}}$ Liquid mass-balance error, (\%)

$W_{\mathrm{G}}$ Mass flow rate of gas (air), $\mathrm{kg} / \mathrm{s}$

$W_{\mathrm{L}}$ Mass flow rate of liquid (water), $\mathrm{kg} / \mathrm{s}$ 
Table B.1: Full-phase-separation experiments

$\begin{array}{ccccccccc}\text { Data } & \boldsymbol{J}_{\mathbf{G 1}} & \boldsymbol{J}_{\mathbf{L} 1} & \boldsymbol{P}_{\mathbf{T S}} & \boldsymbol{T}_{\mathbf{G 1}} & \boldsymbol{F}_{\mathbf{G 3}} & \boldsymbol{F}_{\mathbf{L 3}} & \boldsymbol{M B}_{\mathbf{G}} & \boldsymbol{M B B}_{\mathbf{L}} \\ \text { Point } & (\mathbf{m} / \mathbf{s}) & (\mathbf{m} / \mathbf{s}) & (\mathbf{k P a}) & (\mathbf{K}) & & & (\%) & (\%) \\ \text { FS-1 } & 39.3 & 0.00086 & 202.5 & 293.2 & 0 & 1 & 1.12 \% & - \\ \text { FS-2 } & 39.3 & 0.0013 & 200.4 & 293.1 & 0 & 1 & 0.37 \% & - \\ \text { FS-3 } & 39.3 & 0.0018 & 202.4 & 293 & 0 & 1 & 1.22 \% & - \\ \text { FS-4 } & 37.6 & 0.0034 & 199.2 & 292.7 & 0 & 1 & 0.43 \% & - \\ \text { FS-5 } & 36.7 & 0.0056 & 200.4 & 292.8 & 0 & 1 & 0.34 \% & -0.48 \% \\ \text { FS-6 } & 36.4 & 0.0089 & 199.4 & 292.9 & 0 & 1 & -0.39 \% & 0.99 \% \\ \text { FS-7 } & 34.2 & 0.018 & 198.7 & 292.9 & 0 & 1 & -0.01 \% & 0.43 \% \\ \text { FS-8 } & 32.2 & 0.046 & 200.6 & 292.5 & 0 & 1 & 0.65 \% & 0.18 \% \\ \text { FS-9 } & 27.3 & 0.080 & 204.0 & 292.6 & 0 & 1 & -0.06 \% & 0.16 \% \\ \text { FS-10 } & 20.4 & 0.15 & 202.7 & 292.3 & 0 & 1 & 0.23 \% & -0.94 \% \\ \text { FS-11 } & 14.3 & 0.21 & 201.4 & 292.4 & 0 & 1 & -0.74 \% & -2.18 \% \\ \text { FS-12 } & 10.8 & 0.27 & 202.4 & 292.5 & 0 & 1 & -0.43 \% & 0.81 \% \\ \text { FS-13 } & 7.23 & 0.38 & 198.8 & 292.6 & 0 & 1 & 0.26 \% & -0.44 \% \\ \text { FS-14 } & 3.60 & 0.43 & 204.6 & 293 & 0 & 1 & -0.15 \% & 0.39 \% \\ \text { FS-15 } & 1.72 & 0.46 & 205.5 & 293 & 0 & 1 & -4.65 \% & -0.19 \% \\ \text { FS-16 } & 0.91 & 0.48 & 204.6 & 294 & 0 & 1 & -2.80 \% & -0.60 \% \\ \text { FS-17 } & 0.50 & 0.54 & 204.7 & 292.9 & 0 & 1 & - & -0.48 \% \\ \text { FS-18 } & 0.39 & 0.58 & 203.2 & 293.4 & 0 & 1 & - & -0.43 \% \\ \text { FS-19 } & 0.29 & 0.72 & 204.2 & 292.7 & 0 & 1 & - & -0.49 \% \\ \text { FS-20 } & 0.22 & 0.72 & 202.0 & 293.2 & 0 & 1 & - & 0.55 \%\end{array}$


Table B.2: Mass flow rates for full-phase-separation experiments

$\begin{array}{ccccccc}\text { Data } & \boldsymbol{W}_{\mathbf{G 1}} & \boldsymbol{W}_{\mathbf{G} 2} & \boldsymbol{W}_{\mathbf{G 3}} & \boldsymbol{W}_{\mathbf{L 1}} & \boldsymbol{W}_{\mathbf{L 2}} & \boldsymbol{W}_{\mathbf{L 3}} \\ \text { Point } & (\mathbf{k g} / \mathbf{s}) & (\mathbf{k g} / \mathbf{s}) & (\mathbf{k g} / \mathbf{s}) & (\mathbf{k g} / \mathbf{s}) & (\mathbf{k g} / \mathbf{s}) & (\mathbf{k g} / \mathbf{s}) \\ \text { FS-1 } & 0.0135 & 0.0134 & 0 & 0.000123 & 0 & 0.000122 \\ \text { FS-2 } & 0.0157 & 0.0157 & 0 & 0.000183 & 0 & 0.000185 \\ \text { FS-3 } & 0.0135 & 0.0134 & 0 & 0.000262 & 0 & 0.000265 \\ \text { FS-4 } & 0.0128 & 0.0127 & 0 & 0.000491 & 0 & 0.000488 \\ \text { FS-5 } & 0.0125 & 0.0125 & 0 & 0.000807 & 0 & 0.000810 \\ \text { FS-6 } & 0.0124 & 0.0124 & 0 & 0.00127 & 0 & 0.00125 \\ \text { FS-7 } & 0.0116 & 0.0116 & 0 & 0.00264 & 0 & 0.00262 \\ \text { FS-8 } & 0.0110 & 0.0109 & 0 & 0.00654 & 0 & 0.00652 \\ \text { FS-9 } & 0.00950 & 0.00950 & 0 & 0.0115 & 0 & 0.0115 \\ \text { FS-10 } & 0.00705 & 0.00703 & 0 & 0.0221 & 0 & 0.0223 \\ \text { FS-11 } & 0.00493 & 0.00496 & 0 & 0.0306 & 0 & 0.0313 \\ \text { FS-12 } & 0.00374 & 0.00375 & 0 & 0.0387 & 0 & 0.0384 \\ \text { FS-13 } & 0.00243 & 0.00242 & 0 & 0.0538 & 0 & 0.0540 \\ \text { FS-14 } & 0.00124 & 0.00125 & 0 & 0.0609 & 0 & 0.0607 \\ \text { FS-15 } & 0.000596 & 0.000623 & 0 & 0.0656 & 0 & 0.0658 \\ \text { FS-16 } & 0.000312 & 0.000321 & 0 & 0.0693 & 0 & 0.0697 \\ \text { FS-17 } & 0.000173 & 0.000172 & 0 & 0.0774 & 0 & 0.0778 \\ \text { FS-18 } & 0.000134 & 0.0001334 & 0 & 0.0832 & 0 & 0.0835 \\ \text { FS-19 } & 0.000101 & 0.000101 & 0 & 0.103 & 0 & 0.104 \\ \text { FS-20 } & 7.52 E-05 & 7.51 E-05 & 0 & 0.103 & 0 & 0.103\end{array}$


Table B.3: Partial-phase-separation experiments

\begin{tabular}{|c|c|c|c|c|c|c|c|c|c|}
\hline & $\begin{array}{l}\text { Data } \\
\text { Point }\end{array}$ & $\begin{array}{c}J_{G 1} \\
(\mathrm{~m} / \mathbf{s})\end{array}$ & $\begin{array}{c}J_{\mathrm{L1}} \\
(\mathbf{m} / \mathbf{s})\end{array}$ & $\begin{array}{c}P_{\mathrm{TS}} \\
(\mathbf{k P a})\end{array}$ & $\begin{array}{l}T_{\mathrm{G} 1} \\
(\mathbf{K})\end{array}$ & $F_{\mathrm{G} 3}$ & $F_{\mathrm{L} 3}$ & $\begin{array}{c}M B_{\mathrm{G}} \\
(\%)\end{array}$ & $\begin{array}{r}M B_{\mathrm{L}} \\
(\%)\end{array}$ \\
\hline \multirow[t]{7}{*}{ P1 } & P1-1 & 40.0 & 0.01 & 201.2 & 292.8 & 0 & 0.458 & $0.01 \%$ & $0.24 \%$ \\
\hline & P1-2 & 41.0 & 0.01 & 202.2 & 292.8 & 0.037 & 0.599 & $-0.03 \%$ & $-0.18 \%$ \\
\hline & P1-3 & 41.2 & 0.01 & 202.6 & 292.8 & 0.053 & 0.639 & $-0.10 \%$ & $0.62 \%$ \\
\hline & P1-4 & 40.1 & 0.01 & 200.5 & 293.1 & 0.134 & 0.760 & $-0.05 \%$ & $-0.60 \%$ \\
\hline & P1-5 & 40.1 & 0.01 & 202.8 & 293.2 & 0.196 & 0.933 & $-0.07 \%$ & $0.31 \%$ \\
\hline & P1-6 & 40.0 & 0.01 & 202.8 & 292.6 & 0.259 & 0.983 & $-0.23 \%$ & $-0.22 \%$ \\
\hline & P1-7 & 39.8 & 0.01 & 203.2 & 293.2 & 0.287 & 1 & $-0.19 \%$ & $-0.19 \%$ \\
\hline \multirow[t]{6}{*}{ P2 } & $\mathrm{P} 2-1$ & 40.8 & 0.04 & 203.0 & 292.9 & 0 & 0.776 & $-0.20 \%$ & $-0.37 \%$ \\
\hline & P2-2 & 40.1 & 0.04 & 202.5 & 293.4 & 0.131 & 0.887 & $0.40 \%$ & $-0.22 \%$ \\
\hline & $\mathrm{P} 2-3$ & 40.2 & 0.04 & 203.0 & 293.0 & 0.203 & 0.942 & $-0.02 \%$ & $0.02 \%$ \\
\hline & P2-4 & 40.0 & 0.04 & 203.0 & 293.2 & 0.234 & 0.942 & $0.16 \%$ & $0.02 \%$ \\
\hline & $\mathrm{P} 2-5$ & 40.0 & 0.04 & 202.5 & 292.8 & 0.294 & 0.981 & $0.49 \%$ & $-0.06 \%$ \\
\hline & P2-6 & 39.9 & 0.04 & 203.0 & 292.8 & 0.346 & 1 & $0.33 \%$ & $0.34 \%$ \\
\hline \multirow[t]{7}{*}{ P3 } & P3-1 & 40.6 & 0.18 & 205.0 & 292.8 & 0 & 0.700 & $0.01 \%$ & $1.26 \%$ \\
\hline & P3-2 & 40.8 & 0.18 & 203.0 & 292.9 & 0.142 & 0.888 & $-0.08 \%$ & $0.13 \%$ \\
\hline & P3-3 & 40.6 & 0.18 & 203.5 & 293.3 & 0.203 & 0.924 & $-0.22 \%$ & $0.06 \%$ \\
\hline & P3-4 & 40.6 & 0.18 & 204.0 & 292.8 & 0.274 & 0.934 & $0.13 \%$ & $0.09 \%$ \\
\hline & P3-5 & 40.7 & 0.18 & 203.5 & 293.2 & 0.403 & 0.949 & $0.33 \%$ & $0.36 \%$ \\
\hline & P3-6 & 40.8 & 0.18 & 204.0 & 293.0 & 0.522 & 0.962 & $-0.14 \%$ & $-0.31 \%$ \\
\hline & P3-7 & 41.1 & 0.18 & 202.0 & 293.0 & 0.651 & 1 & $-0.88 \%$ & $0.17 \%$ \\
\hline \multirow[t]{8}{*}{ P7 } & P7-1 & 30.2 & 0.60 & 202.6 & 292.8 & 0 & 0.524 & $0.13 \%$ & $-0.45 \%$ \\
\hline & P7-2 & 30.3 & 0.60 & 202.7 & 292.9 & 0.027 & 0.667 & $-0.39 \%$ & $-0.19 \%$ \\
\hline & P7-3 & 30.0 & 0.60 & 202.7 & 292.6 & 0.038 & 0.717 & $0.09 \%$ & $0.26 \%$ \\
\hline & P7-4 & 29.8 & 0.60 & 203.1 & 292.6 & 0.059 & 0.757 & $0.01 \%$ & $-0.25 \%$ \\
\hline & P7-5 & 30.1 & 0.60 & 202.7 & 292.7 & 0.173 & 0.835 & $0.10 \%$ & $-0.19 \%$ \\
\hline & P7-6 & 30.1 & 0.60 & 203.1 & 292.8 & 0.232 & 0.858 & $-0.38 \%$ & $0.02 \%$ \\
\hline & P7-7 & 30.1 & 0.60 & 203.2 & 292.4 & 0.436 & 0.906 & $-0.16 \%$ & $-0.08 \%$ \\
\hline & P7-8 & 30.0 & 0.60 & 202.8 & 292.7 & 0.649 & 0.968 & $0.01 \%$ & $0.28 \%$ \\
\hline
\end{tabular}




\begin{tabular}{|c|c|c|c|c|c|c|c|c|c|}
\hline & $\begin{array}{l}\text { Data } \\
\text { Point }\end{array}$ & $\begin{array}{c}J_{G 1} \\
(\mathbf{m} / \mathbf{s})\end{array}$ & $\begin{array}{c}J_{L 1} \\
(\mathrm{~m} / \mathrm{s})\end{array}$ & $\begin{array}{c}P_{\mathrm{TS}} \\
(\mathbf{k P a})\end{array}$ & $\begin{array}{l}T_{\mathbf{G 1}} \\
(\mathrm{K})\end{array}$ & $F_{\mathbf{G} 3}$ & $F_{\mathrm{L} 3}$ & $\begin{array}{c}M B_{\mathrm{G}} \\
(\%)\end{array}$ & $\begin{array}{c}M B_{\mathrm{L}} \\
(\%)\end{array}$ \\
\hline & P7-9 & 30.0 & 0.60 & 202.9 & 292.2 & 0.715 & 1 & $0.06 \%$ & $-0.07 \%$ \\
\hline \multirow[t]{6}{*}{ P8 } & P8-1 & 20.0 & 0.30 & 201.4 & 292.8 & 0 & 0.752 & $-0.10 \%$ & $-0.06 \%$ \\
\hline & P8-2 & 20.0 & 0.30 & 200.9 & 292.6 & 0.035 & 0.910 & $-0.78 \%$ & $-0.70 \%$ \\
\hline & P8-3 & 19.9 & 0.30 & 202.5 & 292.4 & 0.062 & 0.947 & $-1.11 \%$ & $-0.13 \%$ \\
\hline & P8-4 & 19.9 & 0.30 & 202.8 & 292.3 & 0.147 & 0.976 & $-0.41 \%$ & $-0.08 \%$ \\
\hline & P8-5 & 19.9 & 0.30 & 202.7 & 292.7 & 0.208 & 0.997 & $-1.43 \%$ & $0.09 \%$ \\
\hline & P8-6 & 19.8 & 0.30 & 202.7 & 292.3 & 0.268 & 1 & $-1.25 \%$ & $-0.14 \%$ \\
\hline \multirow[t]{8}{*}{ P9 } & P9-1 & 20.3 & 0.60 & 200.3 & 292.4 & 0 & 0.458 & $-0.47 \%$ & $0.06 \%$ \\
\hline & P9-2 & 20.1 & 0.60 & 203.6 & 292.6 & 0.039 & 0.792 & $-0.89 \%$ & $0.22 \%$ \\
\hline & P9-3 & 20.2 & 0.60 & 202.6 & 292.6 & 0.068 & 0.840 & $-0.22 \%$ & $-0.14 \%$ \\
\hline & P9-4 & 20.2 & 0.60 & 202.0 & 292.2 & 0.113 & 0.876 & $-0.55 \%$ & $-0.10 \%$ \\
\hline & P9-5 & 20.2 & 0.60 & 203.2 & 292.7 & 0.258 & 0.938 & $-2.02 \%$ & $0.16 \%$ \\
\hline & P9-6 & 20.1 & 0.60 & 202.7 & 292.3 & 0.338 & 0.964 & $-1.11 \%$ & $0.06 \%$ \\
\hline & P9-7 & 20.1 & 0.60 & 202.7 & 292.6 & 0.408 & 0.982 & $-0.37 \%$ & $-0.25 \%$ \\
\hline & P9-8 & 20.1 & 0.60 & 202.7 & 292.6 & 0.464 & 1 & $0.33 \%$ & $0.20 \%$ \\
\hline \multirow[t]{6}{*}{ P10 } & P10-1 & 10.0 & 0.60 & 201.0 & 292.6 & 0 & 0.528 & $0.19 \%$ & $0.02 \%$ \\
\hline & P10-2 & 10.0 & 0.60 & 200.5 & 292.2 & 0.018 & 0.688 & $0.17 \%$ & $0.27 \%$ \\
\hline & P10-3 & 9.9 & 0.60 & 202.0 & 292.4 & 0.031 & 0.762 & $0.26 \%$ & $0.13 \%$ \\
\hline & P10-4 & 10.0 & 0.60 & 201.7 & 292.5 & 0.046 & 0.829 & $0.14 \%$ & $-0.17 \%$ \\
\hline & P10-5 & 10.0 & 0.60 & 202.0 & 292.5 & 0.084 & 0.940 & $0.19 \%$ & $0.14 \%$ \\
\hline & P10-6 & 10.0 & 0.60 & 200.4 & 292.6 & 0.108 & 1 & $-0.19 \%$ & $0.19 \%$ \\
\hline
\end{tabular}


Table B.4: Mass flow rates for partial-phase-separation experiments

\begin{tabular}{|c|c|c|c|c|c|c|c|}
\hline & $\begin{array}{l}\text { Data } \\
\text { Point }\end{array}$ & $\begin{array}{c}W_{\mathrm{G} 1} \\
(\mathrm{~kg} / \mathrm{s})\end{array}$ & $\begin{array}{c}W_{\mathrm{G} 2} \\
(\mathrm{~kg} / \mathrm{s})\end{array}$ & $\begin{array}{c}W_{\mathrm{G3}} \\
(\mathrm{kg} / \mathrm{s})\end{array}$ & $\begin{array}{c}W_{\mathrm{L} 1} \\
(\mathrm{~kg} / \mathrm{s})\end{array}$ & $\begin{array}{c}W_{\mathrm{L} 2} \\
(\mathrm{~kg} / \mathrm{s})\end{array}$ & $\begin{array}{r}W_{\mathrm{L3}} \\
(\mathrm{kg} / \mathrm{s})\end{array}$ \\
\hline \multirow[t]{7}{*}{$\mathbf{P 1}$} & $\mathrm{P} 1-1$ & 0.014 & 0.014 & 0 & 0.0015 & 0.00080 & 0.00068 \\
\hline & P1-2 & 0.014 & 0.013 & 0.00052 & 0.0016 & 0.00063 & 0.00094 \\
\hline & P1-3 & 0.014 & 0.013 & 0.00074 & 0.0016 & 0.00056 & 0.0010 \\
\hline & $\mathrm{P} 1-4$ & 0.014 & 0.012 & 0.0018 & 0.0015 & 0.00036 & 0.0011 \\
\hline & P1-5 & 0.014 & 0.011 & 0.0027 & 0.0015 & 0.00010 & 0.0014 \\
\hline & P1-6 & 0.014 & 0.010 & 0.0036 & 0.0015 & 0.000025 & 0.0015 \\
\hline & P1-7 & 0.014 & 0.010 & 0.0039 & 0.0015 & 0 & 0.0015 \\
\hline \multirow[t]{6}{*}{$\mathbf{P 2}$} & $\mathrm{P} 2-1$ & 0.014 & 0.014 & 0 & 0.0058 & 0.0013 & 0.0045 \\
\hline & P2-2 & 0.014 & 0.012 & 0.0018 & 0.0058 & 0.00065 & 0.0051 \\
\hline & $\mathrm{P} 2-3$ & 0.014 & 0.011 & 0.0028 & 0.0058 & 0.00033 & 0.0054 \\
\hline & $\mathrm{P} 2-4$ & 0.014 & 0.010 & 0.0032 & 0.0058 & 0.00033 & 0.0054 \\
\hline & $\mathrm{P} 2-5$ & 0.014 & 0.010 & 0.0040 & 0.0058 & 0.00011 & 0.0057 \\
\hline & P2-6 & 0.014 & 0.009 & 0.0047 & 0.0058 & 0 & 0.0057 \\
\hline \multirow[t]{7}{*}{ P3 } & P3-1 & 0.014 & 0.014 & 0 & 0.026 & 0.0076 & 0.018 \\
\hline & P3-2 & 0.014 & 0.012 & 0.0020 & 0.026 & 0.0029 & 0.023 \\
\hline & P3-3 & 0.014 & 0.011 & 0.0028 & 0.026 & 0.0020 & 0.024 \\
\hline & P3-4 & 0.014 & 0.010 & 0.0038 & 0.026 & 0.0017 & 0.024 \\
\hline & P3-5 & 0.014 & 0.008 & 0.0056 & 0.026 & 0.0013 & 0.024 \\
\hline & P3-6 & 0.014 & 0.007 & 0.0074 & 0.026 & 0.0010 & 0.025 \\
\hline & P3-7 & 0.014 & 0.005 & 0.0092 & 0.026 & 0 & 0.026 \\
\hline \multirow[t]{8}{*}{ P7 } & P7-1 & 0.01 & 0.010 & 0 & 0.086 & 0.041 & 0.045 \\
\hline & P7-2 & 0.01 & 0.010 & 0.00028 & 0.086 & 0.029 & 0.057 \\
\hline & P7-3 & 0.01 & 0.010 & 0.00039 & 0.086 & 0.024 & 0.061 \\
\hline & P7-4 & 0.01 & 0.010 & 0.00061 & 0.086 & 0.021 & 0.065 \\
\hline & P7-5 & 0.01 & 0.009 & 0.0018 & 0.086 & 0.014 & 0.072 \\
\hline & P7-6 & 0.01 & 0.008 & 0.0024 & 0.086 & 0.012 & 0.074 \\
\hline & P7-7 & 0.01 & 0.006 & 0.0045 & 0.086 & 0.0081 & 0.078 \\
\hline & P7-8 & 0.01 & 0.004 & 0.0067 & 0.085 & 0.0027 & 0.082 \\
\hline
\end{tabular}




\begin{tabular}{|c|c|c|c|c|c|c|c|}
\hline & $\begin{array}{l}\text { Data } \\
\text { Point }\end{array}$ & $\begin{array}{c}W_{\mathrm{G} 1} \\
(\mathrm{~kg} / \mathrm{s})\end{array}$ & $\begin{array}{c}W_{\mathrm{G} 2} \\
(\mathrm{~kg} / \mathrm{s})\end{array}$ & $\begin{array}{c}W_{\mathrm{G} 3} \\
(\mathrm{~kg} / \mathrm{s})\end{array}$ & $\begin{array}{c}W_{\mathrm{L1}} \\
(\mathrm{kg} / \mathrm{s})\end{array}$ & $\begin{array}{c}W_{\mathrm{L} 2} \\
(\mathrm{~kg} / \mathrm{s})\end{array}$ & $\begin{array}{r}W_{\mathrm{L3}} \\
(\mathrm{kg} / \mathrm{s})\end{array}$ \\
\hline & P7-9 & 0.01 & 0.003 & 0.0074 & 0.085 & 0 & 0.085 \\
\hline \multirow[t]{6}{*}{ P8 } & P8-1 & 0.007 & 0.007 & 0 & 0.043 & 0.011 & 0.032 \\
\hline & P8-2 & 0.007 & 0.007 & 0.00024 & 0.043 & 0.0039 & 0.040 \\
\hline & P8-3 & 0.007 & 0.006 & 0.00043 & 0.043 & 0.0023 & 0.041 \\
\hline & P8-4 & 0.007 & 0.006 & 0.0010 & 0.043 & 0.0010 & 0.042 \\
\hline & P8-5 & 0.007 & 0.005 & 0.0014 & 0.043 & 0.00012 & 0.043 \\
\hline & P8-6 & 0.007 & 0.005 & 0.0018 & 0.043 & 0 & 0.043 \\
\hline \multirow[t]{8}{*}{ P9 } & P9-1 & 0.007 & 0.007 & 0 & 0.086 & 0.047 & 0.040 \\
\hline & P9-2 & 0.007 & 0.007 & 0.00027 & 0.086 & 0.018 & 0.068 \\
\hline & P9-3 & 0.007 & 0.006 & 0.00047 & 0.086 & 0.014 & 0.072 \\
\hline & P9-4 & 0.007 & 0.006 & 0.00079 & 0.086 & 0.011 & 0.075 \\
\hline & P9-5 & 0.007 & 0.005 & 0.0018 & 0.086 & 0.0053 & 0.081 \\
\hline & P9-6 & 0.007 & 0.005 & 0.0024 & 0.086 & 0.0031 & 0.083 \\
\hline & P9-7 & 0.007 & 0.004 & 0.0028 & 0.086 & 0.0015 & 0.085 \\
\hline & P9-8 & 0.007 & 0.004 & 0.0032 & 0.086 & 0 & 0.085 \\
\hline \multirow[t]{6}{*}{ P10 } & P10-1 & 0.003 & 0.003 & 0 & 0.086 & 0.041 & 0.045 \\
\hline & P10-2 & 0.003 & 0.003 & 0.000063 & 0.086 & 0.027 & 0.059 \\
\hline & P10-3 & 0.003 & 0.003 & 0.00011 & 0.086 & 0.020 & 0.065 \\
\hline & P10-4 & 0.003 & 0.003 & 0.00016 & 0.086 & 0.015 & 0.071 \\
\hline & P10-5 & 0.003 & 0.003 & 0.00028 & 0.086 & 0.0051 & 0.081 \\
\hline & P10-6 & 0.003 & 0.003 & 0.00037 & 0.086 & 0 & 0.085 \\
\hline
\end{tabular}




\section{APPENDIX C \\ UNCERTAINTY ANALYSIS}

Uncertainty analyses were performed on experimental data to estimate errors in calibration data, and experimental procedures. The steps used in the uncertainty analysis, and tabulated results of the analysis are provided in this appendix. The uncertainty analysis technique used is the numerical method of sequential perturbation. Fixed uncertainty intervals were pre-set for the various measuring instruments (provided in Table 4.3) used in the experiments.

The analyses were done on both partial- and full-phase-separation data for inlet parameters $W_{\mathrm{G} 1}, W_{\mathrm{L} 1}, J_{\mathrm{G} 1}, J_{\mathrm{L} 1}$ and for outlet parameters $W_{\mathrm{G} 2}, W_{\mathrm{G} 3}, W_{\mathrm{L} 2}, W_{\mathrm{L} 3}, F_{\mathrm{G} 3}$ and $F_{\mathrm{L} 3}$. For each term, repeated calculations were done with its highest or lowest value based on the fixed uncertainties of that variable. The positive and negative perturbations of a term were calculated using the Root-sum-method which accounts for the measured variables that are used in calculating that term. The total uncertainty of that term is then calculated by averaging the negative and positive perturbations. The following steps were used to calculate the uncertainty of $W_{\mathrm{G} 1}$ using the method of sequential perturbation to:

i. Calculate $W_{\mathrm{G} 1}$ using all nominal values.

$$
W_{\mathrm{G} 1}=f\left(V_{\mathrm{G} 1}, \rho_{\mathrm{G} 1}\right)=f\left(V_{\mathrm{G} 1}, f\left(T_{\mathrm{G} 1}, P_{\mathrm{G} 1}\right)\right)=f\left(V_{\mathrm{G} 1}, T_{\mathrm{G} 1}, P_{\mathrm{G} 1}\right)
$$

ii. Recalculate $W_{\mathrm{G} 1}$ using nominal values of all parameters, except one, which will be replaced by its positive perturbed value based on fixed uncertainty. For example, for positive perturbed value of $P_{\mathrm{G} 1}$ :

$$
W_{\mathrm{G} 1}{ }^{+\delta P_{\mathrm{G} 1}}=f\left(V_{\mathrm{G} 1}, T_{G 1}, P_{\mathrm{G} 1}+\delta P_{\mathrm{G} 1}\right)
$$


iii. Recalculate $W_{\mathrm{G} 1}$, using nominal values of all parameters, except one, which will be replaced by its negative perturbed value based on fixed uncertainty. For example, for negative perturbed value of $P_{\mathrm{G} 1}$ :

$$
W_{\mathrm{G} 1}{ }^{-\delta P_{\mathrm{G} 1}}=f\left(V_{\mathrm{G} 1}, T_{G 1}, P_{\mathrm{G} 1}-\delta P_{\mathrm{G} 1}\right)
$$

iv. Repeat step ii and iii for all parameters used in calculating $W_{\mathrm{G} 1}$.

v. Calculate the combined effect of all positive perturbations by using the root-sum method.

$$
\delta W_{\mathrm{G} 1}{ }^{+\delta}=\left(\sum\left(W_{\mathrm{G} 1}-W_{\mathrm{G} 1}{ }^{+\delta i}\right)^{2}\right)^{\frac{1}{2}}
$$

vi. Calculate the combined effect of all negative perturbations by using the root-sum method.

$$
\delta W_{\mathrm{G} 1}^{-\delta}=\left(\sum\left(W_{\mathrm{G} 1}-W_{\mathrm{G} 1}{ }^{-\delta i}\right)^{2}\right)^{\frac{1}{2}}
$$

vii. Take average of the effect of both positive and negative perturbations to calculate overall uncertainty.

$$
\delta W_{\mathrm{G} 1}=\left(\delta W_{\mathrm{G} 1}{ }^{+\delta}+\delta W_{\mathrm{G} 1}{ }^{-\delta}\right) / 2
$$

The results of uncertainty analysis for different parameters of full-and partial-phase-separation experiments are shown in Tables C.1 and C.2, respectively. 
Table C.1: Uncertainty analysis for full-phase-separation experiments

\begin{tabular}{|c|c|c|c|c|c|c|c|c|c|c|}
\hline Data & $J_{\mathbf{G} 1}$ & $J_{\mathrm{L} 1}$ & $W_{\mathbf{G} 1}$ & $W_{\mathbf{G} 2}$ & $W_{\mathbf{G} 3}$ & $W_{\mathrm{L} 1}$ & $W_{\mathrm{L} 2}$ & $W_{\mathrm{L} 3}$ & $F_{G 3}$ & $F_{\mathrm{L3}}$ \\
\hline Point & $(\%)$ & $(\%)$ & $(\%)$ & $(\%)$ & $(\%)$ & $(\%)$ & $(\%)$ & $(\%)$ & $(\%)$ & $(\%)$ \\
\hline FS-1 & 3.8 & 4.2 & 2.1 & 2.0 & - & 3.0 & - & 3.0 & - & r.. \\
\hline FS-2 & 3.8 & 4.2 & 2.1 & 2.0 & - & 3.0 & - & 3.0 & - & 4.6 \\
\hline FS-3 & 3.8 & 4.2 & 2.1 & 2.0 & - & 3.0 & - & 3.0 & - & 5 \\
\hline FS-4 & 3.8 & 4.2 & 2.1 & 2.0 & - & 3.0 & - & 3.0 & - & 13 \\
\hline FS-5 & 3.8 & 4.2 & 2.1 & 2.0 & - & 3.0 & - & 3.0 & - & 13 \\
\hline FS-6 & 3.8 & 4.2 & 2.1 & 2.0 & - & 3.0 & - & 3.0 & - & 1 \\
\hline FS-7 & 3.8 & 4.2 & 2.1 & 2.0 & - & 3.0 & - & 3.0 & - & 1 \\
\hline FS-8 & 3.8 & 4.2 & 2.1 & 2.0 & - & 3.0 & - & 3.0 & - & 1 \\
\hline FS-9 & 3.8 & 4.2 & 2.1 & 2.0 & - & 3.0 & - & 3.0 & - & 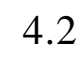 \\
\hline FS-10 & 3.8 & 4.2 & 2.1 & 2.0 & - & 3.0 & - & 3.0 & - & 4.5 \\
\hline FS-11 & 3.7 & 4.2 & 2.1 & 2.0 & - & 3.0 & - & 3.0 & - & \\
\hline FS-12 & 3.7 & 4.2 & 2.1 & 2.0 & - & 3.0 & - & 3.0 & - & \\
\hline FS-13 & 3.7 & 4.2 & 2.1 & 2.0 & - & 3.0 & - & 3.0 & - & \\
\hline FS-14 & 3.8 & 4.2 & 2.1 & 2.0 & - & 3.0 & - & 3.0 & - & \\
\hline FS-15 & 3.7 & 4.2 & 2.1 & 2.1 & - & 3.0 & - & 3.0 & - & \\
\hline FS-16 & 3.7 & 4.2 & 2.1 & 2.1 & - & 3.0 & - & 3.0 & - & \\
\hline FS-17 & 3.7 & 4.2 & 2.1 & 2.0 & - & 3.0 & - & 3.0 & - & \\
\hline FS-18 & 3.8 & 4.2 & 2.1 & 2.0 & - & 3.0 & - & 3.0 & - & \\
\hline FS-19 & 3.7 & 4.2 & 2.1 & 2.0 & - & 3.0 & - & 3.0 & - & \\
\hline FS-20 & 3.7 & 4.2 & 2.1 & 2.0 & - & 3.0 & - & 3.0 & - & \\
\hline
\end{tabular}


Table C.2: Uncertainty analysis for full-phase-separation experiments

$\begin{array}{lllllllllll}\text { Data } & J_{\mathrm{G} 1} & J_{\mathrm{L} 1} & W_{\mathrm{G} 1} & W_{\mathrm{G} 2} & W_{\mathrm{G} 3} & W_{\mathrm{L} 1} & W_{\mathrm{L} 2} & W_{\mathrm{L} 3} & F_{\mathrm{G} 3} & F_{\mathrm{L} 3}\end{array}$

$\begin{array}{lllllllllll}\text { Point } & (\%) & (\%) & (\%) & (\%) & (\%) & (\%) & (\%) & (\%) & (\%) & (\%)\end{array}$

$\begin{array}{lllllllllll}\text { P1 P1-1 } & 3.8 & 4.2 & 2.1 & 2.0 & - & 3.0 & 3.0 & 3.0 & - & 4.2\end{array}$

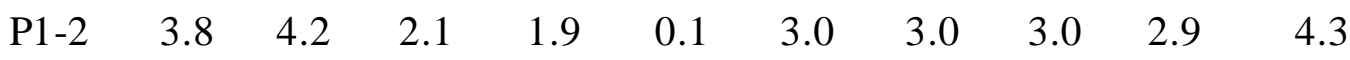

$\begin{array}{lllllllllll}\mathrm{P} 1-3 & 3.8 & 4.2 & 2.1 & 1.9 & 0.1 & 3.0 & 3.0 & 3.0 & 2.9 & 4.3\end{array}$

$\begin{array}{lllllllllll}\mathrm{P} 1-4 & 3.8 & 4.2 & 2.1 & 1.7 & 0.3 & 3.0 & 3.0 & 3.0 & 2.9 & 4.4\end{array}$

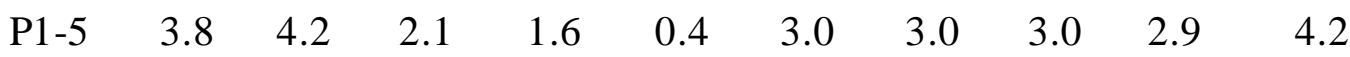

$\begin{array}{lllllllllll}\text { P1-6 } & 3.8 & 4.2 & 2.1 & 1.5 & 0.5 & 3.0 & 3.0 & 3.0 & 2.9 & 4.3\end{array}$

$\begin{array}{lllllllllll}\mathrm{P} 1-7 & 3.8 & 4.2 & 2.1 & 1.4 & 0.6 & 3.0 & - & 3.0 & 2.9 & 4.3\end{array}$

$\begin{array}{llllllllllll}\mathbf{P} 2 & \mathrm{P} 2-1 & 3.8 & 4.2 & 2.1 & 2.0 & - & 3.0 & 3.0 & 3.0 & - & 4.3\end{array}$

$\begin{array}{lllllllllll}\mathrm{P} 2-2 & 3.8 & 4.2 & 2.1 & 1.7 & 0.3 & 3.0 & 3.0 & 3.0 & 2.9 & 4.3\end{array}$

$\begin{array}{lllllllllll}\mathrm{P} 2-3 & 3.8 & 4.2 & 2.1 & 1.6 & 0.4 & 3.0 & 3.0 & 3.0 & 2.9 & 4.2\end{array}$

$\begin{array}{lllllllllll}\text { P2-4 } & 3.8 & 4.2 & 2.1 & 1.5 & 0.5 & 3.0 & 3.0 & 3.0 & 2.9 & 4.2\end{array}$

$\begin{array}{lllllllllll}\text { P2-5 } & 3.8 & 4.2 & 2.1 & 1.4 & 0.6 & 3.0 & 3.0 & 3.0 & 2.9 & 4.2\end{array}$

$\begin{array}{lllllllllll}\text { P2-6 } & 3.8 & 4.2 & 2.1 & 1.3 & 0.7 & 3.0 & - & 3.0 & 2.9 & 4.3\end{array}$

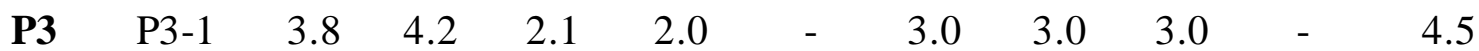

$\begin{array}{lllllllllll}\text { P3-2 } & 3.8 & 4.2 & 2.1 & 1.7 & 0.3 & 3.0 & 3.0 & 3.0 & 2.9 & 4.2\end{array}$

$\begin{array}{lllllllllll}\text { P3-3 } & 3.8 & 4.2 & 2.1 & 1.6 & 0.4 & 3.0 & 3.0 & 3.0 & 2.9 & 4.2\end{array}$

$\begin{array}{lllllllllll}\text { P3-4 } & 3.8 & 4.2 & 2.1 & 1.5 & 0.5 & 3.0 & 3.0 & 3.0 & 2.9 & 4.2\end{array}$

$\begin{array}{lllllllllll}\text { P3-5 } & 3.8 & 4.2 & 2.1 & 1.2 & 0.8 & 3.0 & 3.0 & 3.0 & 2.9 & 4.3\end{array}$

$\begin{array}{lllllllllll}\text { P3-6 } & 3.8 & 4.2 & 2.1 & 1.0 & 1.0 & 3.0 & 3.0 & 3.0 & 2.9 & 4.3\end{array}$

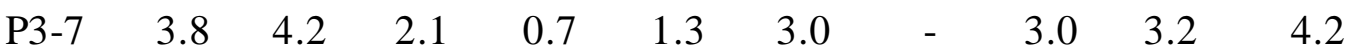

$\begin{array}{llllllllllll}\text { P7 } & \text { P7-1 } & 3.8 & 4.2 & 2.1 & 2.0 & - & 3.0 & 3.0 & 3.0 & - & 4.3\end{array}$

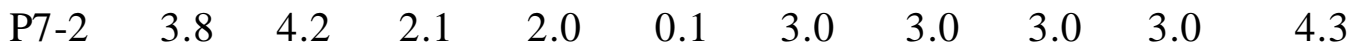

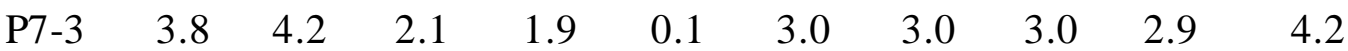

$\begin{array}{lllllllllll}\text { P7-4 } & 3.8 & 4.2 & 2.1 & 1.9 & 0.1 & 3.0 & 3.0 & 3.0 & 2.9 & 4.3\end{array}$

$\begin{array}{lllllllllll}\text { P7-5 } & 3.8 & 4.2 & 2.1 & 1.7 & 0.3 & 3.0 & 3.0 & 3.0 & 2.9 & 4.3\end{array}$

$\begin{array}{lllllllllll}\text { P7-6 } & 3.8 & 4.2 & 2.1 & 1.5 & 0.5 & 3.0 & 3.0 & 3.0 & 2.9 & 4.2\end{array}$

$\begin{array}{lllllllllll}\text { P7-7 } & 3.8 & 4.2 & 2.1 & 1.1 & 0.9 & 3.0 & 3.0 & 3.0 & 2.9 & 4.3\end{array}$ 
$\begin{array}{lllllllllll}\text { Data } & J_{\mathrm{G} 1} & J_{\mathrm{L} 1} & \boldsymbol{W}_{\mathrm{G} 1} & \boldsymbol{W}_{\mathrm{G} 2} & \boldsymbol{W}_{\mathrm{G} 3} & \boldsymbol{W}_{\mathrm{L} 1} & \boldsymbol{W}_{\mathrm{L} 2} & \boldsymbol{W}_{\mathrm{L} 3} & \boldsymbol{F}_{\mathrm{G} 3} & \boldsymbol{F}_{\mathrm{L3}}\end{array}$

$\begin{array}{lllllllllll}\text { Point } & (\%) & (\%) & (\%) & (\%) & (\%) & (\%) & (\%) & (\%) & (\%) & (\%)\end{array}$ $\begin{array}{lllllllllll}\text { P7-8 } & 3.8 & 4.2 & 2.1 & 0.7 & 1.3 & 3.0 & 3.0 & 3.0 & 2.9 & 4.2\end{array}$ $\begin{array}{lllllllllll}\text { P7-9 } & 3.8 & 4.2 & 2.1 & 0.6 & 1.4 & 3.0 & - & 3.0 & 2.9 & 4.3\end{array}$

$\begin{array}{llllllllllll}\mathbf{P 8} & \mathrm{P} 8-1 & 3.8 & 4.2 & 2.1 & 2.0 & - & 3.0 & 3.0 & 3.0 & - & 4.2\end{array}$ $\begin{array}{lllllllllll}\text { P8-2 } & 3.8 & 4.2 & 2.1 & 1.9 & 0.1 & 3.0 & 3.0 & 3.0 & 3.1 & 4.4\end{array}$

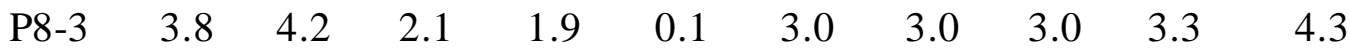
$\begin{array}{lllllllllll}\text { P8-4 } & 3.8 & 4.2 & 2.1 & 1.7 & 0.3 & 3.0 & 3.0 & 3.0 & 2.9 & 4.3\end{array}$ $\begin{array}{lllllllllll}\text { P8-5 } & 3.8 & 4.2 & 2.1 & 1.6 & 0.4 & 3.0 & 3.0 & 3.0 & 3.6 & 4.2\end{array}$ $\begin{array}{lllllllllll}\text { P8-6 } & 3.8 & 4.2 & 2.1 & 1.5 & 0.5 & 3.0 & - & 3.0 & 3.4 & 4.3\end{array}$ $\begin{array}{llllllllllll}\text { P9 } & \text { P9-1 } & 3.8 & 4.2 & 2.1 & 2.0 & - & 3.0 & 3.0 & 3.0 & - & 4.2\end{array}$ $\begin{array}{lllllllllll}\text { P9-2 } & 3.8 & 4.2 & 2.1 & 1.9 & 0.1 & 3.0 & 3.0 & 3.0 & 3.2 & 4.2\end{array}$ $\begin{array}{lllllllllll}\mathrm{P} 9-3 & 3.8 & 4.2 & 2.1 & 1.9 & 0.1 & 3.0 & 3.0 & 3.0 & 2.9 & 4.3\end{array}$ $\begin{array}{lllllllllll}\text { P9-4 } & 3.8 & 4.2 & 2.1 & 1.8 & 0.2 & 3.0 & 3.0 & 3.0 & 3.0 & 4.3\end{array}$ $\begin{array}{lllllllllll}\mathrm{P} 9-5 & 3.8 & 4.2 & 2.1 & 1.5 & 0.5 & 3.0 & 3.0 & 3.0 & 4.1 & 4.2\end{array}$ $\begin{array}{lllllllllll}\text { P9-6 } & 3.8 & 4.2 & 2.1 & 1.3 & 0.7 & 3.0 & 3.0 & 3.0 & 3.3 & 4.2\end{array}$ $\begin{array}{lllllllllll}\mathrm{P} 9-7 & 3.8 & 4.2 & 2.1 & 1.2 & 0.8 & 3.0 & 3.0 & 3.0 & 2.9 & 4.3\end{array}$ $\begin{array}{lllllllllll}\text { P9-8 } & 3.8 & 4.2 & 2.1 & 1.1 & 0.9 & 3.0 & - & 3.0 & 2.9 & 4.2\end{array}$ $\begin{array}{lllllllllll}\text { P10 } & \text { P10-1 } & 3.8 & 4.2 & 2.1 & 2.0 & - & 3.0 & 3.0 & 3.0 & -\end{array}$ $\begin{array}{lllllllllll}\mathrm{P} 10-2 & 3.7 & 4.2 & 2.1 & 2.0 & 0 & 3.0 & 3.0 & 3.0 & 2.9 & 4.2\end{array}$ $\begin{array}{lllllllllll}\mathrm{P} 10-3 & 3.8 & 4.2 & 2.1 & 1.9 & 0.1 & 3.0 & 3.0 & 3.0 & 2.9 & 4.2\end{array}$ $\begin{array}{lllllllllll}\text { P10-4 } & 3.8 & 4.2 & 2.1 & 1.9 & 0.1 & 3.0 & 3.0 & 3.0 & 2.9 & 4.3\end{array}$ $\begin{array}{lllllllllll}\mathrm{P} 10-5 & 3.8 & 4.2 & 2.1 & 1.8 & 0.2 & 3.0 & 3.0 & 3.0 & 2.9 & 4.2\end{array}$ $\begin{array}{lllllllllll}\text { P10-6 } & 3.7 & 4.2 & 2.1 & 1.8 & 0.2 & 3.0 & - & 3.0 & 2.9 & 4.2\end{array}$ 